Portland State University

PDXScholar

Winter 1-16-2019

\title{
From Drought to Food-Energy-Water-Security Nexus: an Assessment of Food Insecurity in the Middle East
}

Maysoun Ayad Hameed

Portland State University

Follow this and additional works at: https://pdxscholar.library.pdx.edu/open_access_etds

Part of the Civil and Environmental Engineering Commons

Let us know how access to this document benefits you.

\section{Recommended Citation}

Hameed, Maysoun Ayad, "From Drought to Food-Energy-Water-Security Nexus: an Assessment of Food Insecurity in the Middle East" (2019). Dissertations and Theses. Paper 4682.

https://doi.org/10.15760/etd.6566

This Dissertation is brought to you for free and open access. It has been accepted for inclusion in Dissertations and Theses by an authorized administrator of PDXScholar. Please contact us if we can make this document more accessible: pdxscholar@pdx.edu. 
From Drought to Food-Energy-Water-Security Nexus: An Assessment of Food Insecurity

in the Middle East

by

Maysoun Ayad Hameed

A dissertation submitted in partial fulfillment of the requirements for the degree of

Doctor of Philosophy

in

Civil and Environmental Engineering

Dissertation Committee:

Hamid Moradkhani, Chair

Robert Fountain

Annette Dietz

Christopher Butenhoff

Portland State University

2019 
(C) 2018 Maysoun Ayad Hameed 


\begin{abstract}
Drought is an extreme climate phenomenon that happens slowly and periodically threatens the environmental and socio-economic sectors. Developing countries have experienced crucial conditions in meeting the needs for food, energy, and water security. Natural disasters contribute as risky sources of food insecurity and vulnerability in the Middle East. This dissertation presents a country-level review and quantitative assessment of the current issues associated with the Food-Energy-Water-Security (FEWS) Nexus in the Middle East. In this study, sixteen countries in the Middle East are chosen, namely, Arabian Peninsula, Iran, Syria, Lebanon, Israel, Palestine, Egypt, and Turkey. The most recent datasets are used to study and analyze the factors that have increased the demand to understand and manage the linkage of FEW systems in the region. Water scarcity, extreme events, population growth, urbanization, economic growth, poverty, and political stability are found to be the key drivers of the current challenges in the Middle East. The results suggest that these factors have created a subsequent stress on FEW resources specifically on the water sector in the region. Therefore, more attention is required to sustain the FEW resources and cope with the socio-economic development.
\end{abstract}

Moreover, this study presented a comprehensive assessment of drought and food-waterenergy-security nexus across the Middle East using rigorous frameworks. Meteorological, agricultural, and hydrological droughts are analyzed using different drought indices at multiple timescales over the region for seven decades for the period of 1948-2017. The study further analyzes food insecurity in the Middle East through the exploration of 
drought (as a water stress factor), energy, and other socio-economic factors in the region. A Bayesian approach is conducted to link all the factors that best predict food insecurity in Middle East pooled from 16 countries in the region. Results reveal that the intensity of agricultural drought are the most aggravated over the region in all cases. Moreover, the results demonstrated the significant impacts of drought (as a water stress factor), agricultural land availability, population growth, livestock, and cereal production on food insecurity in the Middle East. 


\section{Dedication}

To the soul of my beloved mother,

To my lovely father,

To my amazing sisters,

To the most wonderful husband in the world,

To my little son who made me feel so blessed and lucky to have him as my child,

Thanks all for being there for me whenever I needed support ... I love you. 


\section{Acknowledgements}

First of all, many thanks to Allah (God) for giving me the faith and strength to finish this scientific work. I would like to express my deep gratitude to Professor Hamid Moradkhani, the supervisor and the chair of the dissertation committee, for his generous help, support, and countless time of reviewing, reading, editing, and advising. I highly benefitted from his knowledge, guidance, and experience. I would like to also thank my dissertation committee members, Dr. Bob Fountain, Dr. Annette Dietz, and Dr. Christopher Butenhoff for their willingness to serve on my committee and for their valuable comments and feedbacks on my research. Their comments and suggestions helped me significantly improve the quality and clarity of my research. My deep gratitude to my family, especially my husband Yasir Saeed, for their continuous and unconditional love, care, and support. Their encouragement motivated me to strive to achieve my goals, and I could have not completed this work without their support and patience. Special thanks to all the postdoctoral associates and graduate students in the Water Resources and Remote Sensing Lab at Portland State University (PSU) who helped me with my work, especially Mehmet Demirel, Ali Ahmadalipour, Amin Mahdipour Varnousfaderani, Peyman Abbaszadeh, Mahkameh Zarekarizi, Sepideh Khajehei, and Behzad Ahmadi. My gratitude to the Higher Committee for Education Development in Iraq (HCED) for funding this research. I also

like to extend my appreciation to the kind staff of the Department of Civil and Environmental Engineering at PSU, especially Megan Falcone and Ariel Lewis, who were always great resources and helped me navigate my work in the department. 


\section{Table of Contents}

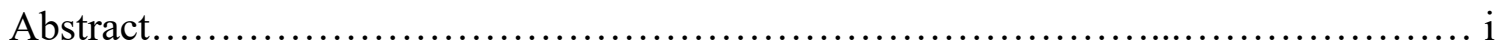

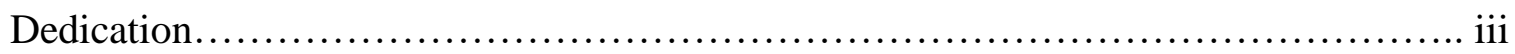

Acknowledgements......................................................... iv

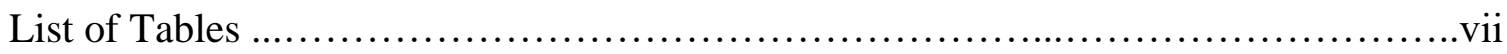

List of Figures............................................................viii

List of Abbreviations .........................................................................................

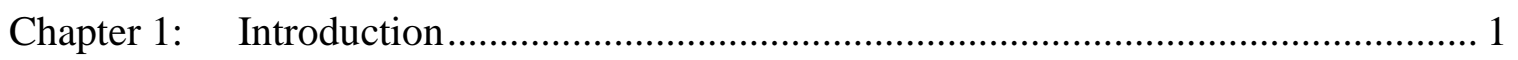

1.1 Water-Food-Energy Security Nexus .......................................................... 1

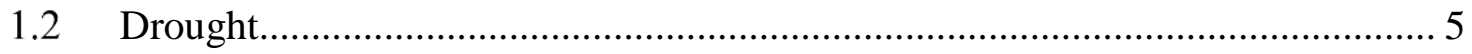

1.2.1. Apprehensive Drought Characteristics over Iraq: Results of a Multidecadal Spatiotemporal Assessment .......................................................................... 7

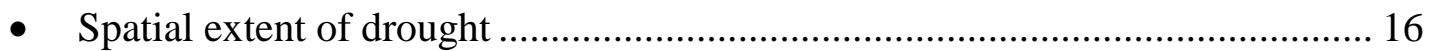

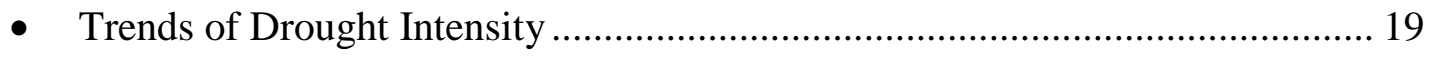

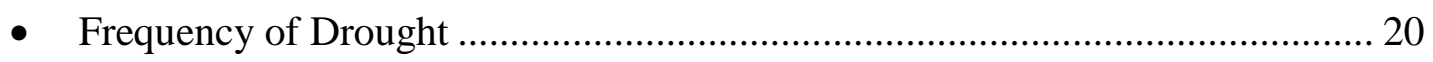

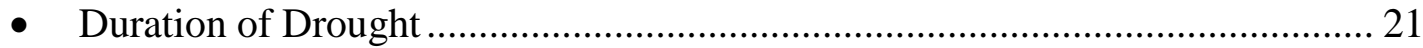

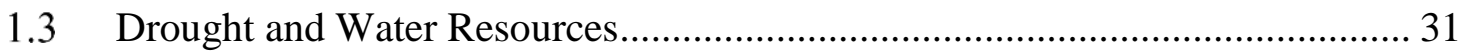

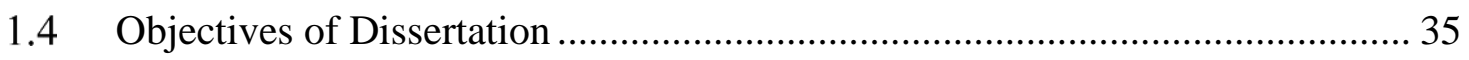

Chapter 2: Challenges in the Food-Energy-Water-Security Nexus in the Middle East 36

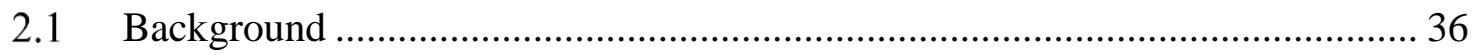

2.2 The Food-Energy-Water-Security (FEWS) Nexus Middle East in the $21^{\text {st }}$

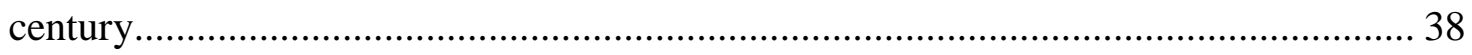

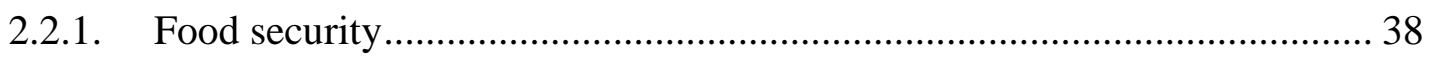

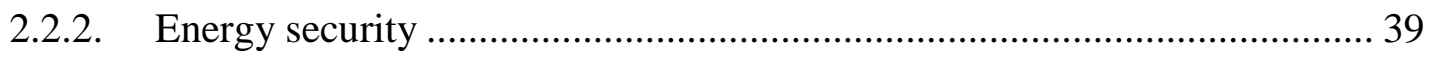

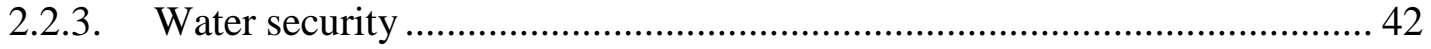

2.3 The Challenges in the Middle East in the $21^{\text {st }}$ century .................................. 44

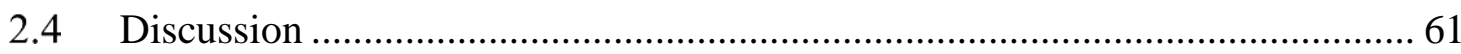

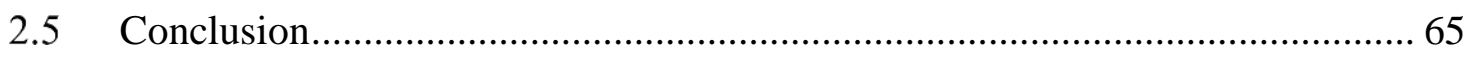

Chapter 3: Drought and Food-Energy-Water-Security Nexus: A Bayesian framework assessment of food insecurity in Middle East 


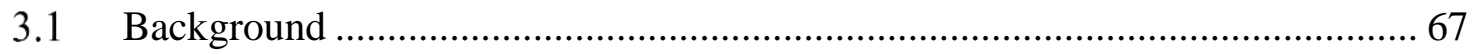

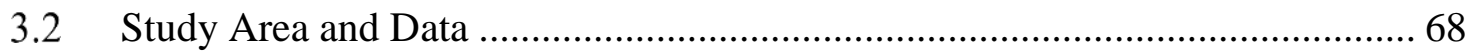

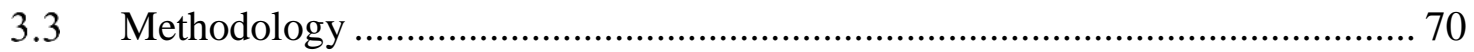

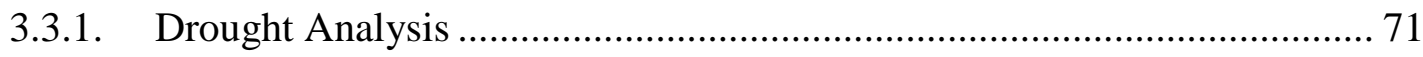

3.3.2. Mann-Kendall test and Sen Method .................................................... 74

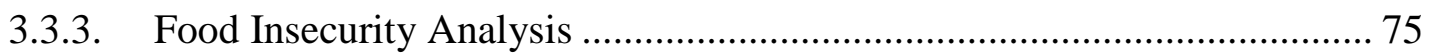

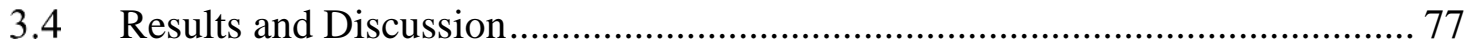

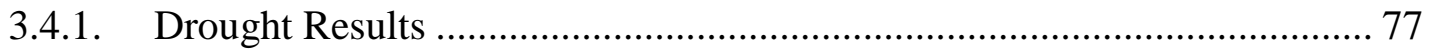

3.4.2. Principle Component Analysis (PCA) ................................................. 88

3.4.3. Bayesian Linear Regression Analysis .................................................. 89

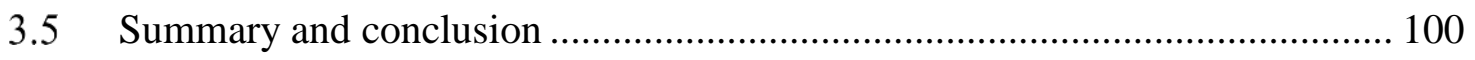

Chapter 4: Conclusions and Future Studies........................................................ 102

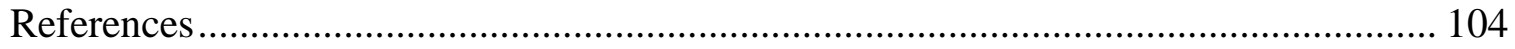




\section{List of Tables}

Table 1-1. Arable land areas and actual renewable water resources (RWR) per capita in the Middle East. Note: * Stressed, Scarce and Severely Scarce are based on FAO classification of renewable water availability per capita. **Adequate and exceptionally scarce are two categories introduced by AFED for this table to reflect special extreme situations in the Arab countries

Table 1-2 Categories of dry/wet classes by the SPEI following McKee et al. (McKee et al. 1993)

Table 1-3 Water stress by country after Negewo (2012)

Table 3-1 Categories of dry/wet classes by drought indices following McKee et al. (McKee et al. 1993).

Table 3-2 The 32 factor considered in the analysis, and the availability of each factor during the historical period (1960-2017). 


\section{List of Figures}

Figure 1-1 Pardee RAND Food-Energy-Water security index (Willis et al. 2016). Note: not listed countries means the FEW index is not provided by the source for these countries due to data availability

Figure 1-2 Elevation map of Iraq and neighboring countries (source: http://www.divagis.org).

Figure 1-3 Decadal variations of drought spatial extent over Iraq. 17

Figure 1-4 Temporal variations of monthly drought $($ SPEI $<-1)$ and wet $($ SPEI $>1)$ extent over Iraq. 18

Figure 1-5 Probability of drought extent based on 12-month SPEI over Iraq for two periods: a) 1948-1997, b) 1998-2009. The stars represent drought extent at the $90^{\text {th }}$ percentile.

Figure 1-6 Long-term trends of drought intensity for the period of 1948-2009 according to the SPEI-12.

Figure 1-7 Drought frequency across Iraq for the period of 1948-2009 based on SPEI-12. A drought event is defined when the SPEI falls below -1 (moderate drought condition or worse) and stays within dry threshold for more than two months.

Figure 1-8 Total duration of drought (in months) for the period of 1998-2009 for each drought type: moderate, severe, and extreme. ...................................................... 22

Figure 1-9 Time series of spatially averaged SPEI-12 over Iraq during 1948-2009...... 24

Figure 1-10 Decadal variations of annual potential evapotranspiration (PET) and precipitation (P) over Iraq from 1950 to 2009. 26

Figure 1-11 Long-term trends of P, T, and PET (mm/month) for the period of 1948-2009

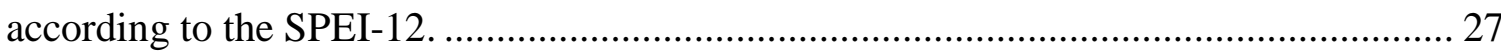

Figure 1-12 major hydrological basins in the Middle East......................................... 32

Figure 1-13 water scarcity by major hydrological basins in the Middle East................. 33

Figure 2-1 Global Food Security Index (0-100, $100=$ best environment). Note: not listed countries means the GFSI is not provided by the source for these countries due to data unavailability. Source: https://idea.usaid.gov/cd/egypt/hunger-and-food-security ......... 39

Figure 2-2 Energy Efficiency Status in the Middle East (RCREEE 2015). .................. 41

Figure 2-3 Water consumption in industry in the Middle East in 2011 (Sakhel et al.

2013). 44

Figure 2-4 The percent of total renewable water resources originating outside a country. A country with a dependency ratio equal to $0 \%$ does not receive any water from neighboring countries. A country with a dependency ratio equal to $100 \%$ receives all its renewable water from upstream countries, without producing any of its own.

Figure 2-5 Number of deaths caused by weather events like storms, floods, temperature extreme and mass movements for the years of 2005, 2010, and 2015. Note: data of Syria for the years of 2015 is not available. Source: https://idea.usaid.gov..... 48 
Figure 2-6 Climate Risk Index Score. The index is a weighted score calculated according to: Number of Deaths (weight: 1/6), Deaths per 100,000 inhabitants (weight: 1/3), Absolute losses in PPP (weight: 1/6), and Losses per GDP unit (weight: 1/3). Lower score indicates a country being more at risk to climate change. Source: https://idea.usaid.gov

Figure 2-7 Five-year compound annual growth rate of the Gross Domestic Product (GDP) based on Purchasing Power Parity (PPP) for the period of (2011-2015) (Miller and Kim 2017).

Figure 2-8 Real GDP Growth for the years of 2015, 2016, and 2017. Source: IMF Data Mapper.

Figure 2-9 Decadal mean annual rate of change of urban population by major area, region and country (United Nations 2015). 54

Figure 2-10 Five-year average of population growth in the Middle East. Source: FAOAQUASTAT Database and Worldometers (www.Worldometers.info) 56

Figure 2-11 Annual growth rate of the Middle East countries in 2017. Source: http://www.worldometers.info. 57

Figure 2-12 Percentage of population that are undernourished in the Middle East. Note: data for Syria was not available. Source: https://idea.usaid.gov..... 59 Figure 2-13 Global Hunger Index (GHI) with the score of 0-100, where lower score is better. Note: data for Syria was not available. Source: https://idea.usaid.gov..... 60

Figure 2-14 Index of Economic Freedom of countries of interest within the MENA region in 2017. Countries in the range of (0-49.9) are repressed, countries in the range of (50-59.9) are mostly unfree, countries in the range of (60-69.9) are moderately free, countries in the range of (70-79.9) are mostly free, and countries in the range of (80-100) are free (Miller and Kim 2017). Note: not listed countries implies data unavailability. .. 64 Figure 3-1 A population map of the Middle East 69

Figure 3-2 Long-term linear trends of drought intensity for the period 1948-2017 according to the SI-1, $-3,-6,-12,-18$, and -24 months over the Middle East. 79 Figure 3-3 Trend test including Sen's slope method using Mann-Kendall Tau-b technique

Figure 3-4 Temporal variations of monthly drought (Index of 12-month time scales $<-1$ ) and wet (Index of 12-month time scales > 1) extent over the Middle East ..... 82 Figure 3-5 Comparison of spatially averaged 12-month time scales of MSDIe, MSDIp , SPI, and SSI over the Middle East during 1948-2017 84 Figure 3-6 Comparison of spatially averaged 12-month time scales of MSDIe, MSDIp , SRI, and SSI over the Middle East during 1948-2017 .......................................... 85 Figure 3-7 Comparison of spatially averaged 12-month time scales of MSDIe, MSDIp , SPI, and SRI over the Middle East during 1948-2017 ............................................ 85 Figure 3-8 Comparison of spatially averaged 12-month time scales of MSDIe, MSDIp , SPI, and SSIrz over the Middle East during 1948-2017 86 
Figure 3-9 Comparison of spatially averaged 12-month time scales of MSDIe, MSDIp , SRI, and SSIrz over the Middle East during 1948-2017

Figure 3-10 Results of the Principal Component Analysis (PCA). Components 1 and 2 accounted for $53 \%, 25 \%$ of the variability respectively. Coefficient vectors represent how much each factor contributed to the component, with the longer vectors contributing more than the shorter vectors.

Figure 3-11 Comparing the time series of the selected factors as indicators of food insecurity in Middle East with drought indices based on precipitation (SPI, blue bars), runoff and soil moisture at root zone (SSIrzSRI, red bars) over the same period (19922015)

Figure 3-12 The correlation between the predicted food deficit and observation. The first model is based on agricultural land, population growth, energy used in agriculture, meteorological drought, and agricultural-hydrological droughts

Figure 3-13 The correlation between the predicted food deficit and observation. The second model is based on livestock, cereal production, population growth, meteorological drought, and agricultural-hydrological droughts

Figure 3-14 The correlation between the predicted food deficit and observation. The third model is based on livestock, cereal production, and population growth.....

Figure 3-15 The correlation between the predicted crop production index and observation. The first model is based on agricultural land, population growth, energy used in agriculture, meteorological drought, and agricultural-hydrological droughts..... 98 Figure 3-16 The correlation between the predicted crop production index and observation. The second model is based on agricultural land, food deficit, energy used in agriculture, meteorological drought, and agricultural-hydrological droughts

Figure 3-17 The correlation between the predicted crop production index and observation. The third model is based on agricultural land, food deficit, and energy used in agriculture 100 


\section{List of Abbreviations}

FEWS: Food-Energy-Water-Security

MENA: Middle East and North Africa

EMME: Eastern Mediterranean and the Middle East

FAO: Food and Agricultural Organization of the United Nations

IEA: International Energy Agency

ESCWA: United Nations Economic and Social Commission for Western Asia

GLDAS: Global Land Data Assimilation System

ECMWF: European Centre for Medium-Range Weather Forecasts

NMME: North American Multi-Model Ensemble

GCM: Global Climate Model

PET: Potential Evapotranspiration

D: Deficit

SPEI: Standardized Precipitation Evapotranspiration Index

PDSI: Palmer Drought Severity Index

sc_PDSI_pm: Penman-Monteith potential evapotranspiration

SPI: Standardized Precipitation Index

SRI: Standardized Runoff Index

SSI: Standardized Soil Moisture Index

SSIrz: Standardized Soil Moisture Index at root zone

SI: Drought Index

MSDI: Multivariate Standardized Drought Index

VIF: Variance Inflation Factors

PCA: Principle Component Analysis

SDAT: Standardized Drought Analysis Toolbox

MCMC: Markov chain Monte Carlo

AIC: Akaike information criteria 
AICc: Corrected Akaike information criteria

BIC: Bayesian information criterion

RMSE: Root Mean Square Error

CDF: Cumulative Probability Distribution 


\section{Chapter 1: Introduction}

\subsection{Water-Food-Energy Security Nexus}

The Food-Energy-Water-Security (FEWS) nexus is of paramount importance in the Middle East region since the nexus between these sectors can be of high importance for the region's stability and economic growth (Borgomeo et al. 2018). For instance, an extensive amount of energy is consumed powering the desalination and wastewater recycling units for water supply in the Gulf region (McDonnell 2014). Siddiqi \& Anadon (2011) studied the water-energy nexus over the MENA region and found that there is a strong dependency of water sector on energy sector but not the opposite. In the Arabian Peninsula countries, groundwater contributes to about $84 \%$ of total water supply whereas desalinated water covers about $8 \%$ of water withdrawals. However, both groundwater extraction and desalination are energy demanding. Carbon dioxide emissions can be another limitation for energy consumption when fossil fuels are used (Nematollahi et al. 2016). Globally, the GCC countries are one of the top twenty-five countries for $\mathrm{CO}_{2}$ emissions/capita because of their highly dependency on fossil fuels to cover the domestic energy demands (Bekhet et al. 2017). In 2004, KSA and Iran were reported as the $13^{\text {th }}$ and $16^{\text {th }}$ highest carbon dioxide emitters in the world, respectively (Ozcan 2013). Therefore, there is a need to use green energy that is produced from natural resources, e.g. wind, sunlight, geothermal heat, and hydro sources (Khan et al. 2014).

The water-food security in the Arab region is limited by several factors: socioeconomic growth, dry climate, reliance on external resources, climate change, and political conflict (Mohtar et al. 2017). Figure 1-1 presents the Pardee RAND FEW security index 
(Willis et al. 2016). The FEW index provides information about the availability and accessibility of the three resources in any region or country in the world. According to the definition, and as shown in Figure 1-1, Turkey is the most secure country in the Middle East whereas Yemen is the most insecure country. The World Economic Forum 2010 Report underlined water insufficiency, energy security, and weak investments in infrastructure as the most mutually dependent and chronic risks in the Middle East and North Africa (MENA) region. It is found that these risks (including food security as a related risk) are extremely affected by economic production, population growth, and industrial potency in the region (WEF 2010).

\section{Food-Energy-Water Index}

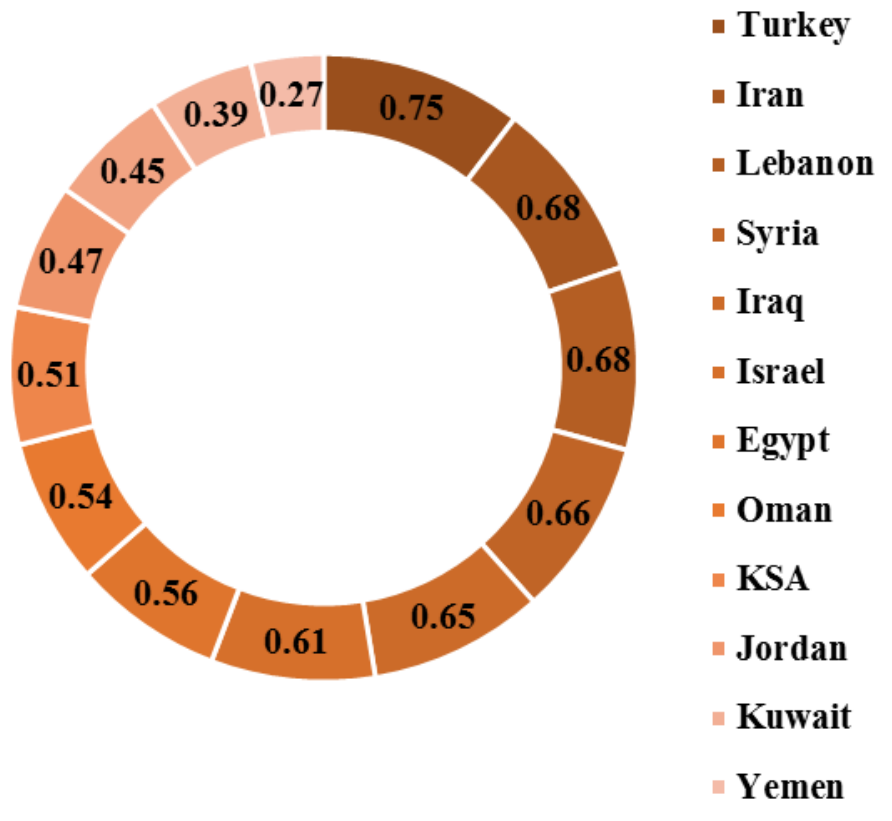

Figure 1-1 Pardee RAND Food-Energy-Water security index (Willis et al. 2016). Note: not listed countries means the FEW index is not provided by the source for these countries due to data availability 
Food production is the most limited sector by water scarcity in the Arab region (Sewilam and Nasr 2017). Table 1-1 displays the arable land areas and actual renewable water resources (RWR) per capita in the Middle East. Most of the countries in the region suffer from scarcity of lands that are capable of being planted except KSA and Yemen. For the renewable water resources, exceptionally scarce is the dominant condition in the region except Iraq (adequate) and Lebanon (stressed) (Table 1-1). 
Table 1-1. Arable land areas and actual renewable water resources (RWR) per capita in the Middle East. Note: * Stressed, Scarce and Severely Scarce are based on FAO classification of renewable water availability per capita. **Adequate and exceptionally scarce are two categories introduced by AFED for this table to reflect special extreme situations in the Arab countries.

\begin{tabular}{|c|c|c|}
\hline $\begin{array}{c}\text { Arable } \\
\text { Land } \\
\text { (ha/capita }\end{array}$ & $\begin{array}{c}\text { RWR } \\
\text { (m3/capita/year) }\end{array}$ & Scale \\
\hline$>2.5$ & $>1500$ & Adequate** \\
\hline $1.0-2.5$ & $1000-1499$ & Stressed* \\
\hline $0.5-1.0$ & $500-999$ & Scarce* \\
\hline $0.05-0.5$ & $100-499$ & $\begin{array}{l}\text { Severely } \\
\text { scarce** }\end{array}$ \\
\hline $0-0.05$ & $0-99$ & $\begin{array}{l}\text { Exceptionally } \\
\text { Scarce** }\end{array}$ \\
\hline Country & $\begin{array}{l}\text { Arable Land/Capita } \\
\text { (ha) }\end{array}$ & $\begin{array}{c}\text { RWR/Capita } \\
\left(\mathbf{m}^{3}\right)\end{array}$ \\
\hline Bahrain & 0.01 & 83.36 \\
\hline Kuwait & 0.05 & 6.92 \\
\hline Oman & 0.56 & 482.1 \\
\hline Qatar & 0.03 & 29.91 \\
\hline KSA & 6.16 & 83.61 \\
\hline UAE & 0.05 & 18.5 \\
\hline Yemen & 0.97 & 82.13 \\
\hline Iraq & 0.25 & 2666 \\
\hline Jordan & 0.15 & 145.1 \\
\hline Lebanon & 0.14 & 1049 \\
\hline Syria & 0.61 & 795.5 \\
\hline Palestine & 0.06 & 196 \\
\hline Egypt & 0.05 & 682.5 \\
\hline
\end{tabular}




\subsection{Drought}

Drought is an extreme event that happens periodically mostly because of precipitation deficit. Other climatic variables may also contribute to drought occurrence, e.g. temperature, wind, relative humidity, and precipitation timing. Drought is considered to be part of the hydrologic cycle since it has devastating impacts on water components such as: water supply, water quality, crop yield, surface and subsurface water availability, and management of water resources (van Loon et al. 2014; Amin et al. 2016; FAO 2017; Scanlon et al. 2017; Ahmadalipour et al. 2017b). Moreover, drought has a substantial impact on agricultural and economic sectors (UNDP 2010; Ahmadalipour and Moradkhani 2017). Several studies have shown that global warming and climate change will aggravate the consequences of drought (Dai 2011a; Madadgar and Moradkhani 2013a; Cook et al. 2014). Dai (2011a) argued that the atmospheric demand of moisture has increased with the current warming and it has probably changed the atmospheric circulation patterns, which contributes to drought. Mishra and Singh (Mishra and Singh 2010) stated that the rate of global warming has experienced an increasing trend in the past 25 years resulting in an overall increase of extreme events.

Drought is generally categorized to four types including: (1) Meteorological drought which is primarily related to precipitation deficit (Beguería et al. 2014; Das et al. 2015; Ahmadalipour et al. 2016); (2) Agricultural drought which is mainly related to soil moisture shortage (Gao et al. 2015; Mishra et al. 2015; Nichol and Abbas 2015; VicenteSerrano et al. 2015; Yan et al. 2017); (3) Hydrological drought which is associated with surface and subsurface water shortfall (Lorenzo-Lacruz et al. 2013; Madadgar and 
Moradkhani 2013b; Mo and Lettenmaier 2014; Van Loon and Laaha 2015; Zhang et al. 2015; Barker et al. 2016; Ahmadalipour et al. 2017a); (4) Socioeconomic drought which is related to a deficiency in the water resources system as a result of the other drought types (van Loon et al. 2014; Maia et al. 2015; Rajsekhar et al. 2015; Huang et al. 2016). The aforementioned drought types constitute the same process but under distinct phases as a function of time and location (Carrão et al. 2014).

Many regions in the Middle East have faced serious drought-related challenges in the $21^{\text {st }}$ century, e.g. deficiency of precipitation, lack of irrigation water, and diminished water storage. Drought has been a characteristic of the Middle East climate (UNDP 2010). A study in the Eastern Mediterranean and the Middle East (EMME) by Lelieveld et al. (Lelieveld et al. 2012) showed that the Middle East region is likely to be highly impacted by climate change resulting in more intense and frequent droughts. A study by Hoerling et al. (Hoerling et al. 2012) assessed droughts in the Mediterranean region by applying global climate models. They showed that drying conditions widely spread from the Atlantic coast to the Middle East during the period of 1971-2010 compared to 1902-1970. In addition, they found that drought frequency has increased after 1970 along with a change toward drier conditions during the cold-season precipitation in the Mediterranean region for the period of 1902-2010. Gleick (Gleick 2014) showed that since 2008, drought frequency and intensity have changed over the eastern Mediterranean region. A study in the Eastern Mediterranean and the Middle East (EMME) by Lelieveld et al. (Lelieveld et al. 2012) showed that the Middle East region is likely to be highly impacted by climate change resulting in more intense and frequent droughts. Iraq, as one of the Middle East countries, 
has recently experienced drought (UNESCO 2014). Since the prolonged meteorological drought is considered as the main factor for the occurrence of other types of drought like the agricultural and socioeconomic droughts (Deo et al. 2016), monitoring meteorological drought may be a preliminary but useful investigation for understanding drought over a certain region. Therefore, the following section will introduce a case study of drought monitoring across Iraq as a Middle Eastern country (Hameed et al. 2018).

\subsubsection{Apprehensive Drought Characteristics over Iraq: Results of a Multidecadal}

\section{Spatiotemporal Assessment}

Many meteorological drought indices are available in the literature. For example, the Palmer Drought Severity Index (PDSI) (Palmer 1965), the standardized precipitation index (SPI) (McKee et al. 1993), and the standardized precipitation-evapotranspiration index (SPEI) (Vicente-Serrano et al. 2010). Some of these indices, e.g. SPEI or PDSI, account for water balance by incorporating the precipitation and evapotranspiration anomalies, and some others are precipitation-based drought indices, e.g. SPI (Das et al. 2015). The PDSI needs calibration to be used in different regions and it can be calculated at fixed time-scales of 9-12 months (Vicente-Serrano et al. 2010), whereas the SPEI provides the multi-scalar feature. Cook et al. (Cook et al. 2014) showed that the SPEI is more sensitive to the potential evapotranspiration (PET) than the PDSI in arid regions, e.g. the Sahara and Middle East. Also, Zhang et al. (Zhang et al. 2015) explained that estimating water demand based on PET over arid and semi-arid regions may be unrealistic. Therefore, 
estimating water demand and also drought quantification can be enhanced by considering PET, runoff, and soil moisture (Mo and Lettenmaier 2014; Zhang et al. 2015).

Numerous studies have investigated meteorological drought at global scale as well as national or regional scales. For global scale, Dutra et al. (Dutra et al. 2014) presented a probabilistic meteorological drought monitoring methodology based on The European Centre for Medium-Range Weather Forecasts (ECMWF) probabilistic forecasts estimating the SPI. Mo and Lyon (Mo and Lyon 2015) applied the North American Multi-Model Ensemble (NMME) to predict the global meteorological drought using the SPI. In another study, the self-calibrated Palmer drought severity index with the Penman-Monteith potential evapotranspiration (sc_PDSI_pm) was examined under a low-moderate emissions scenario to analyze the magnitude and key drivers of global drought changes in the twenty-first century (Zhao and Dai 2015). Stagge and Tallaksen (Stagge and Tallaksen 2014) compared the SPEI with the SPI over Europe to address the differences among them and to investigate the sensitivity of the SPEI to different potential evapotranspiration (PET) methods.

Several researchers have studied drought over Iraq (AL-Timimi and AL-Jiboori 2013; Al-Faraj and Al-Dabbagh 2015; Eklund and Seaquist 2015; Amini et al. 2016). ALTimimi and AL-Jiboori (AL-Timimi and AL-Jiboori 2013) assessed the spatial and temporal changes in drought over Iraq using the SPI for the period of 1980-2010. They found that drought has deteriorated from normal to extreme levels over Iraq during the period of 2000-2010, and 2008 was the driest year. Another study by Robaa and AlBarazanji (Robaa, S. M., Al-Barazanji, Z. J. 2013) showed that after 1995, the rising trend 
of the annual mean temperature over Iraq is about $0.5^{\circ} \mathrm{C} / \mathrm{decade}$. Eklund and Seaquist (Eklund and Seaquist 2015) investigated agricultural drought using the enhanced vegetation index (EVI) in the Duhok Governorate, Iraqi Kurdistan. Their results indicated about $50 \%$ decrease in precipitation over the region leading to a $62 \%$ reduced vegetated area in 2008. Al-Faraj and Al-Dabbag (Al-Faraj and Al-Dabbagh 2015) investigated the combined effects of basin-wide multi-year drought and upstream human-induced activities on the development of the Diyala river basin shared between Iraq and Iran. Recently, a drought analysis was conducted to inspect the Euphrates-Tigris basin located in Iran, Turkey, Iraq, and Syria using the SPI drought index (Amini et al. 2016). They found that Syria has faced the most severe and frequent droughts in the past 15 years.

The intention of the present study is to utilize a multi-scalar climatic drought index sensitive to global warming (the standardized precipitation evapotranspiration index; SPEI) to study drought over Iraq while addressing the effects of temperature variability on drought. The potential evapotranspiration is calculated using the Thornthwaite method (Thornthwaite 1948) as an estimate for the water demand in the region. While other studies focused on some parts of Iraq, the current study covers the entire Iraq and investigates several main spatiotemporal characteristics of drought for the period of 1948-2009.

\subsubsection{Study Area and Data}

Iraq is located in the southwestern Asia and covers about 435,000 $\mathrm{km}^{2}$. A large area of the country is arid and semi-arid regions. Most of the topography is broad plains, and the mountains spread in the north and northeastern regions (along the border with Turkey and Iran) (Figure1-2). The climate of Iraq varies to be continental and subtropical. Winters 
tends to be cold (below freezing) with relatively low and uneven precipitation. Precipitation occurs between October and May with higher precipitation amounts falling between December to February. The mean annual precipitation over Iraq is about $154 \mathrm{~mm}$ (The World Bank 2006). However, 60\% of the country receives less than $100 \mathrm{~mm} / \mathrm{year}$ (southern parts of Iraq) whereas the mountains regions (north-eastern parts of Iraq) receive the highest amount of precipitation up to $1200 \mathrm{~mm} / \mathrm{year}$ (The World Bank 2006). Summers are dry, hot in the northern parts, and extremely hot (higher than $48^{\circ} \mathrm{C}$ ) across the rest of Iraq. Spring and fall are very short in Iraq.

Most of the agriculture in Iraq depends on irrigation because of the dry climate, except for the northeastern parts (mountains region) where the rain-fed agriculture is practiced. The Tigris and Euphrates rivers are the main sources of water in Iraq. The two rivers originate from Turkey and enter Iraq from the north and west borders with Turkey and Syria (Figure 1). The Tigris watershed area is about $371,562 \mathrm{~km}^{2}$ that surrounds about $38 \%$ of Iraq. The Euphrates watershed is about $579,314 \mathrm{~km}^{2}$ and covers about $49 \%$ of Iraq (The World Bank 2006). Recently, the amount of water in both rivers has decreased substantially as a result of drought and dam constructions (UNDP 2010).

The Global Land Data Assimilation System Version 2 (GLDAS-2) monthly data with a $0.25^{\circ}$ spatial resolution is used in this study (Beaudoing and Rodell 2015). The components of GLDAS-2 are the GLDAS-2.0 that is forced entirely with the Princeton meteorological forcing data and the GLDAS-2.1 that is forced with a combination of model and observation-based forcing datasets. For this study, the monthly precipitation and 
temperature data were extracted and utilized for 62 years historical period of January 1948 to December 2009.

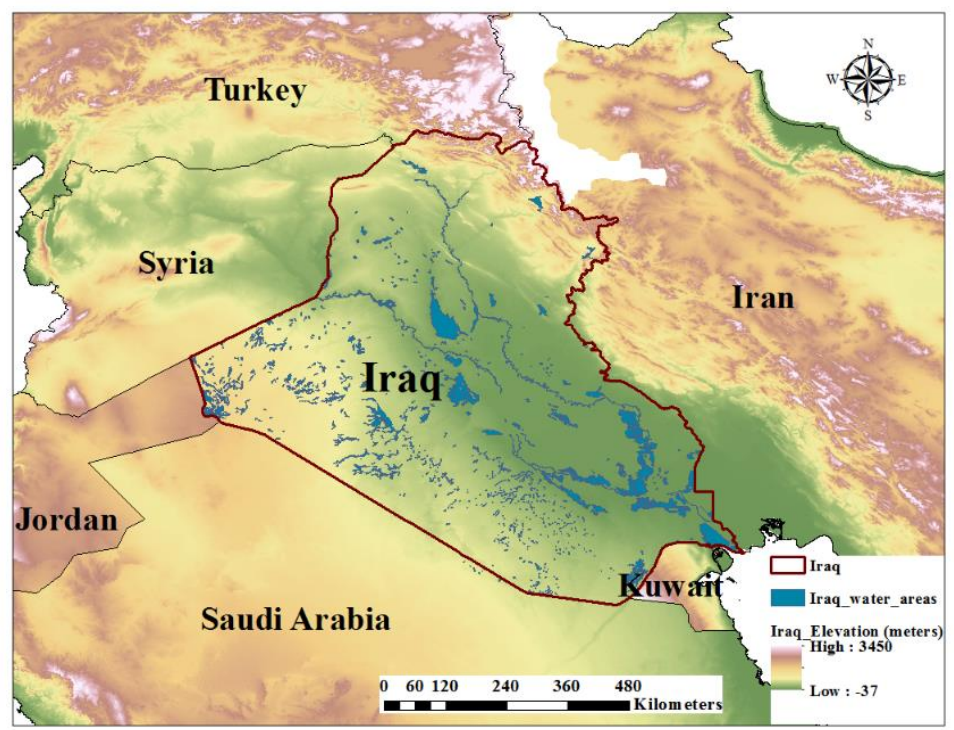

Figure 1-2 Elevation map of Iraq and neighboring countries (source: http://www.divagis.org).

\subsubsection{Methodology}

\section{- Standardized Precipitation Evapotranspiration Index}

The standardized precipitation evapotranspiration index (SPEI) is a multi-scalar drought index which was introduced by Vicente-Serrano et al. (Vicente-Serrano et al. 2010). The SPEI is a well-received drought index, which includes two climatic quantities: precipitation (P) and potential evapotranspiration (PET). The SPEI estimates water deficiency (D) by considering the difference between the monthly precipitation and potential evapotranspiration (P-PET). The water deficit (D) is the parameter used to explain drought. SPEI is a standardized index that can be calculated at different timescales. 
In this study, the accumulation period for SPEI is set to 12 months as an intermediate to long-term analysis. In order to calculate PET, different procedures can be adopted. PET equations can be classified as temperature-based, radiation-based, and a combination of both (Stagge et al. 2015a). Four of the most common PET methods are Penman-Monteith (PM) (Allen et al. 2006), Priestley and Taylor (PRIESTLEY and TAYLOR 1972), Hargreaves (Hargreaves and Samani 1985), and Thornthwaite (Thornthwaite 1948). The Penman-Monteith method (PM) is known as a temperatureradiation based method and is considered the standard method for PET estimation by the International Commission on Irrigation and Drainage (ICID), the Food and Agriculture Organization of the United Nations (FAO), and the American Society of Civil Engineers (ASCE). The simple version of (PM) method is the Priestley-Taylor (Colaizzi et al. 2014). However, both methods require at least climate data of daily average surface temperature, daily $\mathrm{min} / \mathrm{max}$ surface temperature, and wind speed (Stagge et al. 2015a) which are not available with acceptable accuracy for the study region. Nonetheless, Hargreaves and Thornthwaite method are simple methods that are commonly used, as they only require the temperature to calculate PET.

Some of the previous studies have indicated that the use of different PET techniques do not show a remarkable effect on drought assessment (Mavromatis T. 2007; Dai 2011b; Vangelis et al. 2013; Mohammed and Scholz 2017). Mohammed and Scholz (Mohammed and Scholz 2017) mentioned that there are no significant differences of using different PET approaches at low elevations and large time scales of 12 months and above. However, this might not be the case for small periods (e.g. 3, 6, and 9 months) and especially in 
mountainous regions. Beguería et al. (Beguería et al. 2014) showed that estimating drought indices using different PET methods is still questionable. They also found that using different PET methods to estimate the SPEI series could be significantly larger in semiarid regions, and smaller in humid regions.

Thornthwaite method as described by Vicente-Serrano et al. (Vicente-Serrano et al. 2010) is applied here for $0 \leq \mathrm{T} \leq 26.5^{\circ} \mathrm{C}$ as shown in Eq.1-1:

$$
P E T=16 * K\left(\frac{10 * T}{I}\right)^{m}
$$

Where $\mathrm{T}$ is the monthly mean temperature in ${ }^{\circ} \mathrm{C}$; $\mathrm{I}$ is a heat index, which is calculated from the sum of 12 monthly index values $i$, which is derived from the mean monthly temperature; $\mathrm{K}$ is a correction coefficient as a function of the month and latitude; and $\mathrm{m}$ is a coefficient depending on $\mathrm{I}$. For $\mathrm{T} \geq 26.5^{\circ} \mathrm{C}$, PET is determined directly from temperature as shown in Eq.1-2 (Willmott et al. 1985; Caporusso and Rolim 2015):

$$
P E T=\left(-415.85+32.24 T-0.43 T^{2}\right) * K
$$

In other words, the relationship between PET and $\mathrm{T}$ in hot weather is independent of the overall cold or warm conditions of the annual climate (Hulme et al. 1992). By calculating PET, the water deficit (D) is calculated for the month i using the formula:

$$
D_{i}=P_{i}-P E T_{i}
$$

To calculate the SPEI-12, a monthly time-series of water deficit (D) is accumulated to 12 months (starting from each month of the year) and then fitted to a probability distribution function. Choosing the most proper distribution for the water deficit is not an easy task and there is a discrepancy among the suggested distributions in different studies 
(Vicente-Serrano et al. 2010; Stagge et al. 2015a). Several studies have focused on frameworks for calculating standardized drought indices, and the methodology to calculate the indices have advanced over time. For instance, Stagge et al. (Stagge et al. 2015b) demonstrated that the optimal distribution for standardization may vary for different regions. Touma et al. (Touma et al. 2015) carried out analyses on several drought indices and they also reported varied candidate distributions for different locations. In recent years, more attention has been given to the non-parametric approaches (e.g. Huang et al (Huang et al. 2015)). The calculated drought index value was subject to the chosen distribution in the conventional distribution fitting approaches, and it was unbounded resulting in very high or very low values, which could affect long-term trends. The non-parametric approach relaxes such issues of the conventional methods and removes the subjectivity in the calculations (Ahmadalipour and Moradkhani 2017). Therefore, a non-parametric approach is more practical to use and more suitable for this study since the focus is on all drought types and not only the extreme drought (Ahmadalipour et al. 2016). In this study, the empirical Weibull plotting position (Weibull 1939; Makkonen 2006) is used as a nonparametric approach as shown in Eq. 1-4:

$$
p\left(x_{i}\right)=\frac{i}{n+1}
$$

Where $\mathrm{n}$ is the sample size, $i$ is the rank of data from the smallest, and $p\left(x_{i}\right)$ is the empirical probability. The final step for obtaining the SPEI is to standardize the outcomes of Eq. 4 as shown in Eq. 1-5:

$$
S I=\phi^{-1}(p)
$$


Where $\phi$ is the standard normal distribution function and $p$ is the empirical probability from Eq.1. The procedure is applied separately for each month for 692 grid cells covering Iraq. SPEI is then classified into seven categories ranging from extreme drought to extreme wet condition as shown in Table 1-2.

Table 1-2 Categories of dry/wet classes by the SPEI following McKee et al. (McKee et al. 1993).

\begin{tabular}{ll}
\hline \multirow{2}{*}{ Category } & SPEI values \\
\cline { 2 - 2 } & (min-max) \\
\hline Extremely dry & Less than -2 \\
Severe dry & -1.99 to -1.5 \\
Moderate dry & -1.49 to -1.0 \\
Near normal & -1.0 to 1.0 \\
Moderate wet & 1.0 to 1.49 \\
Severe wet & 1.50 to 1.99 \\
Extremely wet & More than 2 \\
\hline
\end{tabular}

- Drought Characteristics

The following drought characteristics are studied in this study:

- Spatial extent of drought

- Trends of drought intensity

- Frequency of drought (number of drought events)

- Duration of drought

Spatial extent of drought is assessed by calculating the ratio of the number of grids experiencing a certain type of drought (e.g. moderate, severe, and extreme drought) to the total number of grids across Iraq. The linear trends of drought intensity are detected for each grid according to SPEI during 1948-2009. Number of drought events is investigated 
over Iraq during 1948-2009. A drought event is defined when the SPEI falls below -1 (moderate drought condition or worse) and stays within dry threshold for more than two months. Similar procedure has been utilized in previous researches to assess drought frequency (e.g. Ahmadalipour et al. (Ahmadalipour et al. 2016) and Van Loon, A. F. (Van Loon 2015)). Drought duration is defined for each grid as the accumulative period of dry months experiencing each of the three types of drought (i.e. moderate, severe, and extreme). Therefore, drought duration refers to the total duration of dry period. Since the duration of droughts would vary a lot among different locations and drought events, the focus in this study is on the total drought duration. Lastly, the decadal spatiotemporal variations of PET and P are investigated over Iraq to better understand the effects of these two variables on drought.

\subsubsection{Results}

\section{- Spatial extent of drought}

Time series of decadal drought extent over Iraq is calculated for the three types of drought: moderate, severe, and extreme, and the results are shown in Figure 1-3. As it can be seen, the decadal patterns vary towards greater drought extent in the late 1990s and the 2000s. Unlikely, the other decades (1950s, 1960s, 1970s, and 1980s) show lower drought extent, which is usually moderate drought covering at most $83.5 \%$ of area in the late $1950 \mathrm{~s}$ with no extreme drought. However, severe drought reaches its maximum in the late 1990s with about $87 \%$ drought extent recording the worst drought in Iraq by the end of the 20th century. The 2007-2008 period seems to be the worst drought with about 55\%-82\% of Iraq experiencing extreme drought. 


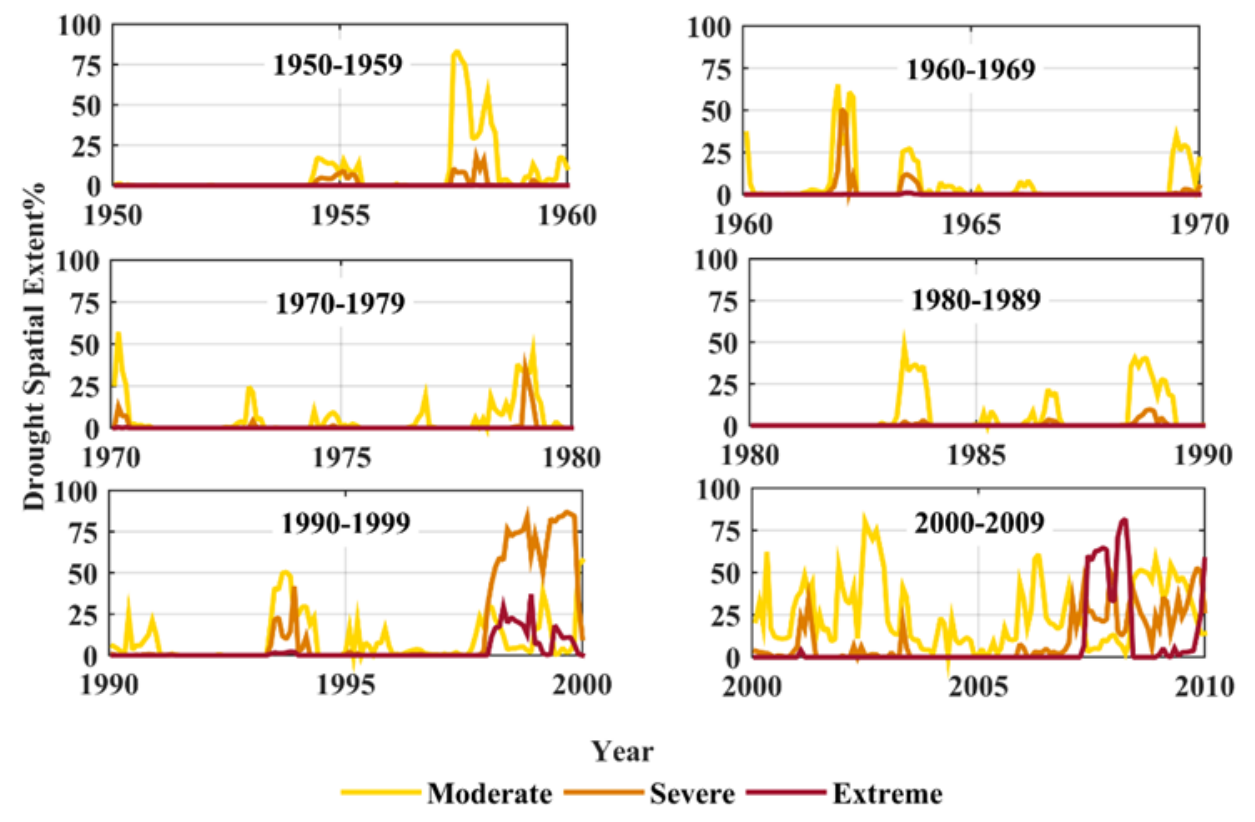

Figure 1-3 Decadal variations of drought spatial extent over Iraq.

The temporal variations of monthly drought condition (SPEI<-1) and wet condition (SPEI $>1)$ are studied by taking the ratio of the number of grids with SPEI $<-1$ and the grids with SPEI $>1$ to the total number of grids in Iraq during the study period of $1948-2009$ (Figure 1-4). From Figure 1-4, the wet condition governs the period of 1948 to 1997, whereas from 1998 to 2009 dry conditions are being experienced across Iraq. 


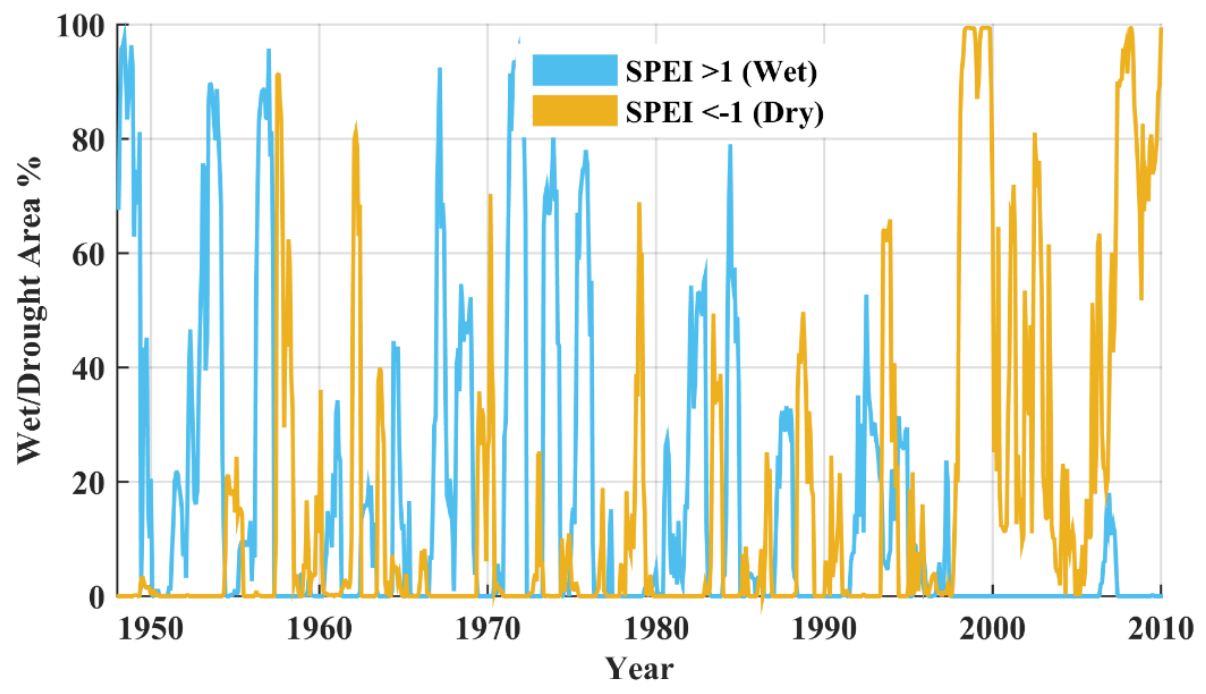

Figure 1-4 Temporal variations of monthly drought (SPEI $<-1)$ and wet (SPEI $>1)$ extent over Iraq.

To better understand the changes in the spatial extent of drought, the probability of SPEI drought extents are plotted for each drought type using the empirical CDF (Figure 15). To generate Figure 1-5, the time series of drought extent for each drought class is extracted for each period, and the cumulative probability distribution (CDF) of drought extent is obtained for each case. The stars refer to the drought extent at the 90th percentile chosen to compare the drought extent of each class between the two periods. In Figure 15, the empirical CDF is presented for two periods of 1948-1997 (wet period) and 19982009 (dry period), and the change in the distribution of drought extent is investigated. For the wet period, moderate drought governs about $25 \%$ drought extent at the 90 th percentile, while severe drought is about $2.5 \%$ at the 90 th percentile along with no extreme drought. However, the change of probability during the dry period (1998-2009) is more significant and indicates serious drought conditions over the region. Severe drought condition covers 
an area of about $68 \%$ at the 90th percentile. Moderate and extreme droughts show drought extents of about $51.1 \%$ and $29.4 \%$ at the 90 th percentile, respectively.

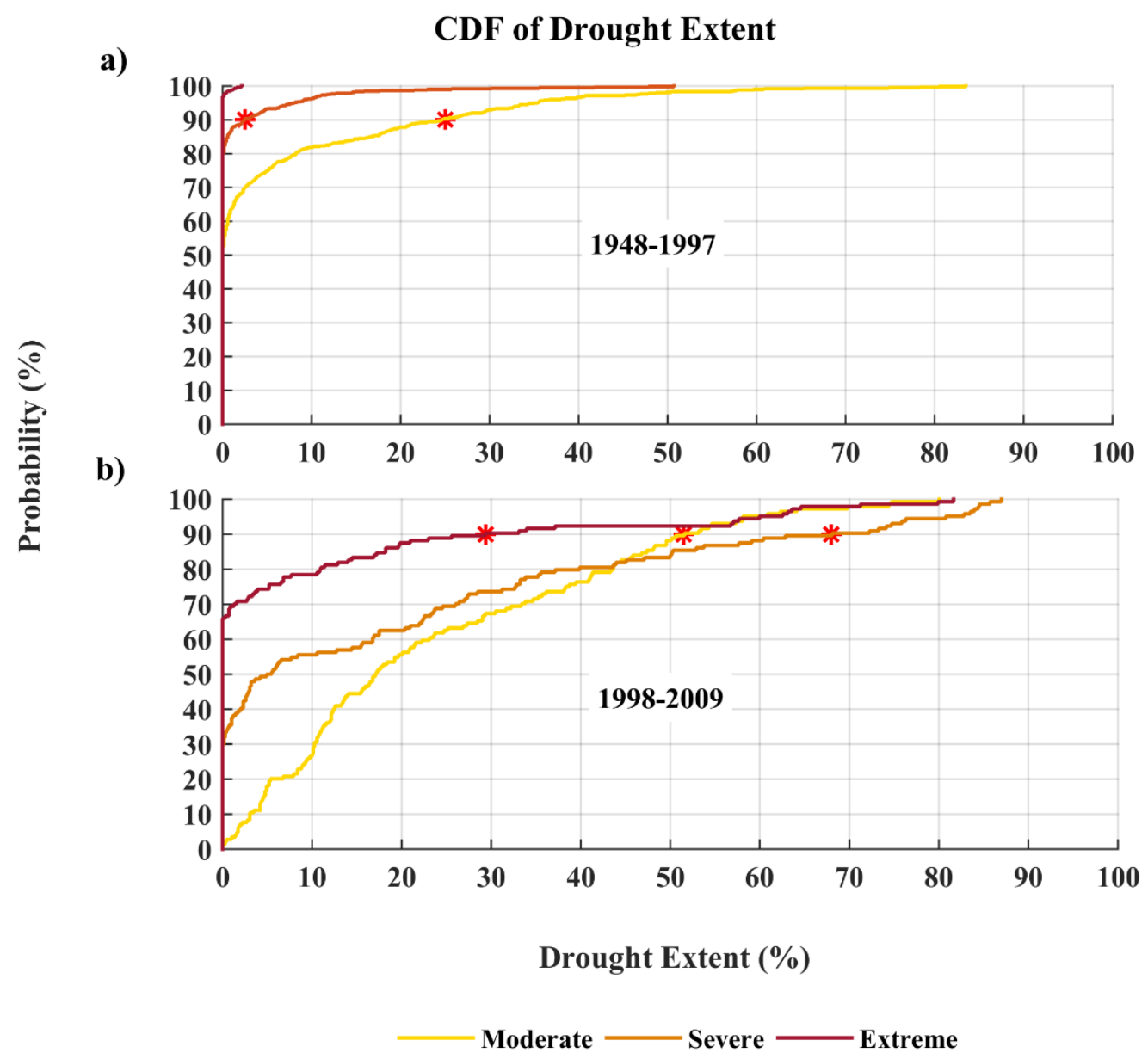

Figure 1-5 Probability of drought extent based on 12-month SPEI over Iraq for two periods: a) 1948-1997, b) 1998-2009. The stars represent drought extent at the $90^{\text {th }}$ percentile.

\section{- Trends of Drought Intensity}

Understanding the changes in drought intensity is another important step in drought analysis. Therefore, the trends of drought intensity are detected over Iraq according to the SPEI-12. Figure 1-6 shows the linear trend of SPEI for each grid cell 
during the study period (1948-2009). A negative trend indicates a decrease in the SPEI and therefore, an aggravation in drought intensity. For example, a trend value of -0.01 indicates that SPEI has decreased about 0.62 during the past 62 years $(0.01 \times 62=0.62)$ and therefore, drought has intensified. From Figure 1-6, all the grids across Iraq indicate a slightly negative trend for SPEI (intensification of drought). The most intensified drought trend of -0.0026 is detected mostly over the mid-west parts of Iraq indicating that SPEI has decreased about 0.16 during the past 62 years. However, the trends are not significant over the other parts of Iraq.

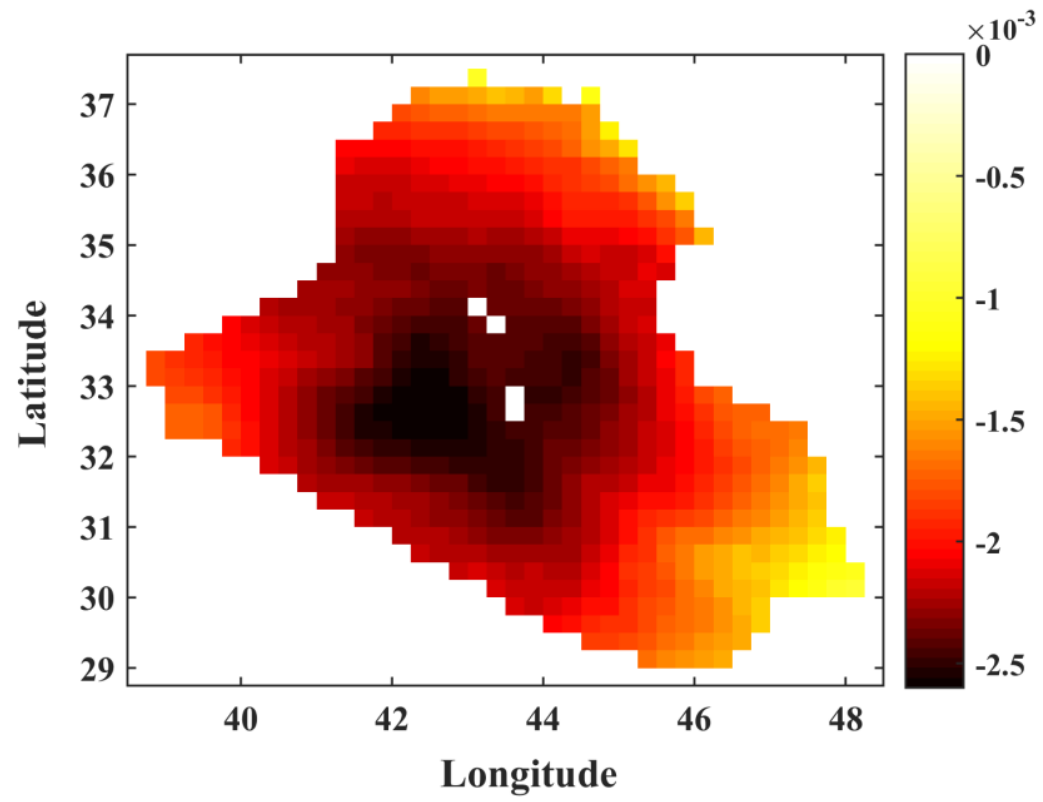

Figure 1-6 Long-term trends of drought intensity for the period of 1948-2009 according to the SPEI-12.

\section{- Frequency of Drought}

The number of drought events are investigated for each grid for the study period of 1948-2009, and the results are shown in Figure 1-7. Figure 1-7 shows the drought 
occurrence to be more frequent at the western, central, and southeastern parts of Iraq. However, the northern and southern parts indicate less frequent drought.

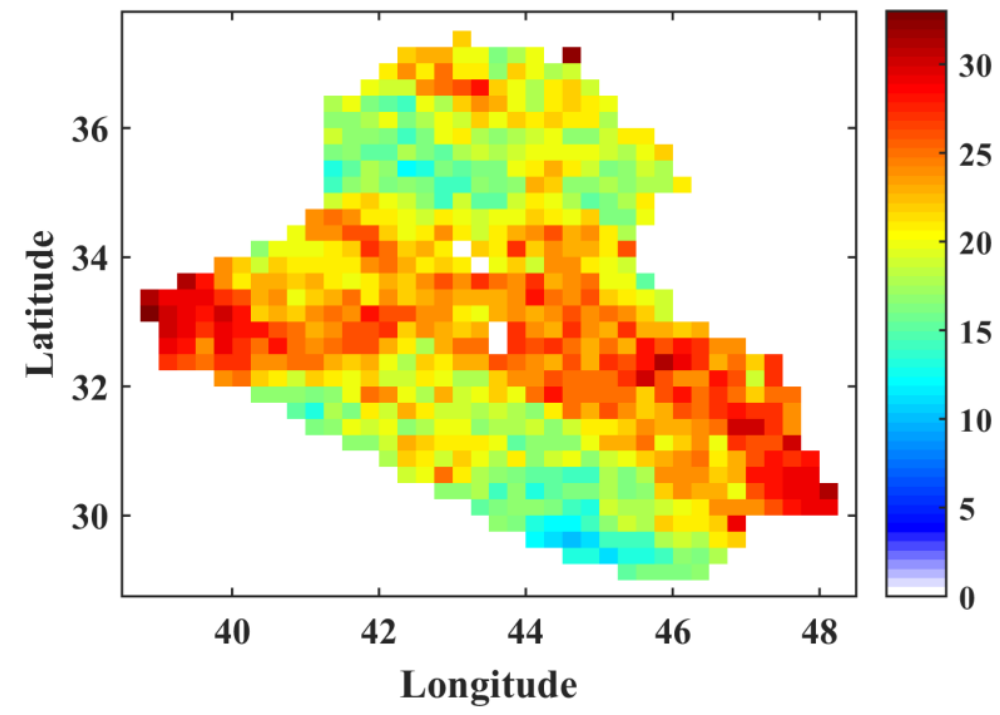

Figure 1-7 Drought frequency across Iraq for the period of 1948-2009 based on SPEI-12. A drought event is defined when the SPEI falls below -1 (moderate drought condition or worse) and stays within dry threshold for more than two months.

\section{- Duration of Drought}

Drought duration is calculated at a monthly timescale for three types of drought, i.e. moderate, severe, and extreme, for the period of 1998-2009 and the results are shown in Figure 1-8. Figure 1-8 shows that most of the drought that has happened over Iraq during 1998-2009 is moderate drought of up to 56 months at the southwestern parts of Iraq. Severe drought seems to happen similarly across Iraq, and most regions have faced about 30 to 36 months of severe drought during 1998-2009. Extreme drought condition happens rarely, as most of the grids show about 12 months of extreme drought condition in the period of 1998-2009. 

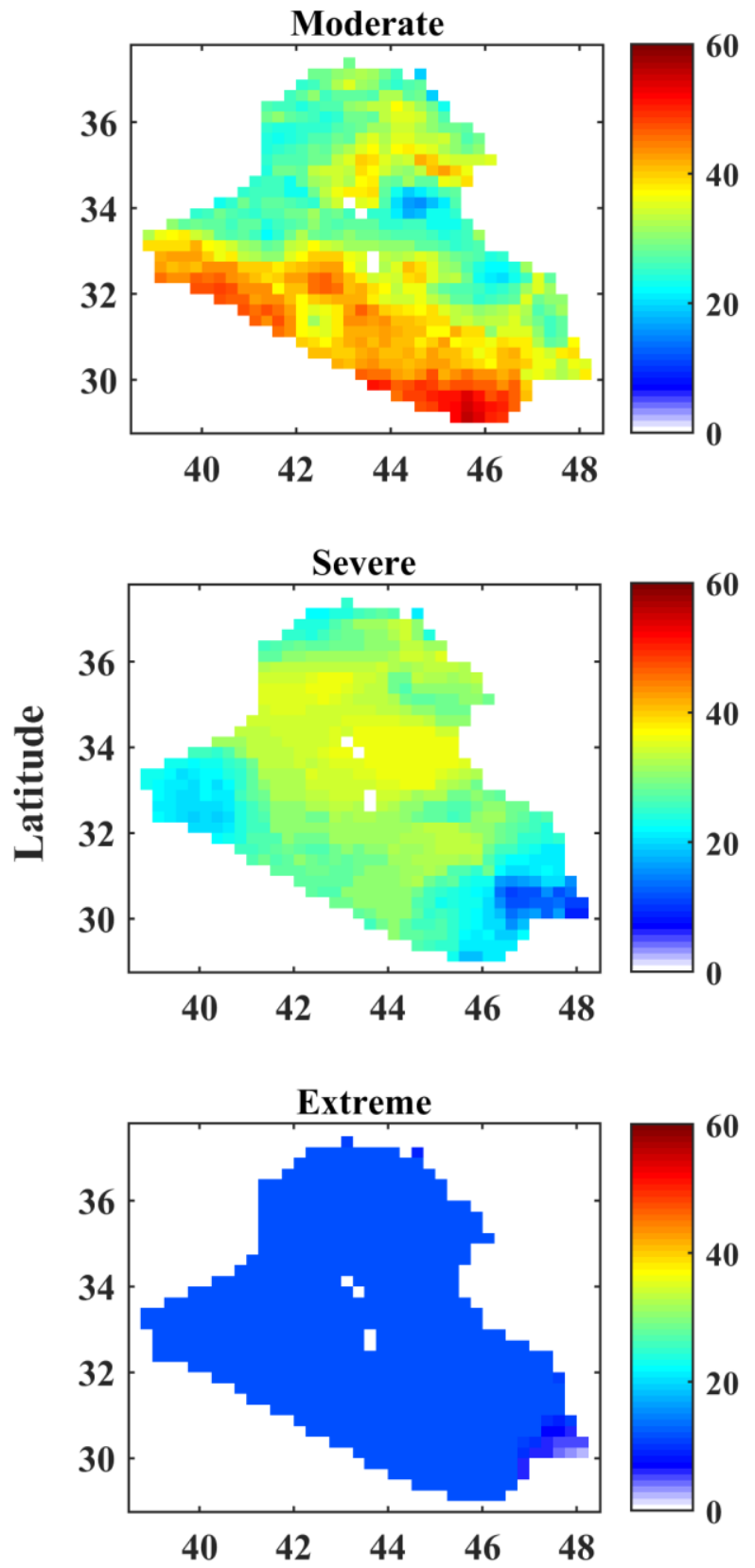

Longitude

Figure 1-8 Total duration of drought (in months) for the period of 1998-2009 for each drought type: moderate, severe, and extreme. 
Comparing the spatial patterns of drought frequency (Figure 1-7) and drought duration (Figure 1-8), it is noticed that the regions with higher drought duration correspond to lower drought frequency, and vice versa. Understanding such a pattern correspondence and considering the results of drought intensity analysis (Figure 1-6), it can be concluded that the central part of Iraq shows the most aggravating drought intensity. In other words, the spatial pattern of the long-term trend of drought intensity (Figure 1-6) is more correspondent to the spatial pattern of drought frequency (Figure 1-7) rather than drought duration (Figure 1-8).

At last, an assessment is carried out by focusing on Iraq as a whole and by generating the time series of the spatially averaged SPEI-12 over Iraq. To do so, the monthly precipitation and temperature data are spatially averaged over Iraq for each month in the study period (1948-2009), and the PET and water deficit (D) are calculated for the spatially averaged data to represent the entire Iraq. Then, SPEI- 12 is calculated providing a general idea about the fluctuations of dry and wet conditions across Iraq. Figure 1-9 shows the spatially averaged SPEI results for seven different conditions ranging from extremely wet (dark-blue color) to extremely dry (red color). The SPEI indicates a substantial decreasing trend (drying pattern) over Iraq. In the late 1950s, severe and moderate drought have occurred with the lowest SPEI values of -1.6 and -1.34 , respectively. Whereas, only moderate droughts have occurred in the 1960s, 1970s, and 1980 s with the lowest SPEI values of $-1.45,-1.25$, and -1.45 , respectively. The driest periods over Iraq are found to be the late 1990s with the lowest SPEI value of -2.4 (extreme 
drought) and 2000-2009 with the lowest range of SPEI values of -1.96 to -1.74 for severe drought and a value of -2.4 for extreme drought.

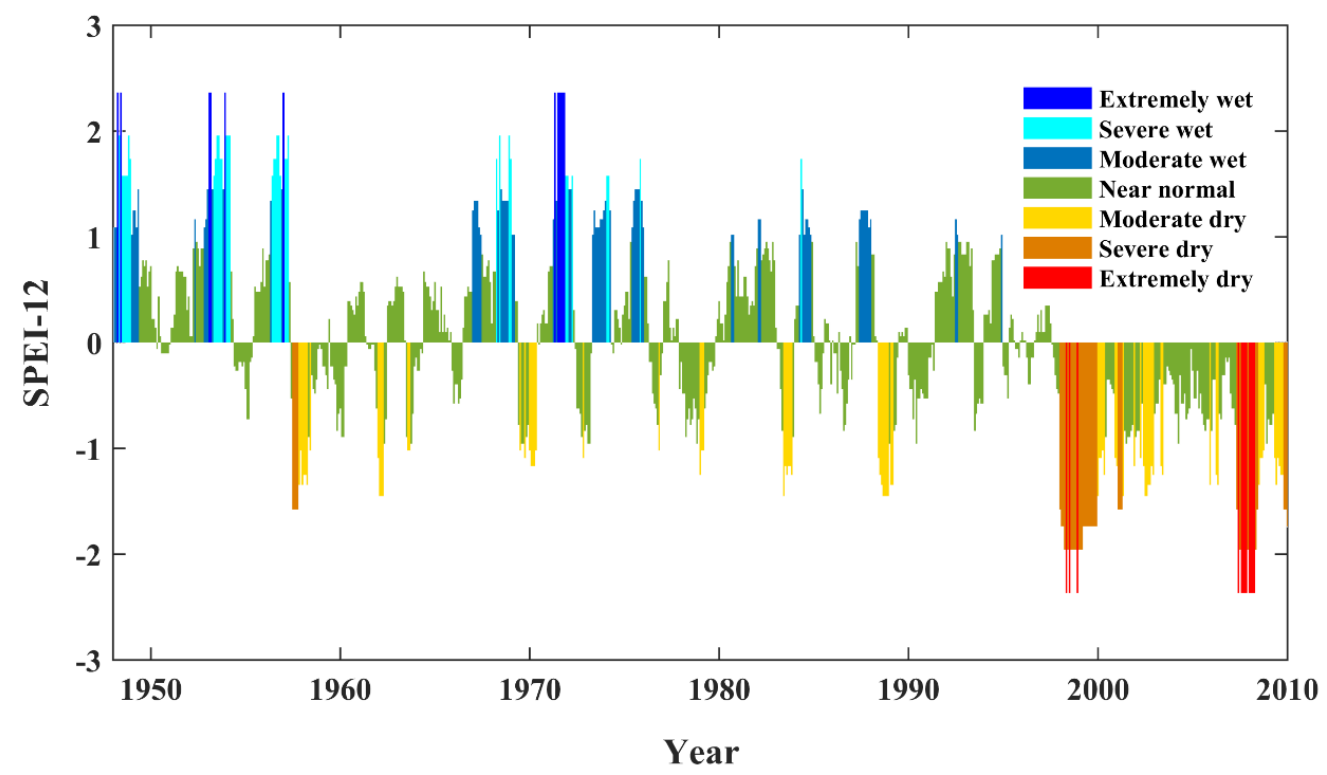

Figure 1-9 Time series of spatially averaged SPEI-12 over Iraq during 1948-2009.

\subsubsection{Discussion}

Many regions in the Middle East have faced serious drought-related challenges in the $21^{\text {st }}$ century, e.g. deficiency of precipitation, lack of irrigation water, and diminished water storage (UNDP 2010). Iraq is one of the Middle East countries that has also been facing serious drought conditions (Lelieveld et al. 2012). Therefore, questions may arise about the contribution of the climatic variables in drought occurrence in the region.

In this study, the SPEI was employed to study drought. SPEI accounts for variations in PET and precipitation $(\mathrm{P})$. The literature has proposed the application of PM method for 
SPEI calculation when data availability is not a limitation, while the Thornthwaite method can be used as an alternative when data is limited (Beguería et al. 2014).

In the present study, PET depends on temperature, and thus SPEI can be affected indirectly by temperature and directly by PET and P (Ahmadalipour et al. 2016). Therefore, it is of high importance to understand the contribution of these factors on drought. The decadal variations of annual PET and P for the period of 1950-2009 are shown in Figure 1-10. From Figure 1-10, PET has increased dramatically in the 1990s and 2000s with the highest PET values of $1349 \mathrm{~mm} /$ year and $1374 \mathrm{~mm} /$ year, respectively. The increase in PET is found mostly at the central, eastern, and southeastern parts of Iraq. These findings are correspondent to drought characteristics results of this study. For instance, drought extent has significantly increased in the late 1990s and most of the 2000s. Furthermore, the spatial pattern of drought frequency (Figure 1-7) is reasonably similar to PET. Likewise, PET variation is consistent with drought duration results, especially for moderate and severe drought conditions (Figure 1-8). From Figure 1-10, precipitation has decreased noticeably in the northern and northeastern parts of Iraq (the mountains region) and slightly over the rest of Iraq. The lowest amount of precipitation is found during the 1970s and 2000s, i.e. the mean precipitation of $539 \mathrm{~mm} /$ year in $1970 \mathrm{~s}$ and $545 \mathrm{~mm} /$ year in $2000 \mathrm{~s}$ were recorded in northern part of Iraq. 

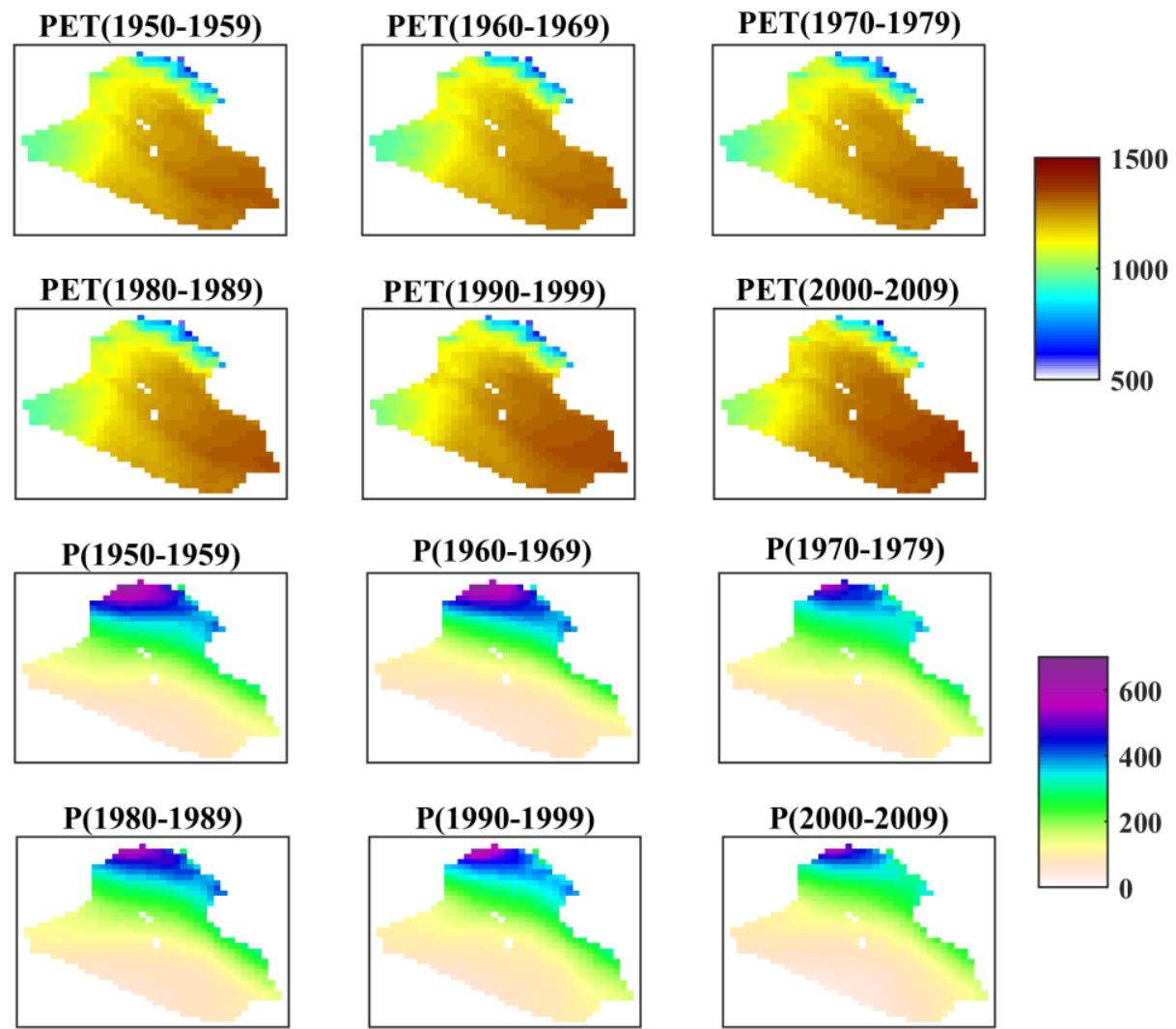

Figure 1-10 Decadal variations of annual potential evapotranspiration (PET) and precipitation (P) over Iraq from 1950 to 2009.

To better understand the impact of each climate variable on drought, the longterm trends of precipitation, temperature, and PET are calculated at a monthly timescale and the results are shown in Figure 1-11. From Figure 1-11, precipitation has decreased in the northern parts of Iraq. However, temperature has increased over the region mostly on the eastern part of Iraq. Most of Iraq has experienced increasing PET especially in the mid-west parts of Iraq. 

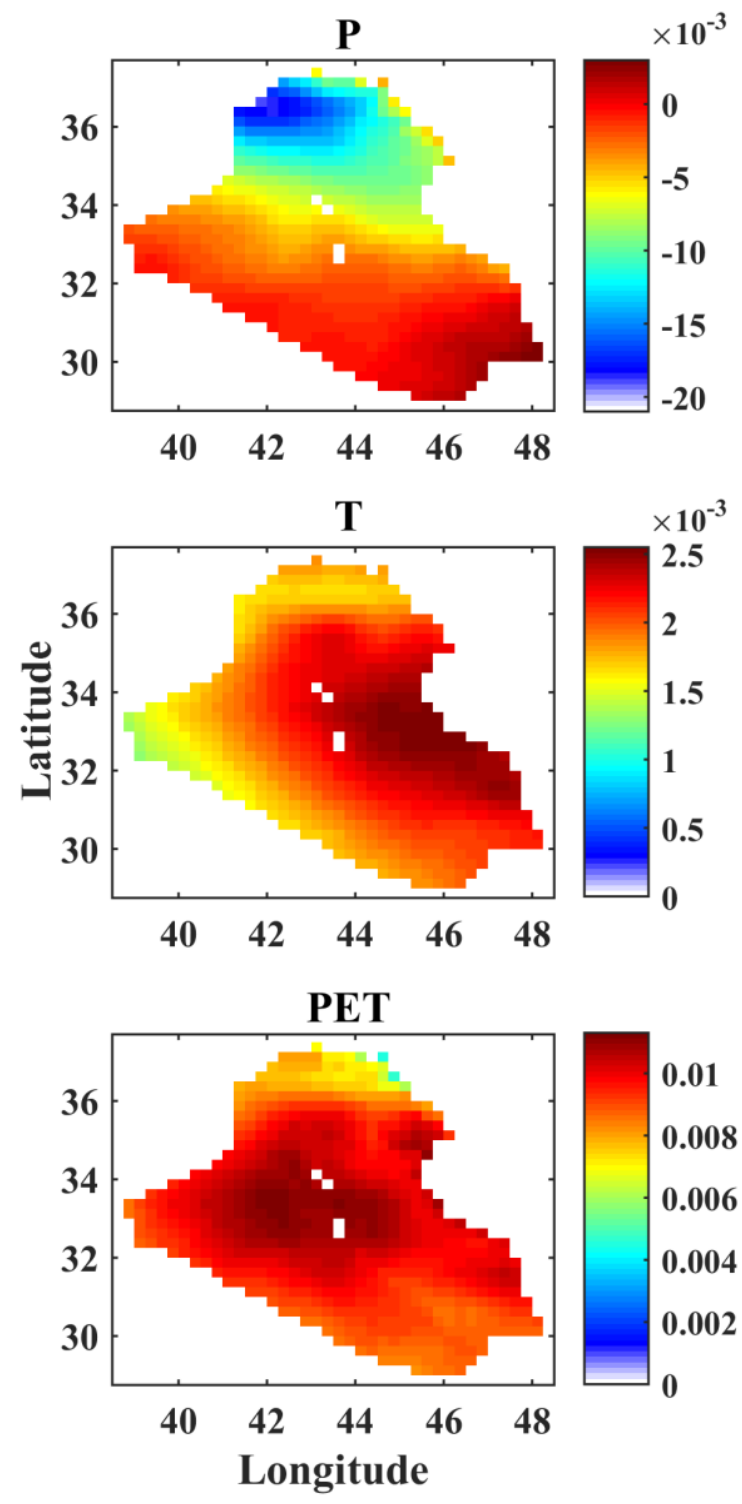

Figure 1-11 Long-term trends of P, T, and PET (mm/month) for the period of 1948-2009 according to the SPEI-12.

Shubbar et al. (Shubbar et al. 2016) reported that precipitation has decreased over Iraq and it has been accompanied by very high temperature and dust storms especially in summer when temperature higher than $45^{\circ} \mathrm{C}$ has been recorded in Baghdad city (the capitol of Iraq) and the southern parts of Iraq. Furthermore, Hoerling et al. (Hoerling et al. 2012) showed that the winter precipitation has changed toward drier conditions during the period 
of 1902-2010 in the Mediterranean region. They explained that after 1970, the drought occurrence has become more frequent over the region. The analysis of precipitation variations of this study (Figure 1-10) is in accordance with the findings of previous studies, i.e. the decrease in precipitation has occurred in the 1970s over Iraq.

The results of this study revealed a significant drought worsening across Iraq during the period of 1998-2009 versus a mild increase in drought extent for the period of 19481997. Gleick (Gleick 2014) reported that the Middle East and North Africa (MENA) region might experience temperature increase and precipitation decrease resulting in worse drought conditions in future.

In this study, two periods of severe drought during 1998-1999 and 2007-2008 were identified over Iraq droughts covered about $87 \%$ and $82 \%$ of Iraq in those periods respectively. These results are in accordance with the UNESCO report results where the results of SPI-12 showed a significant increase in drought severity during the period of 1999-2011 recording two significant drought years of 1999 and 2008 (UNESCO 2014).

Several other studies over Iraq and the Middle East region have also found similar results. Al-Faraj and Tigkas (Al-Faraj and Tigkas 2016) found that Diyala river basin has suffered from lack of precipitation along with higher temperature and potential evapotranspiration during the multi-year drought periods of 1999-2001 and 2008-2009. A study by AL-Timimi and AL-Jiboori (AL-Timimi and AL-Jiboori 2013) showed that the years 1983, 1990, 1998-2001, and 2007-2009 are the dry years over Iraq and considered years 1999 and 2008 as the driest years according to the SPI drought index. They also mentioned that all drought types occurred increasingly and reached the highest levels 
during the period of 2000-2010. Moreover, using GRACE it was found by Longuevergne et al. (Longuevergne et al. 2013) that the Total Water Storage (TWS) in the TigrisEuphrates basin declined by about $93 \mathrm{Km} 3$ during the drought period of 2007-2009 in the region. Voss et al. (Voss et al. 2013) studied the groundwater depletion using GRACE satellite mission in the north-central part of the Middle East. They also concluded that during the period of 2003-2009, the groundwater usage in Iraq increased due to drought and surface water shortage in the region.

Results of this study showed that drought has become more intense at the central and southwestern parts of Iraq compared to the northern and southeastern parts. Meanwhile, more frequent drought has been experienced at the western, central, and southeastern parts of Iraq. In terms of drought duration, moderate drought has been experienced with the longest duration of up to 56 months at the northeastern and southwestern parts of Iraq for the period of 1998-2009. Whereas severe and extreme droughts occurred with the duration of about 30 and 12 months, respectively.

\subsubsection{Conclusions}

This study investigated meteorological drought over Iraq during the period of 1948-2009 using a $0.25^{\circ}$ reanalysis dataset (GLDAS-2). Four major drought characteristics including drought extent, intensity, frequency, and duration were assessed using the SPEI-12 drought index. The main conclusions are summarized as follows:

- A drying trend is detected over Iraq with severe to extreme drought conditions governing the first decade of the 21 st century. 
- The worst drought condition has occurred during 2007-2008 when severe and extreme drought covered about $25 \%$ and $60 \%$ of Iraq, respectively.

- The intensity of drought has exacerbated during the past decades, with the most aggravation happening in the central regions of Iraq.

- Droughts are found to be more frequent but shorter at the western, central, and southeastern parts of Iraq.

In this study, the historical data were used to investigate various drought characteristics across Iraq. However, climate change is expected to have considerable effects on future drought. Therefore, assessment of future drought conditions using Global Climate Models (GCMs) is of high importance for Iraq, which can be further studied over the region. 


\subsection{Drought and Water Resources}

Lately, extreme events, i.e. droughts, floods, storm surges, and dust storms have occurred more frequently in most of the countries in the Middle East but rarely the consequences of these events have been considered in these countries (Elasha 2010). Frequent drought events have aggravated in the Fertile Crescent countries, namely, Iraq, Syria, Jordan, Israel, and western Iran since 2006 wet season. This long-term drying trend coincides with the active period of dust storms, which has evoked during the period of 2007-2013 in the region (Notaro et al. 2015). Given that agriculture is the most sensitive sector to drought (FAO 2017) and because of persistent drought over the Fertile Crescent region, the vegetation cover has decreased in the region intensifying dust occurrence in the aforementioned Fertile Crescent countries, and transporting dust to the Arabian Peninsula (Notaro et al. 2015).

On the water resources side, addressing the challenges of water deficiency for a region may differ across the spatiotemporal scales, according to people needs and resources availability (Rijsberman 2006). Figure 1-12 shows major hydrological basins in the Middle East. 


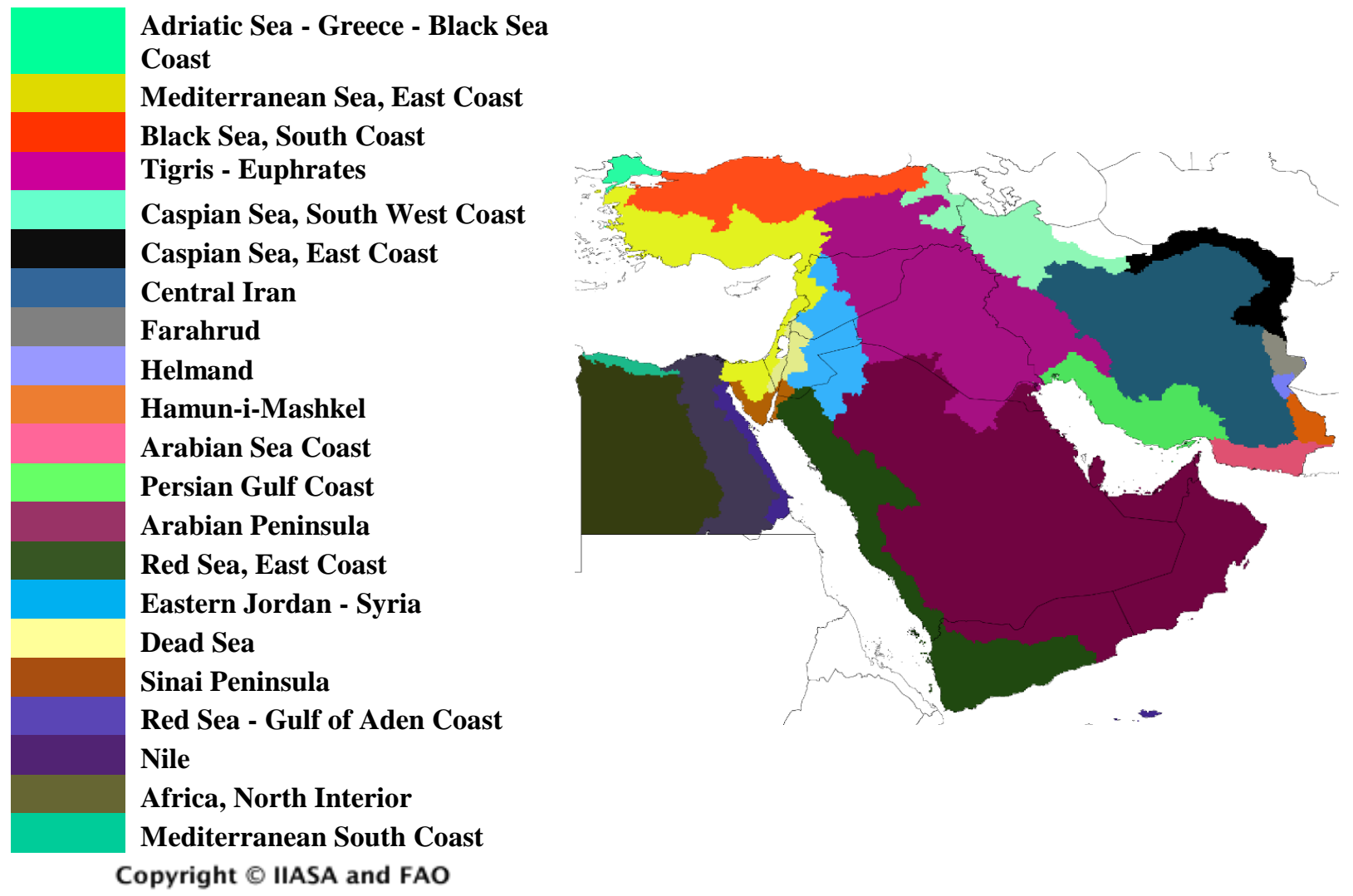

Figure 1-12 major hydrological basins in the Middle East

Countries in the Middle East and North Africa (MENA) region are exposed to water crisis in distinct mechanisms. For example, Iran and Lebanon have diverse water resources but are facing an interior distribution problem, GCC countries are facing massive renewable freshwater deficiency, and Iraq and Egypt are relying on transboundary water bodies (WEF 2010). Figure (1-13) shows water scarcity by major hydrological basins in the Middle East. 


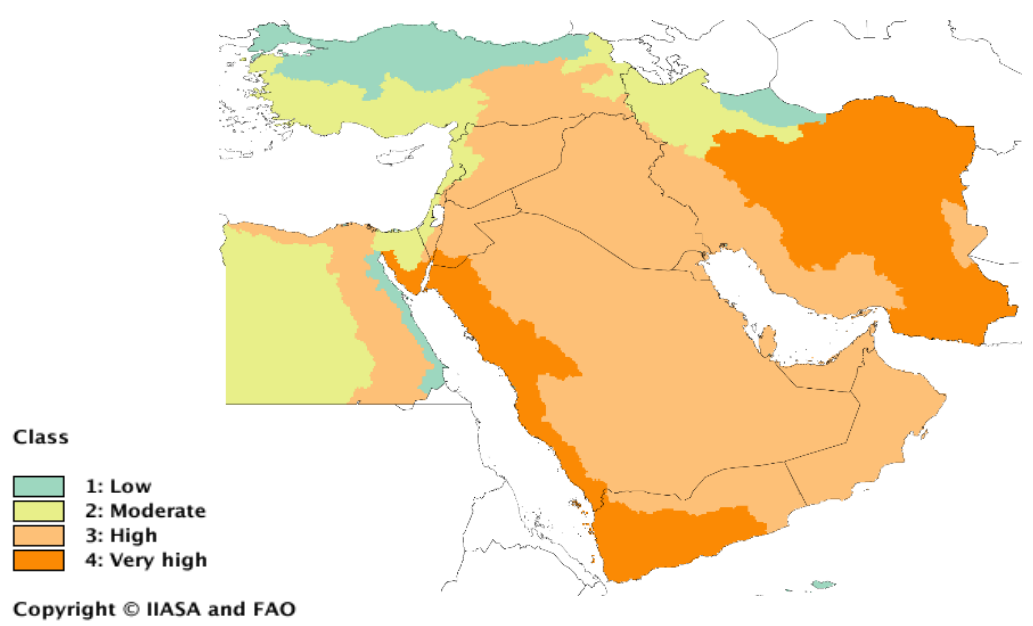

Figure 1-13 water scarcity by major hydrological basins in the Middle East

Countries in the MENA region are exposed to water crisis in distinct mechanisms. For example, Iran and Lebanon have diverse water resources but are facing an interior distribution problem, GCC countries are facing massive renewable freshwater deficiency, and Iraq and Egypt are relying on transboundary water bodies (WEF 2010). Negewo (2012) mentioned that for the period of 2000-2009, the Gulf countries had the lowest per capita water availability in the MENA region, with an annual average of $<300 \mathrm{~m}^{3} /$ capita. The author further suggested that according to the projections for the period of 2020-2030, most of the MENA countries may have a mean annual of $<200 \mathrm{~m}^{3} /$ capita (Table $1-3$ ). 
Table 1-3 Water stress by country after Negewo (2012)

\begin{tabular}{ccc}
\hline Country & $\begin{array}{c}\text { Average water availability } \\
\left(\mathbf{m}^{3} / \mathbf{c a p i t a}\right) \mathbf{2 0 0 0 - 2 0 0 9}\end{array}$ & Average water availability $\left(\mathbf{m}^{\mathbf{3}} / \mathbf{c a p i t a}\right) \mathbf{2 0 2 0 - 2 0 3 0}$ \\
\hline Syria & $>1,000$ & $501-1,000$ \\
\hline Iraq & $>1,000$ & $<200$ \\
\hline KSA & $200-500$ & $<200$ \\
\hline Iran & $501-1,000$ & $200-500$ \\
\hline Kuwait & $<200$ & $<200$ \\
\hline Bahrain & $200-500$ & $<200$ \\
\hline Qatar & $200-500$ & $<200$ \\
\hline UAE & $<200$ & $<200$ \\
\hline Oman & $200-500$ & $<200$ \\
\hline Yemen & $<200$ & $<200$ \\
\hline Jordan & $<200$ & $<200$ \\
\hline Palestine & $<200$ & $200-500$ \\
\hline Israel & $501-1,000$ & $200-500$ \\
\hline Egypt & $501-1,000$ & $<200$ \\
\hline Lebanon & $200-500$ &
\end{tabular}

The Food and Agriculture Organization (FAO) of the United Nation in 2014 listed Yemen and Jordan as countries under absolute water scarcity whereas Egypt and Syria as countries under chronic water scarcity of $<500 \mathrm{~m}^{3} /$ year and $500-1000 \mathrm{~m}^{3} /$ year of total renewable water resources per inhabitant. Iraq, Iran, and Turkey are listed as water stressed countries of $1000-1700 \mathrm{~m}^{3} /$ year of total renewable water resources per inhabitant (Waterbury 2017). However, Jordan is the most water scarce country in the Middle East and globe with its annual renewable resources of $145 \mathrm{~m}^{3} /$ capita (Berg et al. 2016). 


\subsection{Objectives of Dissertation}

The objective of this dissertation is to assess food insecurity in Middle East, as a function of drought, water availability, energy, and other socio-economic factors in the region. The primary objectives of the study can be categorized as follows:

i. Providing an overview of the current challenges related to Food-Energy-WaterSecurity (FEWS) nexus in the Middle East (Chapter 2)

ii. Providing a quantitative assessment for sixteen selected countries in the Middle East to identify the issues and interpret the results as pertained to the nexus concept (Chapter 2)

iii. Performing a comprehensive assessment of drought and socio-economic variables to analyze food insecurity in Middle East (Chapter 3)

iv. Analyzing the historical variations and trends of meteorological, agricultural, and hydrological droughts over the Middle East (Chapter 3)

v. Utilizing climate data and multi-scalar drought indices to investigate historical drought in the Middle East (Chapter 3)

vi. Applying a Bayesian framework to find the best model that define food insecurity in the Middle East (Chapter 3) 


\section{Chapter 2: Challenges in the Food-Energy-Water-Security Nexus in the Middle East}

\subsection{Background}

Despite the fact that water, food, and energy sectors are of high importance to sustain and develop human life, access to secure water, food, and energy is not an option for everyone in the world. Globally, it is reported that 1.2 billion of people have no access to safe water (Garcia and You 2016). Therefore, it is crucial to understand the complicated connection between food, energy, and water sectors to insure a safe and sustainable development for any nation (Hamdy et al. 2014). Typically, there is no single definition of nexus but globally nexus is introduced as a process of linking stakeholders' ideas and activities under various conditions (i.e. sectors and states) to attain sustainable evolution (Endo et al. 2015). The Stockholm Environment Institute (SEI) in the Bonn 2011 Nexus Conference introduced the water-food-energy nexus where it first started. Next, the 2011/2012 European Report on Development proposed the water-energy-land (WEL) nexus.

Studies in the Middle East about the nexus concept have been conducted recently. Dubreuil et al. ( 2013) proposed an optimized model to assess the water-energy nexus in the Middle East region taking into account the reused water and the non-conventional water, i.e. desalination and wastewater. Saif et al. (2014) analyzed the current state of water resources in the Gulf Cooperation Council (GCC) countries. The authors concluded that the region faces serious challenges in water-food security systems. Al-Mulali and Ozturk (2015) studied the reasons behind the environmental degradation in the MENA region and 
discovered that ecological footprint, energy consumption, urbanization, trade openness, industrial development and political stability are the main contributors to induce environmental degradation in the region. Moreover, a water- energy-food nexus modeling tool was developed by Daher and Mohtar (2015); the tool provides an assessment of resources demand under different scenarios. Another study by Magazzino (2016) investigated the carbon dioxide emissions, economic growth, and energy use nexus for a total of ten Middle Eastern countries, i.e. GCC countries, Iran, Jordan, Syria, and Yemen, for the period 1971-2006.

Other dimensions can be integrated with the FEW nexus to address sustainability challenges and opportunities involving trade-offs, i.e. land, climate, and ecosystems (Chang et al. 2016). The climate dimension has been linked with either all or some of the sectors in FEW system (Chenoweth et al. 2011; ESCWA 2011; Sowers et al. 2011; UNWater 2011; El Kharraz et al. 2012; Scanlon et al. 2013; King and Jaafar 2015; Howarth and Monasterolo 2016; Berardy and Chester 2017; Feitelson and Tubi 2017). Al-Saidi et al. (2016) developed a Country Vulnerability Index of Water Resources (CVIW), which is a country-level vulnerability assessment in the MENA region. The index is a combination of socio-economic and natural components considering energy and virtual water, that is the required amount of water to produce a product (Antonelli and Tamea 2015), interconnections.

This study was designed to provide an overview of the current issues related to FEWS nexus in the Middle East region. A quantitative assessment for sixteen selected countries in the region is carried out to identify these challenges and interpret the results as 
pertained to the nexus concept. The following sections will present the assessment of the FEWS nexus in Middle East.

\subsection{The Food-Energy-Water-Security (FEWS) Nexus Middle East in the $21^{\text {st }}$ century}

\subsubsection{Food security}

The right that all individuals at any time have access to adequate, safe, and healthy food in meeting the required nutrients and food desire to insure vital and nutritious life is called food security (ESCWA 2010). Two conclusive factors should be considered determining food security: food quantities and demand. In other words, how much food can be produced under certain amount of water and environmental circumstances that is economically affordable? (Falkenmark and Lundqvist 1998). For instance, KSA was the sixth largest wheat exporter by the last decade of the 20th century; however, this was at the expense of groundwater depletion in the region resulting in unsustainable agricultural production (Ahmed et al. 2014).

Food production is the most limited sector by water scarcity in the Arab region (Sewilam and Nasr 2017). Figure 3-1 shows the Global Food Security Index (GFSI) for the years of 2012, 2014, and 2016 across the Middle East region. The GFSI accounts for the fundamental issues of food affordability, availability, quality, and safety in 113 countries around the world (EIU 2017). From Figure 2-1, Israel, Qatar, and Kuwait are categorized as the best environment during the selected years. However, Syria and Yemen are classified as countries that need improvement. 


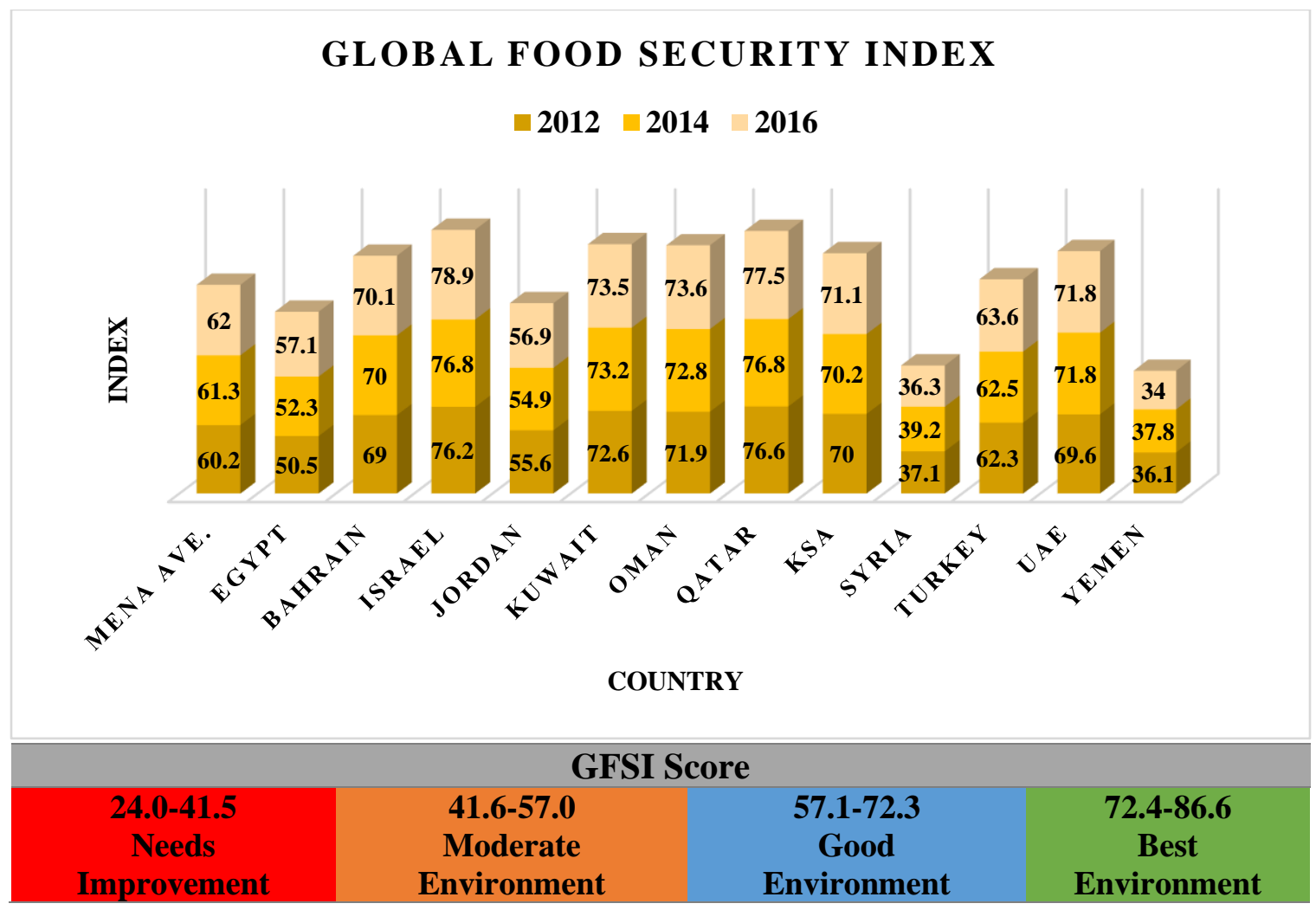

Figure 2-1 Global Food Security Index (0-100, $100=$ best environment). Note: not listed countries means the GFSI is not provided by the source for these countries due to data unavailability. Source: https://idea.usaid.gov/cd/egypt/hunger-and-food-security

\subsubsection{Energy security}

Energy security concept may include a broad range of aspects. Some of these aspects can be motivated by energy supply, geopolitical power, economic growth, sustainability, and social expansion (Willis et al. 2016). In 2012, the Middle East countries consumed about $6.6 \%$ of total residential energy consumption of the world. Moreover, it is projected to increase by $1.9 \% / y e a r$ on average in the IEO2016 Reference case. It is worth mentioning that electricity is the main consumer of energy in the Middle East region (EIA 2016). For instance, buildings account for $35 \%$ on average of total energy consumption in Arab countries (AFED 2012). 
The Middle East has a significant impact on the oil/gas market in the world. That the main income source to the Middle Eastern countries is oil and natural gas resources. More than $56 \%$ of the world oil reserves and about $36 \%$ of the world natural gas reserves are in the Middle East (Nematollahi et al. 2016). In 2009, the five largest natural gas reserves reported in the world were Russia, Iran, Qatar, KSA, and UAE, respectively (IEA 2014). Although the natural gas production has increased considerably in the Middle East during the period of $2010-2014$, the demand has also increased significantly in the region due to population growth, economic expansion, urbanization, and desalination plants (IEA 2016). As a result, Qatar, KSA, and UAE are facing considerable energy deficiency mainly in the natural gas resources (IEA 2014).

According to the Regional Center for Renewable Energy and Energy Efficiency (RCREEE) 2015 report, Jordan performs the best among 12 Middle Eastern countries given its energy efficiency status. Figure 2-2 displays the efficiency status of energy in the Middle East. The energy efficiency score reported in Figure 2-2 is evaluated under four categories, that is energy pricing, policy framework, institutional capacity, and utility (RCREEE 2015). 


\section{Energy Efficiency Status}

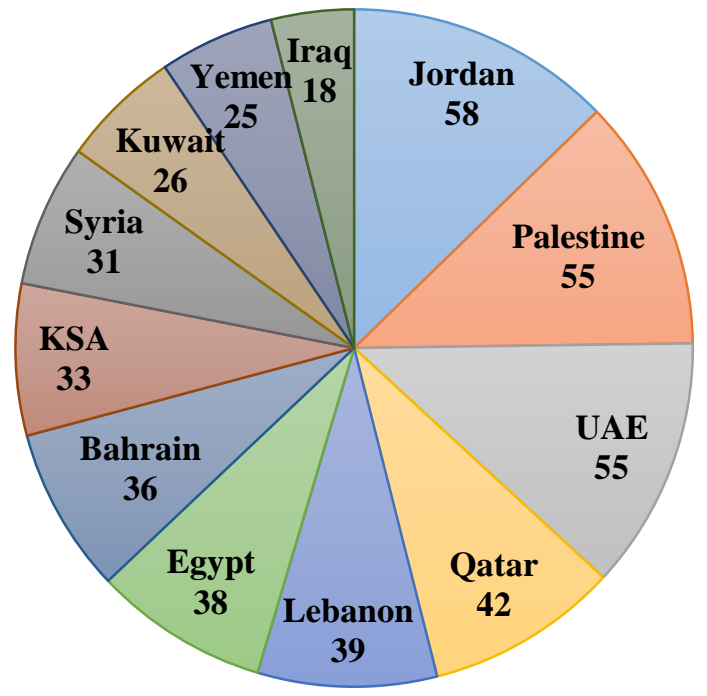

Figure 2-2 Energy Efficiency Status in the Middle East (RCREEE 2015).

Although the Arab region has abundant resources of renewable and non-renewable energy, the region is one of the most energy insecure regions in the globe. The absence of coherent policies, endowments, and governance can be the reasons behind energy insecurity in the region (ESCWA 2016a). The prospective of solar and wind energy sources were estimated in the Middle East by Nematollahi et al. (2016). The results showed that the Middle East is of high potential to use renewable energy resources. Furthermore, El Bassam (2017) mentioned that the Middle East has the highest potential of solar energy source on the earth. However, solar energy accounts for less than $0.2 \%$ in average of the electricity supply in the region. In addition, the percentage of the used renewable energy in electricity production (including hydro) in the Middle East has decreased from $4.3 \%$ in 2005 to $2.2 \%$ in 2015 (IEA 2016) whereas, electricity production by wind energy is approximately $0.6 \%$ in the Arab region (Hajj 2017). 


\subsubsection{Water security}

Water security is defined by the UN as the proportion of people that can insure sustainable access to sufficient amounts of usable water to sustain living needs, human welfare, and socio-economic progress; to protect people from water related pollution and disasters, and to guard ecosystems in peaceful and politically stable circumstances (UNWater 2013). Water security is the most risky challenge in the Arab region (Mohtar et al. 2017). Freshwater in the Arab region has declined due to the reliance on transboundary water bodies, poor water quality, political instability, climate change, non-beneficial water losses, absence of water use efficiently, and excessive population growth (ESCWA 2016b). In addition, the mean annual evaporation rate might exceed $2000 \mathrm{~mm} /$ year which contributes significantly to freshwater reduction in the region (Saleh et al. 2010). In 2011, most of the Arab countries reported that the total renewable water resources were less than $1000 \mathrm{~m}^{3} /$ capita, which represents the water poverty line. For Bahrain, Kuwait, Qatar, KSA, UAE and Yemen, the total renewable water resources were even less than $100 \mathrm{~m}^{3} / \mathrm{capita}$ (ESCWA, 2015).

Groundwater depletion is of high concern in the Middle East especially in the Gulf countries where groundwater has over-exploited for irrigation and agricultural purposes. Extreme pressure on the already scarce groundwater resources in the GCC countries has occurred because of rapid population growth, urbanization, industrialization, and agricultural production since the 1970s (Saif et al. 2014). Therefore, currently the Gulf countries are mainly relying on the desalinated water supply to assure their water demands 
(Keulertz et al. 2016). However, water production via the desalination process has increased energy consumption.

Moreover, Industry is one of the main drivers of water usage in the Middle East especially crude oil industry. Figure 2-3 shows water consumption in industry in the Middle East in 2011 Oil exporter countries use large amounts of water to produce crude oil. For instance, KSA consumes about $16,389 * 10^{5} \mathrm{~m}^{3} / \mathrm{year}$ of its water in crude oil production (Sakhel et al. 2013). Using brackish water or dry cooling and encouraging renewables can save more water for energy in power-plant generation. In oil and gas industries, water can be conserved by reusing the produced water (Scanlon et al. 2017).

The transition in fresh water demand for energy extraction and conversion was examined in the MENA region over the $21^{\text {st }}$ century by considering population growth and economic production. It is found that by improving efficiency, depending on renewable energy, and minimizing energy exports, water consumption for energy is twice the current amount, which is $2 \%$ of the available sustainable supply, by the end of the current century. In contrast, the water consumption might be five times as high as the current amount in the case of continuing the use of fossil resources in the region (Damerau et al. 2015). Climate change and social development including population growth, globalization, economic progression, and urbanization play a part in emerging the food-energy-water (FEW) nexus (Endo et al. 2015). Therefore, the next section will highlight the predominant challenges in the Middle East and their interconnection with the FEWS nexus in the region. 


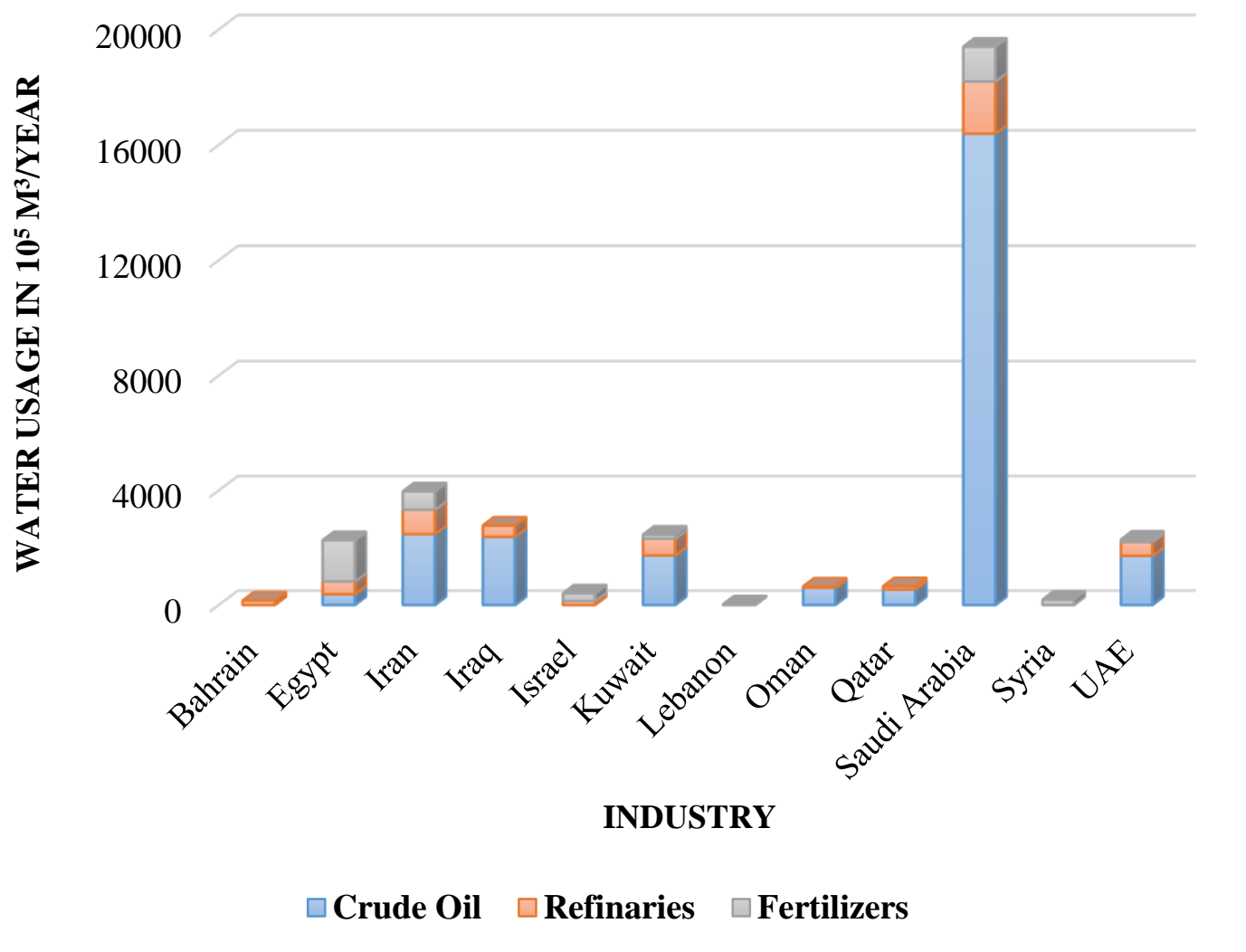

Figure 2-3 Water consumption in industry in the Middle East in 2011 (Sakhel et al. 2013).

\subsection{The Challenges in the Middle East in the $21^{\text {st }}$ century}

\section{- Water scarcity}

Addressing the challenges of water deficiency for a region may differ across the spatiotemporal scales, according to people needs and resources availability (Rijsberman 2006). Rijsberman (2006) defined the water being "insecure" when safe and consumable water is not available to satisfy individual living needs whereas he defined the water being "scarce" when a large group of people is water insecure for a long period in a specific 
region. Dubreuil et al. (2013) explained that water scarcity happens when the water demands exceed water supply.

The Middle East region is one of the most arid regions in the world suffering significantly from scarce water resources (Paul et al. 2016). Despite the fact that large rivers are located in the Middle East region, transboundary water resources are also a struggle in the region. For example, the Tigris-Euphrates basin water is shared between Turkey, Syria, and Iraq. Mainly, Turkey has been controlling the discharge of both rivers across its borders with Syria and Iraq. Turkey has constructed 15 major dams on the Tigris and Euphrates rivers. Based on FAO AQUASTAT Database, $98 \%$ of Turkey water resources originate within its borders. Whereas Syria and Iraq respectively have about $28 \%$ and $39 \%$ of their water inside their borders (Waterbury 2017). Figure 2-4 expresses the percent of total renewable water resources that originate outside the country borders. From Figure 2-4, Kuwait, Egypt, and Bahrain are the most dependent countries on the shared water resources from neighboring countries. 


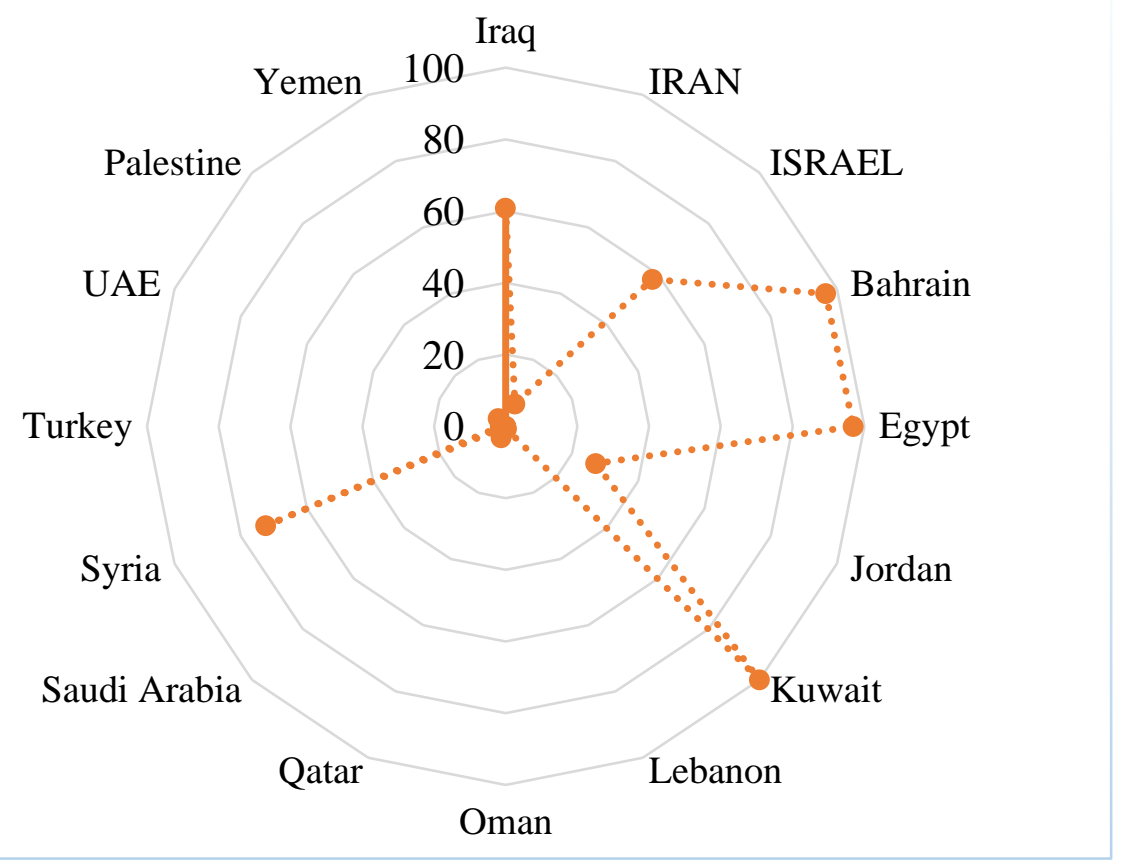

Figure 2-4 The percent of total renewable water resources originating outside a country. A country with a dependency ratio equal to $0 \%$ does not receive any water from neighboring countries. A country with a dependency ratio equal to $100 \%$ receives all its renewable water from upstream countries, without producing any of its own.

Negewo (2012) mentioned that for the period of 2000-2009, the Gulf countries had the lowest per capita water availability in the MENA region, with an annual average of < $300 \mathrm{~m}^{3} /$ capita. The author further suggested that according to the projections for the period of 2020-2030, most of the MENA countries might have a mean annual of $<200 \mathrm{~m}^{3} /$ capita. Voss et al., (2013) reported that about $144 \mathrm{~km}^{3}$ of water was depleted mostly from the groundwater in the Tigris-Euphrates-Western Iran region during the period of 2003-2009 due to a combined effect of drought and groundwater withdrawals. The authors further concluded that water depletion resulted in drop of crop yields and economics in the region. On the other hand, water scarcity in the Middle East is a limitation factor on energy productivity (IEA 2014). 


\section{- Extreme Events: Droughts, Flood, Storm Surges, and Dust Storms}

Disaster risk management is one of the top concerns in the MENA region. Floods, droughts, and earthquakes events are the most risky catastrophes that threaten growth and resources security in the region. Historically, it is identified that food security is vulnerable to extreme weather events. Moreover, these events constitute a potential risk to water security due to water deficiency (Silva et al. 2018). For the period of 1981-2011, it is reported that $53 \%$ of the total number of disasters in the MENA region was floods, $24 \%$ was earthquakes, and about $10 \%$ for storms and droughts. However, data availability is a limitation for drought events records (The World Bank 2014).

In most arid regions, flash flood is a natural phenomenon because rainfall can be very intense in a short time period and especially when these events accompanied with the presence of dry or low infiltration capacity soils in the region (Deng et al. 2015). The flash flood events in 2009, 2010, and 2011 in KSA were documented as the worse since the 1980s (The World Bank 2014). Regarding the seismic risk, Iran is the most vulnerable country in the Middle East to seismic hazard where it accounts to about $95 \%$ of the total mortality during catastrophes in Iran. Moreover, Egypt and Yemen have also experienced earthquake events, floods, and landslides (The World Bank 2014). These events are crucial risk of failure in infrastructures concerning energy security as well in the region.

Figure 2-5 shows number of deaths caused by different weather events, i.e. storms, floods, temperature extreme and mass movements, for the years of 2005, 2010, and 2015. From the Figure, Yemen lost the highest number of people in the Middle East because of weather events in the years of 2005 and 2010. Whereas, the highest number of mortality in the 
region due to weather events were 145 and 140 in Egypt and KSA, respectively, in 2015. These numbers are much higher than the average number of mortality caused by weather events in the MENA region (Figure 2-5).

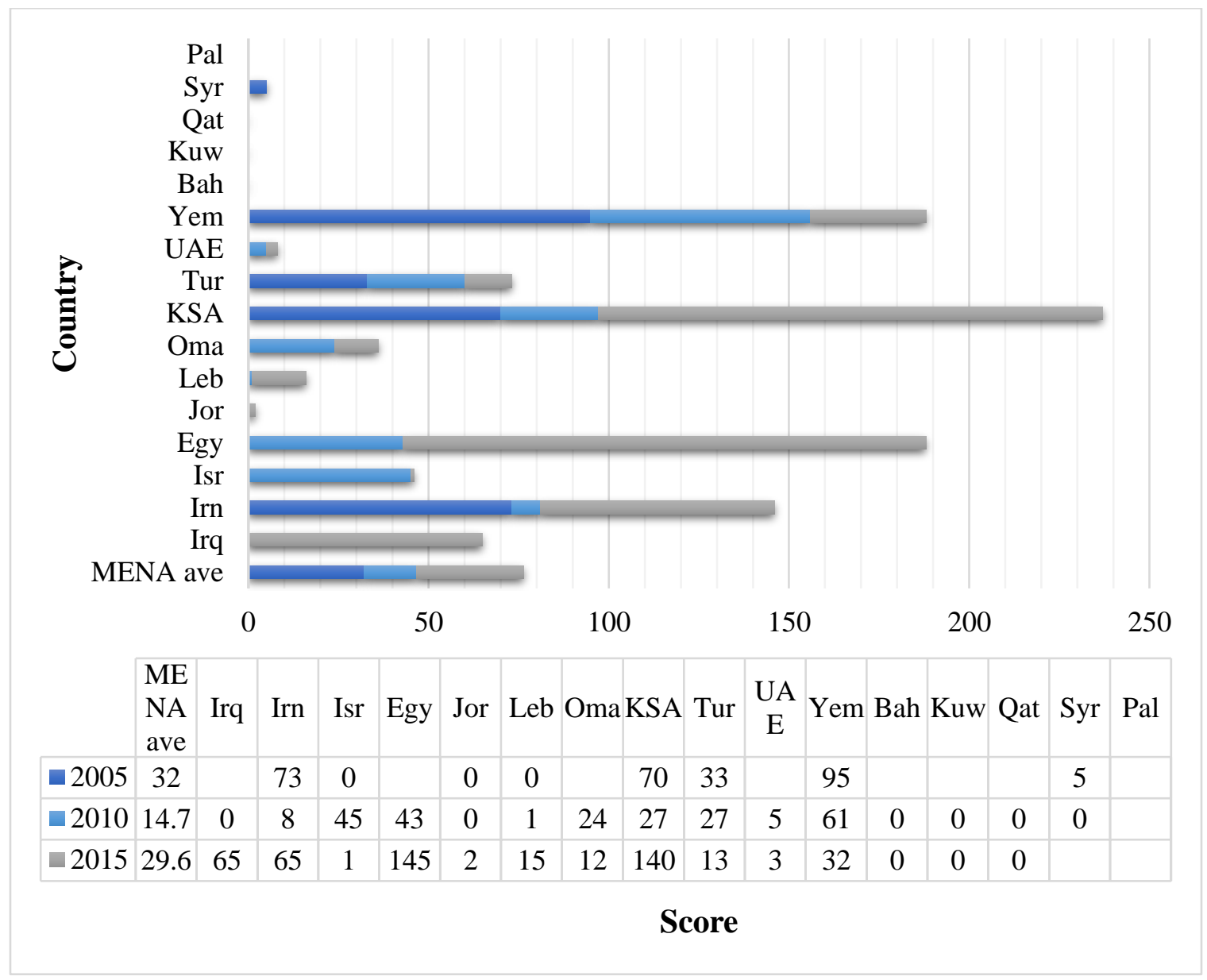

Figure 2-5 Number of deaths caused by weather events like storms, floods, temperature extreme and mass movements for the years of 2005, 2010, and 2015. Note: data of Syria for the years of 2015 is not available. Source: https://idea.usaid.gov

A study by Amin et al. (2016) revealed that in the past twenty years KSA has faced severe and extreme drought conditions mostly in agricultural areas alarming the risk of water depletion and vegetation cover reduction in the region. In Turkey, about $15.3 \%$ 
reduction in crops production level occurred in 2007 (FAO 2017). Figure 2-6 shows country vulnerability to climate change in the Middle East where countries with lower scores indicate those at higher risk to climate change. From figure 2-6, Oman and Yemen are the most vulnerable countries to the hazards of climate change in the Middle East.

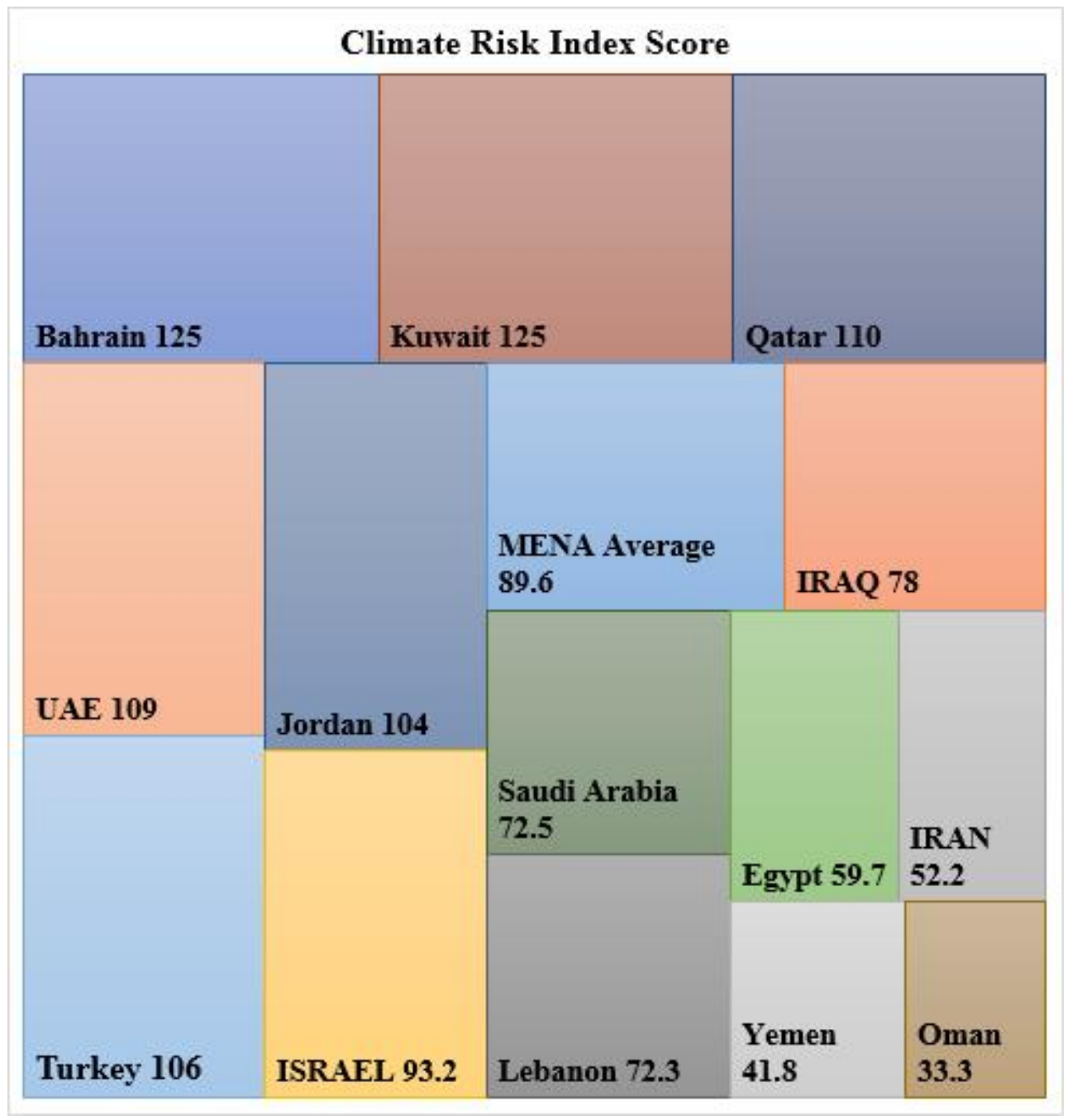

Figure 2-6 Climate Risk Index Score. The index is a weighted score calculated according to: Number of Deaths (weight: 1/6), Deaths per 100,000 inhabitants (weight: 1/3), Absolute losses in PPP (weight: 1/6), and Losses per GDP unit (weight: 1/3). Lower score indicates a country being more at risk to climate change. Source: https://idea.usaid.gov 


\section{- Economic growth}

The Middle East is known for being rich economically. Because of the abundant oil resources, the economic growth level in the region is high. However, the economic growth is different from the economic advancement or sustainable development (Ozcan 2013). Al-Awad and Harb (2005) argued that the weakness of the financial sector and unstable economic growth in the Middle East are essential factors that may affect any sustainable economic development in the region. The gross domestic product (GDP) is a measurement of total products of a country (Miller and Kim 2017). The GDP refers to the GDP that is calculated in terms of purchasing power parity (PPP) and it is one of the main indicators to estimate a country's economy. Figure 2-7 displays a five-year GDP (PPP) growth rate of the Middle East countries. From the Figure, Qatar and Iraq have experienced the highest growth rate in the Middle East during the period of 20112015. In contrast, the compound growth rate for the period of 2011-2015 in Yemen reveals a decline and in Iran, there is no growth. However, economy in Iran was estimated to grow at a mean annual rate of 4.6\% for the period of 2016-2018 (Devarajan et al. 2016). Silva et al., (2018) mentioned that absence of investments in infrastructure could be a potential risk to FEW security in any region. For instance, food processing and production is affected by infrastructure significantly. 


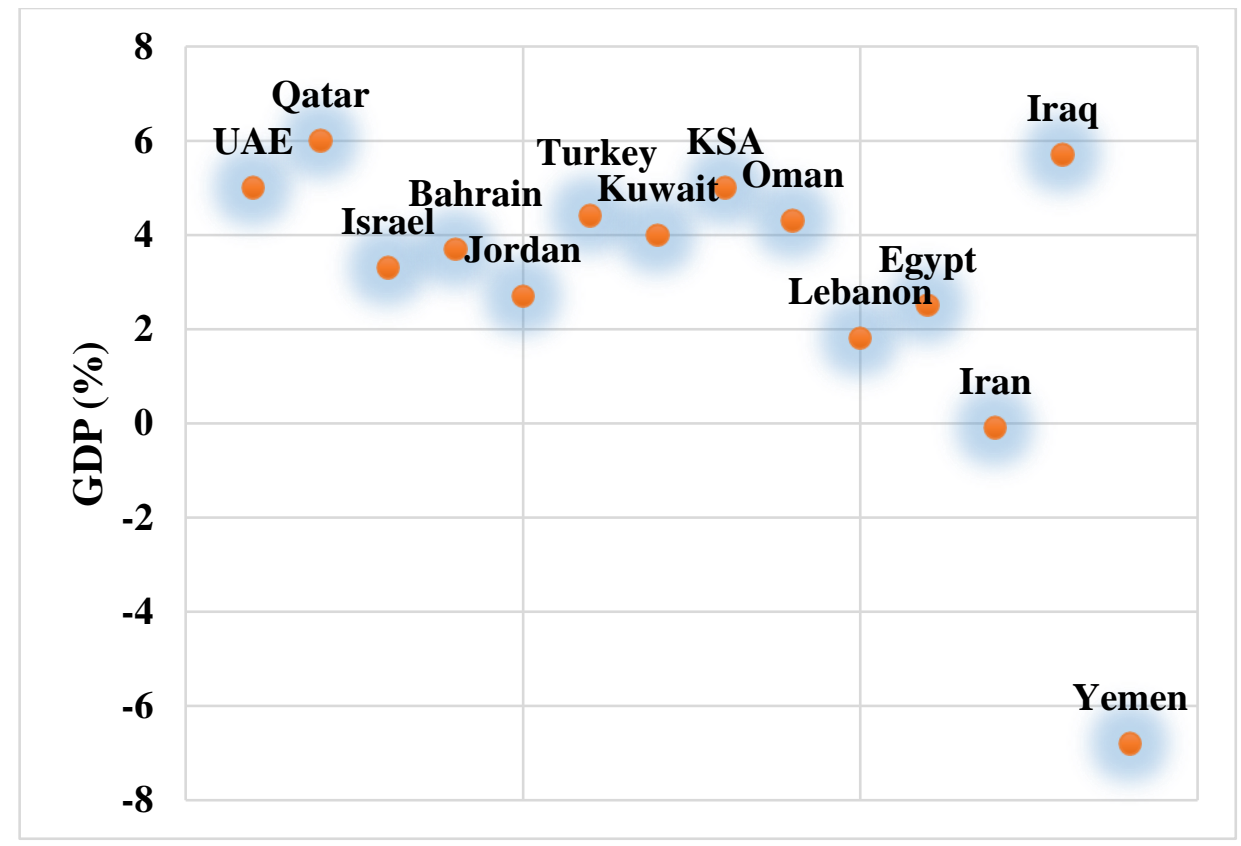

Figure 2-7 Five-year compound annual growth rate of the Gross Domestic Product (GDP) based on Purchasing Power Parity (PPP) for the period of (2011-2015) (Miller and Kim 2017).

GDP growth in is highly connected to oil and natural gas investments in the Middle East region. The dependency of the GCC countries on oil has increased since 2006 (Devarajan et al. 2016). For instance, by mid-2014 to 2016, oil prices had sharply declined affecting the economy of the oil exporting countries of MENA region (Griffiths 2017). Therefore, the GDP growth in the MENA region is expected to be lower in 2017 (Devarajan and Mottaghi 2017). Figure 2-8 shows the real GDP growth in the Middle East for the years of 2015, 2016, and 2017. The GDP estimates shows that Yemen has faced the worse growth decline in 2015 and 2016 over the Middle East .The GDP growth for 2017 exhibits that Iraq is experiencing a declined growth. It is worth mentioning that the oil importing countries in the MENA region could not benefit from lower energy prices due to the civil wars and political conflicts in the region. For example, Jordan and Lebanon have been 
coping with the Syrian refugee issue while Egypt was dealing with the economic stagnation and political unrest (Griffiths 2017).

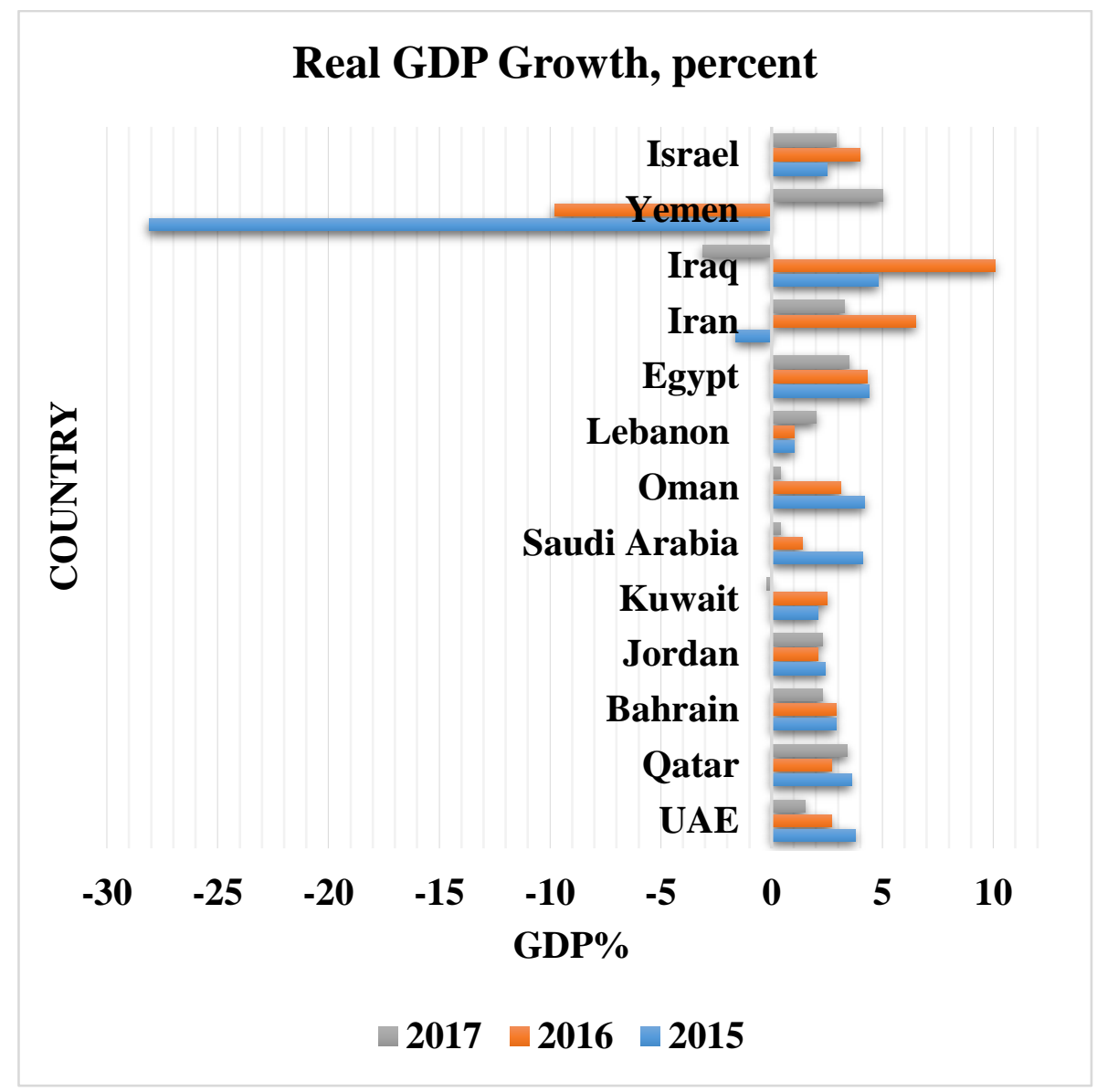

Figure 2-8 Real GDP Growth for the years of 2015, 2016, and 2017. Source: IMF Data Mapper.

- Urbanization

The world has witnessed a relatively rapid growth in urbanization since the 1950s. This growth in urban population has created serious challenges like poverty and job crisis 
(ESCWA 2015b). By the beginning of the $21^{\text {st }}$ century, urban population in the MENA region was about $60 \%$ of total population and increased up to $70 \%$ in 2015 . However, urbanization in the MENA region can be a main challenge because it is unplanned (AlMulali and Ozturk 2015). Efficient urban planning and sustainable food supply system are required to have a healthy growing urban population (Silva et al. 2018).

The general trends of the expanded urbanization and reduced agricultural share in the MENA region may have serious direct effect on water demand and indirect effect on energy sector (Siddiqi and Anadon 2011). Evidently, the most water scarce countries in the Middle East are the most urbanized countries. Qatar and Kuwait were among the ten most urbanized countries with 90,000 inhabitants or more in 2014 estimates and expected to be the same in 2050 projections (United Nations 2015). Figure 2-9 presents the decadal mean annual rate of change of urban population in the Middle East. Overall, the increase in urban population was the highest starting from the mid-1950s to mid-1970s in the region. For the decade of 1985-1995, the urban population rate in Kuwait decreased possibly due to the First Gulf War. For the most recent decade (2005-2015), Qatar and UAE have witnessed the highest growth in urbanization. 


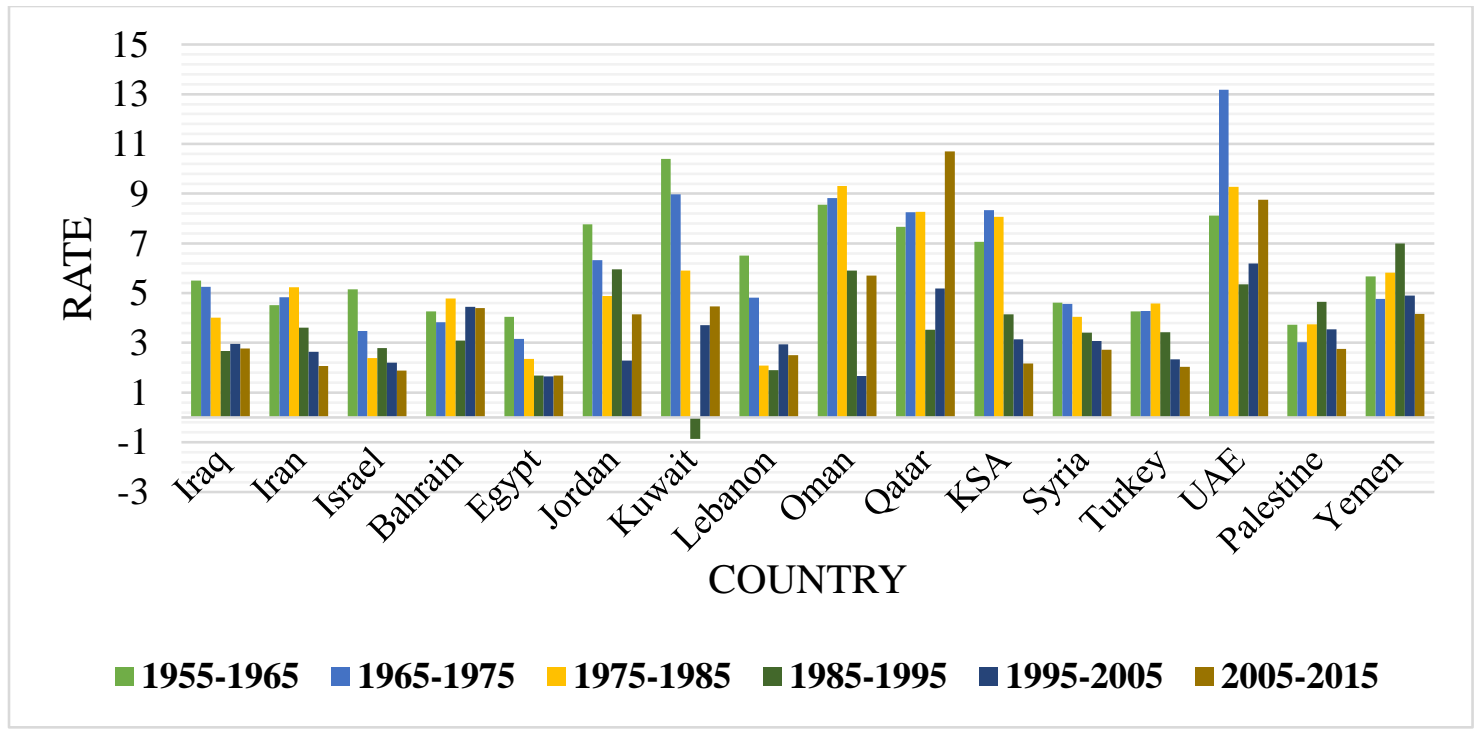

Figure 2-9 Decadal mean annual rate of change of urban population by major area, region and country (United Nations 2015).

\section{- Population growth}

In a world suffering from severe poverty, scarce water resources, and persisting hunger, rapid population growth may pose serious problems. In terms of poverty, growing population may mitigate infrastructure, aggravate natural resources depletion, and intensify the dependency ratio (Population Institute 2015). Moreover, population growth is a main contributor of industrial and municipal water consumption (Negewo 2012). Thereby, population expansion can be a direct threat to resource exhaustion especially in developing countries (Gupta 2013). The significant modifications in population dynamics in the Arab region are population growth, urbanization, population age, and migration fluxes, which have increased water demand in the region in the last three decades. For example, growing population imposed unsustainable activities in agriculture sector adding more tension on the diminished freshwater resources in the Arab region. 
In addition, it is found that the population growth in the Arab region for the period of 19822012 caused approximately 50\% reduction in the mean amount of total water resource per capita. The high rates of growing population in developing countries may affect the health and education sectors, that is, it can influence poverty mitigation efforts and possible economic growth in the region (ESCWA 2015c).

Based on population size, the most crowded countries in the Middle East are Egypt, Iran, and Turkey, respectively. Figure 1-11 shows a five-year average population growth in the Middle East countries. From the Figure, the first cluster indicates that Egypt, one of the poorest countries in the region, has the highest population growth considerably from the beginning of the 21 st century followed by Iran and Turkey. The second cluster including Iraq, KSA, and Yemen have also witnessed population growth since the end of the 1980s. In contrast, the growth in Syria has declined after 2008 most likely due to the political conflict in the country. Furthermore, the World Meter reported that Iraq, Palestine, Yemen, and Kuwait have the highest growth rate in 2017, respectively as seen in Figure 2-11. 


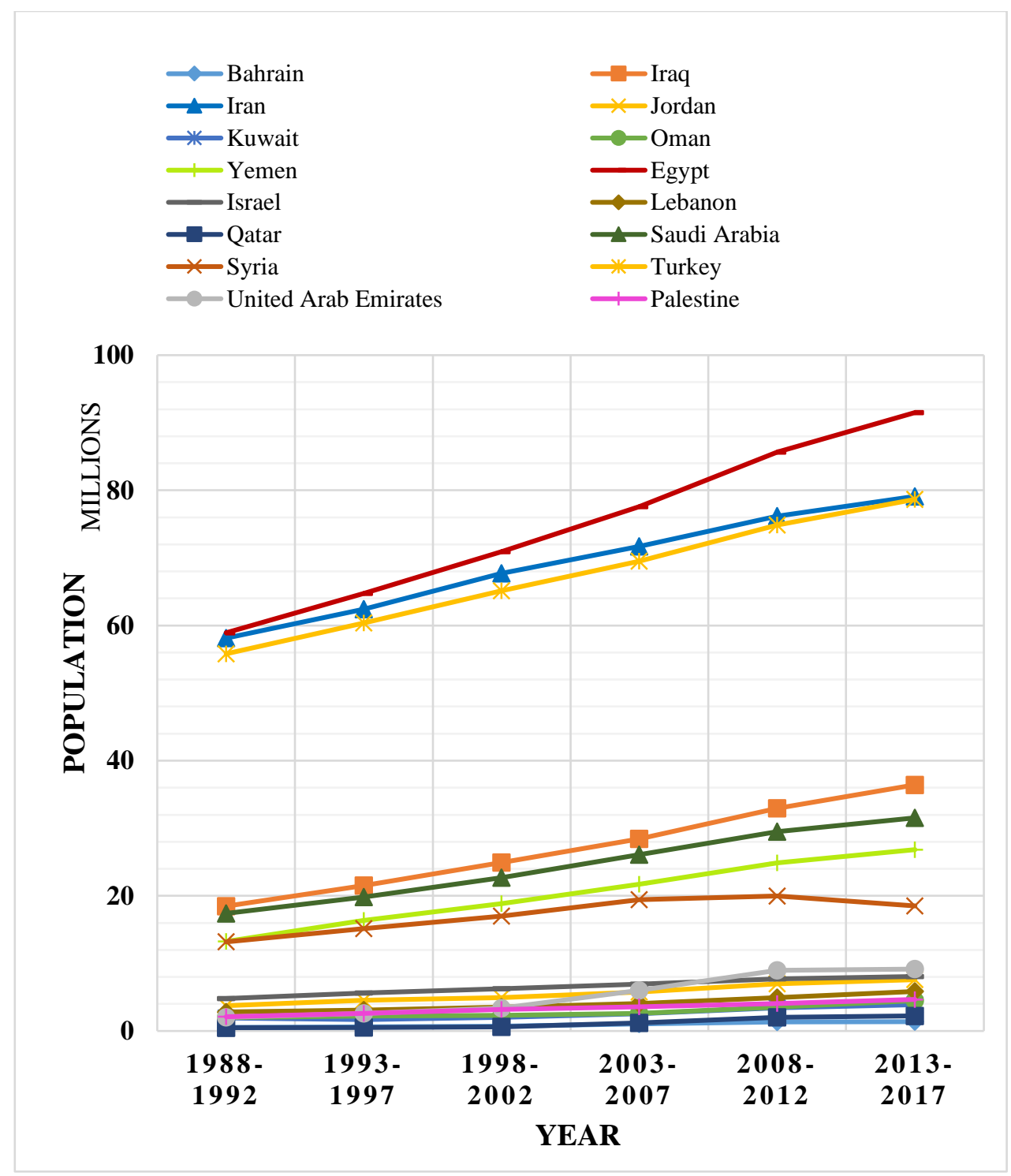

Figure 2-10 Five-year average of population growth in the Middle East. Source: FAOAQUASTAT Database and Worldometers (www.Worldometers.info) 


\section{7- GROWTH RATE (\%)}

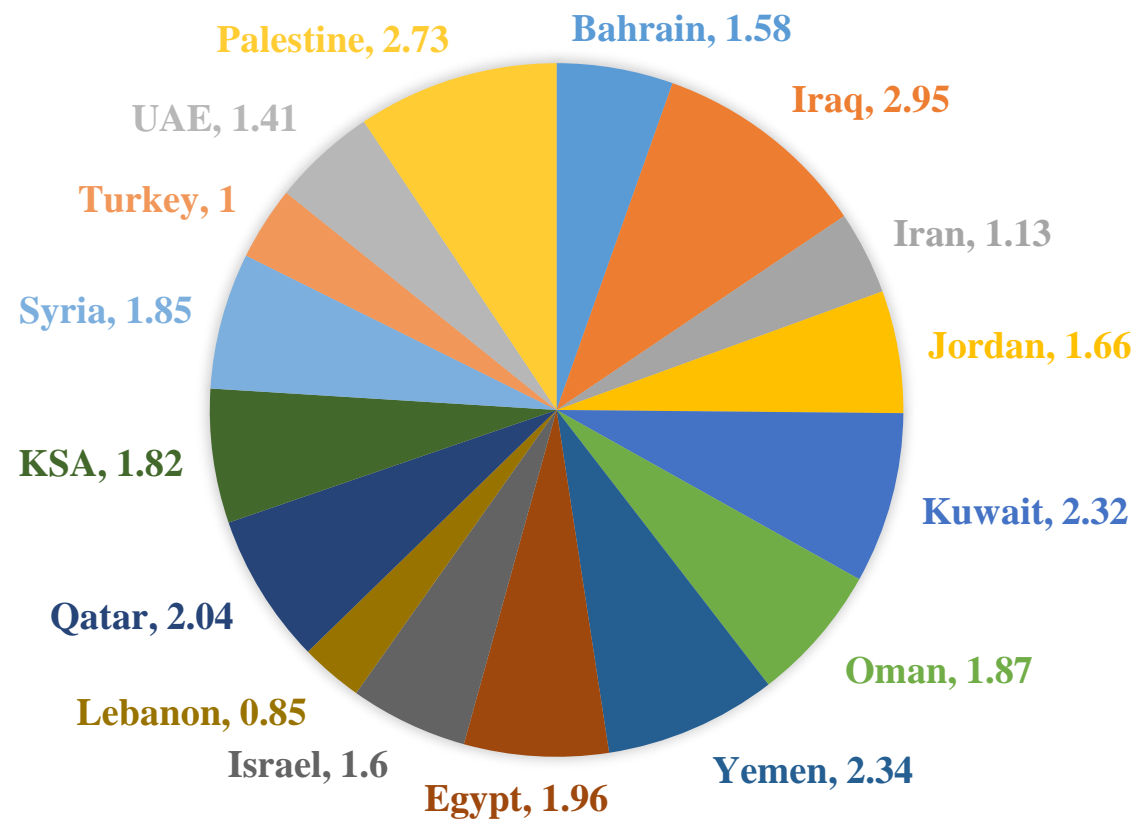

Figure 2-11 Annual growth rate of the Middle East countries in 2017. Source: http://www.worldometers.info

\section{- Poverty}

Societies with insufficient market access and scarce natural resources are exposed communities to prolonged poverty. Awulachew et al. (2010) studied the food-waterpoverty nexus across ten countries within the Nile basin. The authors defined poverty as composite of different elements, i.e. politics, economy, environment, socio-culture, and historic. Vulnerability to poverty is of very high level in the MENA region that large groups of people are living arround the poverty line. For instance, a roughly large portion of population are distributed close to the poverty line in Iraq and Yemen, thereby people are at high risk to any collapse in these countries (ESCWA 2010). According to FAOAQUASTAT database, Iraq has recorded the highest number of people (8.1 million) undernourished for the period of (2013-2017). Yemen was the second highest in terms of 
number of people (6.7 million) who are undernourished in the Middle East. Water scarcity that impacted the agriculture sector, population growth that decreased job opportunities, and economic policy failure are believed to be the key drivers for the high poverty rate in Yemen (Devarajan and Mottaghi 2017). Figure 2-12 displays the percentage of population that were undernourished in the Middle East in 2005 and 2015 (data of Syria are not available from this source). From the Figure, the percentage of undernourished people in 2015 is lower than in 2005. Most of the countries were below the MENA average except Yemen and Iraq which were way above the average in both years.

In contrast, Syria is the poorest country in the Middle East currently. The Syrian Center for Policy Research (SCPR) reported that the poverty rate in Syria has increased by a percentage of $14 \%$ in 2014 compared to 2010. Dramatically, the percentage of people who live in poverty in Syria became $85.2 \%$ in 2015 compared to $64.8 \%$ in 2013, and about 35\% of whom lived in extreme poverty levels (limited access to basic food) especially in conflict zones (Devarajan and Mottaghi 2017). 


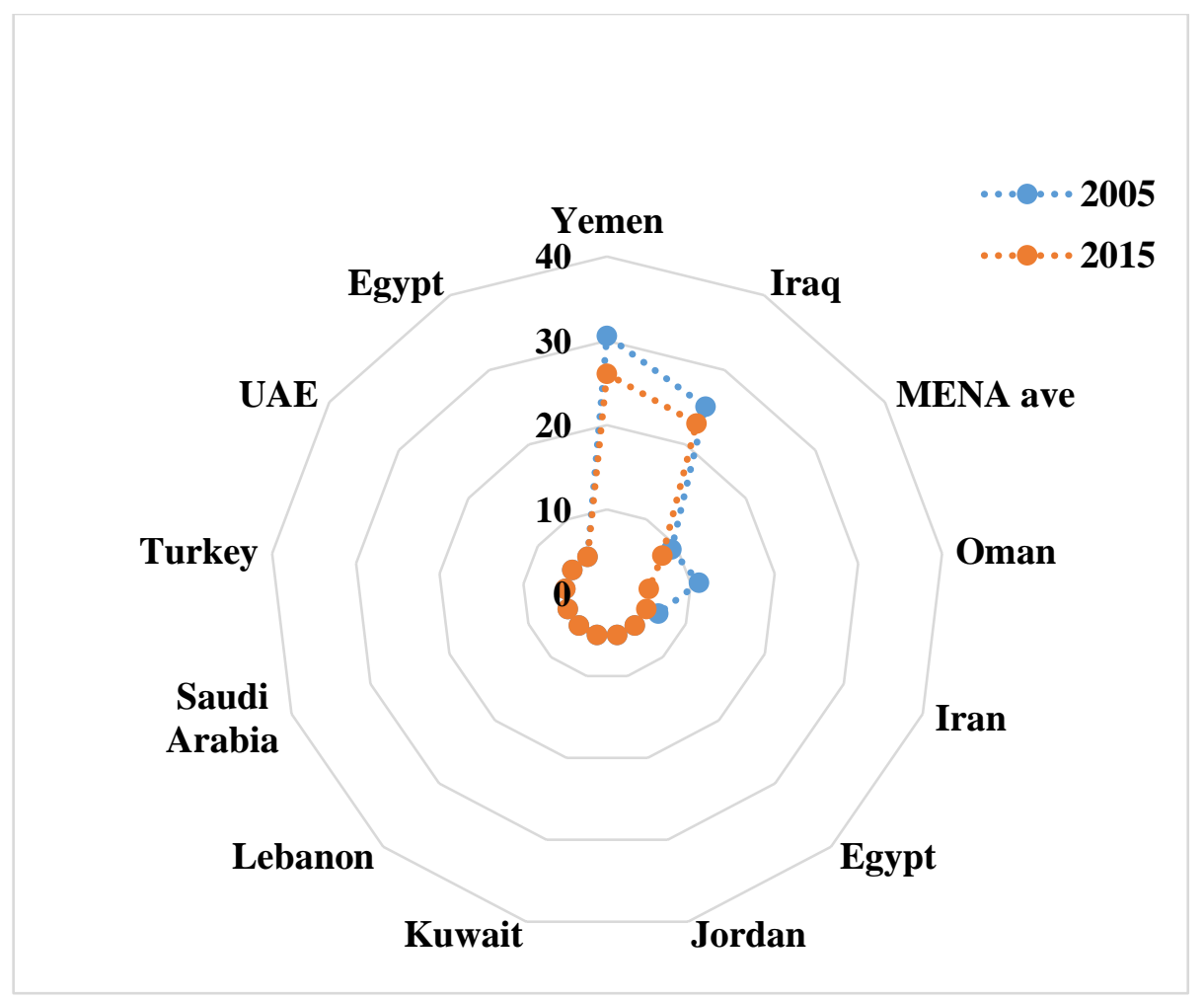

Figure 2-12 Percentage of population that are undernourished in the Middle East. Note: data for Syria was not available. Source: https://idea.usaid.gov

Figure 2-13 shows the Global Hunger Index (GHI) for the years of 2008 and 2016 over the Middle East region. The index is a tool to estimate and trace hunger at different scales, i.e. global, regional, and local levels. The GHI is generated based on four indicators that are undernourishment, child wasting, child stunting, and child mortality. The range of scores is from 0 to 100 where zero indicates no hunger (von Grebmer et al. 2016). Overall, the GHI in 2016 revealed less hunger levels than in 2008 . However, the reduction in hunger levels were not significant within a decade. According to the GHI severity scale, Yemen is at an alarming stage of hunger, Iraq faces a serious hunger condition, and rest of the countries are under moderate to low hunger conditions (Figure 2-13). 

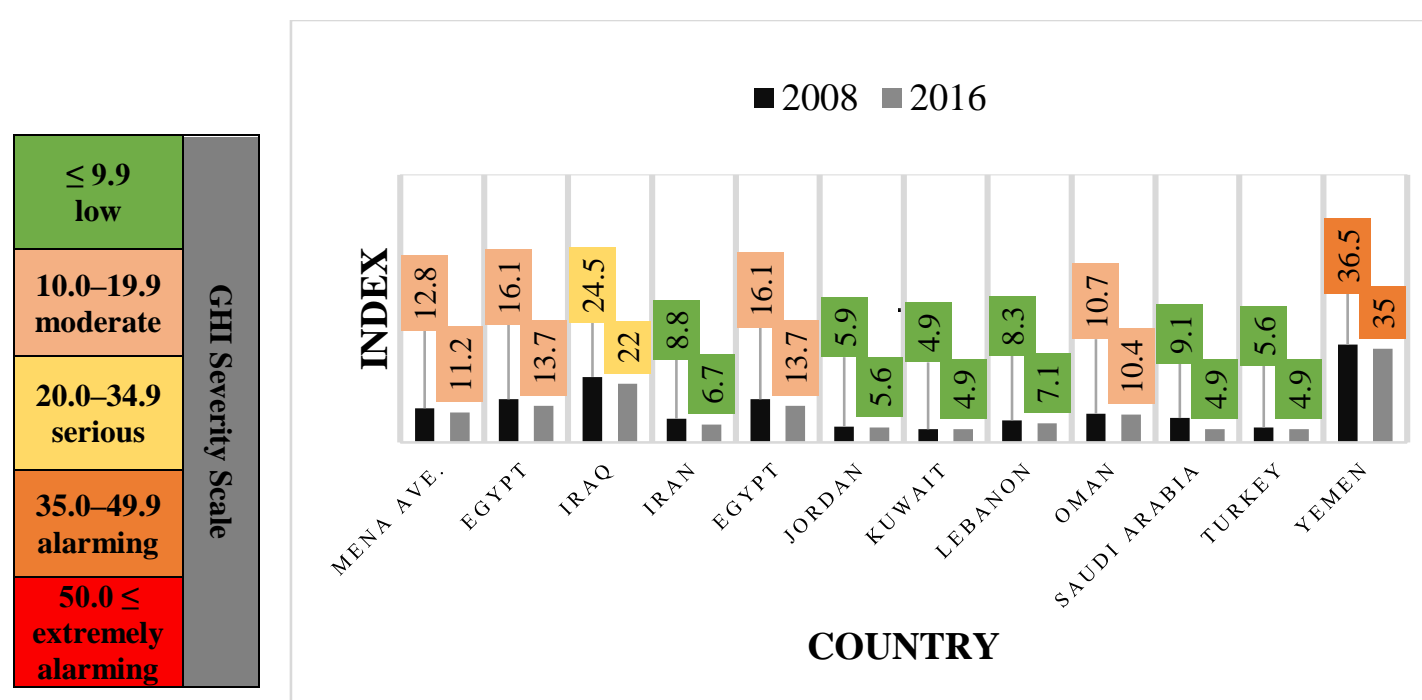

\section{COUNTRY}

Figure 2-13 Global Hunger Index (GHI) with the score of 0-100, where lower score is better. Note: data for Syria was not available. Source: https://idea.usaid.gov

\section{- Political stability}

Political insecurity is the key feature of the Middle East (Mohtar et al. 2017). Conflict and insecure conditions are the main obstacles to progression in the MENA region in 2016. Most intensely in Iraq, Libya, Syria, and Yemen where approximately $50 \%$ of the population demanding aid (IFPRI 2017). Seven years of Conflict in Syria has affected the socio-economic development of the country. The United Nations high Commissioner for Refugees (UNHCR) in September 2016 reported that the total number of Syrian refugees into neighboring countries, i.e. Egypt, Iraq, Jordan, Lebanon, and Turkey, was about 4.8 million. Moreover, the United Nations Office for the Coordination of Humanitarian Affairs (OCHA) in August 2016 reported that about 6.1 million of Syrians displaced from the conflict zones into more secure areas inside the country (FAO 2016).

Evidence from the Middle East revealed that the political unrest is associated with economic inequality (income inequality), where the last can be the main reason of civil 
anxiety. For example, income inequality in Egypt was counted as one of the causes of the Egyptian revolution during the Arab Spring uprisings period (Ianchovichina et al. 2015). In Syria ,the economic sector has totally destroyed because of the Syrian civil war since 2011 (Devarajan and Mottaghi 2017). In Iraq, conflict and instabilities have severe impact on agricultural and rural environment of the country (Ahmed and Holloway 2017). Sowers (2014) asserted that countries facing wars and civil unrest or occupation are the most vulnerable countries to water and energy systems destruction. Whereas Elasha (2010) argued that climate change can be a threat in regions experiencing political instability that it may aggravate stress in the region especially between nations sharing hydrological, geographical, and political boundaries. The author further explained that water scarcity might exacerbate potential anxiety in the region knowing that about $80 \%$ of surface water resources and $66 \%$ of total water resources are shared in the region.

\subsection{Discussion}

It is worth mentioning that the presented issues in this paper are interconnected and have either direct or indirect effects on the FEW system in the Middle East region. For instance, limited access to water resources diminishes agricultural activities, intensifies poverty, and limits poor people ability to face risks. Furthermore, the extreme water deficit in the Eastern Mediterranean region has affected the socio-economic potency, exacerbated land vulnerability to salinization and desertification, and increased the risk of political unrest in the Middle East. In general, political unrest for any reason can cause food instability and struggle (Hillman and Baydoun 2017). For instance, the food security sector in June 2016 
identified 9.4 million of Syrians at food insecure condition and about 2.7 million out of the 9.4 million at risk of food insecurity (FAO 2016).

Moreover, wars and political instability made the urbanization process more complicated in the Arab region (ESCWA 2015b). In general, urbanization is controlled by natural urban population growth, rural to urban migration, and reduced urban mortality compared to rural (ESCWA 2015c). For instance, the drought period (2006-2009) in eastern Syria has influenced 1.3 million people after the loss of 2008 harvest resulting in increased migration from rural to urban areas and extreme poverty levels in the region (Sowers et al. 2011).

The connection between population growth and food insecurity is evident (Population Institute 2015). Egypt as the most crowded country in the Middle East is one of the most food insecure countries in the region. In the Middle East, food security is impacted by several current challenges, namely, political unrest, global financial crisis, poverty, growing population, corruption, parochialism, and climate change related disasters (Hillman and Baydoun 2017). However, decreasing fertility might play an important role in poor countries by reducing poverty, lowering the pressure on livelihoods, and expediting economic growth (Gupta 2013).

Despite the fact that economic growth in developing countries may reduce poverty, the rate of poverty reduction depends on how economic growth is characterized. For example, there is a significantly negative relationship between economic growth and poverty when it is defined in terms of consumptions. However, a non-significant relationship occurs between economic growth and poverty when it is measured based on 
the changes in GDP/capita (Adams 2004). Ncube et al. (2014) supported this by concluding that income inequality in the MENA region can increase poverty and decrease economic growth. Countries can make an instant improvement in their economic growth by increasing the economic freedom in the society regardless of their current level of development. The index of economic freedom provides a comprehensive evaluation of an individual well-being, i.e. health, education, environment, innovation, society development, democratic governance, and freedom in acquiring and benefitting economic resources in countries that are more economically free (Miller and Kim 2017). Figure 2-14 shows the economic freedom of countries of interest within the MENA region. From Figure 2-14, most of the Middle East countries are moderately free countries in terms of liberty and free markets. UAE and Qatar are mostly free whereas Iran, Egypt, and Lebanon are mostly unfree countries. 


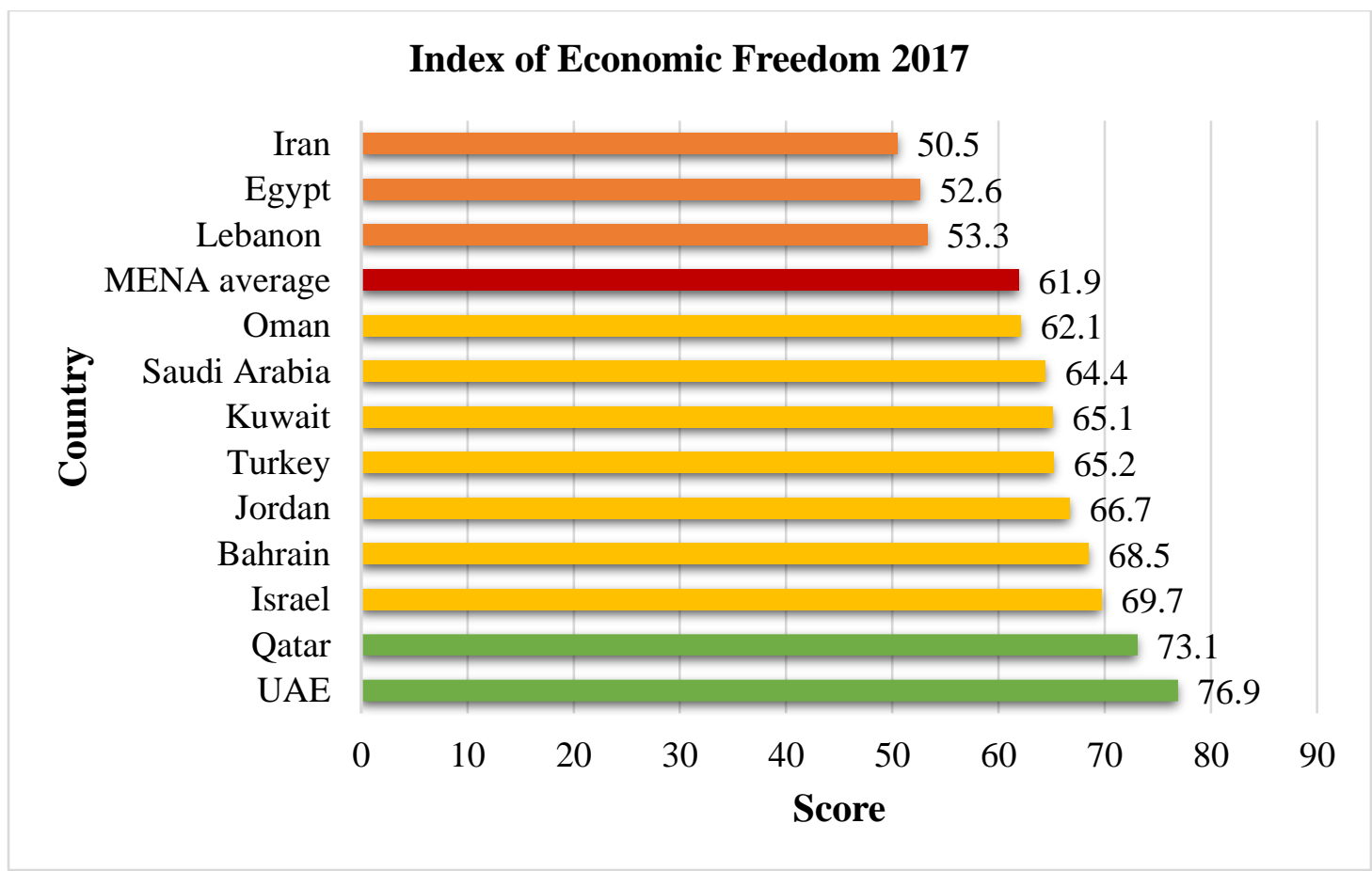

Figure 2-14 Index of Economic Freedom of countries of interest within the MENA region in 2017. Countries in the range of (0-49.9) are repressed, countries in the range of (50-59.9) are mostly unfree, countries in the range of (60-69.9) are moderately free, countries in the range of (70-79.9) are mostly free, and countries in the range of (80-100) are free (Miller and Kim 2017). Note: not listed countries implies data unavailability.

With respect to energy sector, it is found that energy production in the Middle East is highly constrained by water deficiency (IEA 2014). For example, drought may affect electricity supplies significantly because of high temperatures which increase electricity demand during the low water supplies (Scanlon et al. 2017). Moreover, rapid growth of population and economy have contributed to intensifying energy consumption in the region (Dargin 2010). Therefore, energy consumption is expected to increase up to $95 \%$ in the Middle East region for the period from 2012 to 2040 as projected in the IEO2016 Reference case (EIA 2016). 
Adaptation to scarcity in FEWS nexus can be managed through reducing demands, increasing supplies, and maximizing storage and transports of resources (Scanlon et al. 2017). Rainwater-harvesting techniques has been used in water scarce countries increasing the efficiency of rainwater usage (Qadir et al. 2007). Building seawater desalination plants over the Persian Gulf and the Red Sea is one the most reliable sources of water in the Gulf countries, i.e. Kuwait, KSA, Bahrain, Qatar, and the UAE. However, this solution should not be at the expense of affecting the environment of the Persian Gulf or the Red Sea by increasing salinity levels. Naturally, the salt content is high in the Persian Gulf and the Red Sea waters due to high rate of evaporation. Therefore, more attention is required to sustain this vital water resource and improve the socio-economic progression (Purnama et al. 2005).

\subsection{Conclusion}

The food, energy, and water nexus integrated with security are together an emerging issue in the Middle East. One should first study the dynamics behind the FEWS nexus concern in the region. Therefore, this study introduced the most critical challenges by retracing the FEWS nexus problems that the Middle East has been facing recently.

The assessment suggested that most of the selected countries are facing FEW insecure resources condition. However, water sector is the scarcest resource in the Middle East. Although large rivers are located in the region, transboundary water resources are additional problem. For instance, it is of high expectation that Iraq and Syria will experience increasing water insufficiency due to the construction of the Southeast Anatolia 
Development project. Similar cases are experienced in Jordan and the Nile River basins. Water policy in the Middle East is of high importance to shape the future of water-food security. Moreover, to solve water allocation issue, more participation and joint decisions need to take place between the transboundary countries. Finally, the lack of consistent management combined with unsustainable use of resources in the Middle East region will probably pose critical FEWS challenges in the near future. 


\section{Chapter 3: Drought and Food-Energy-Water-Security Nexus: A Bayesian framework assessment of food insecurity in Middle East}

\subsection{Background}

Harsh and expanding aridity associated with environmental stress factors like frequent drought and heat stresses impose serious threat to food security in the Middle East region. Drought occurrence has vital impact on agricultural productivity. For instance, early-season drought delays crop planting activities which reduces agricultural area and production, mid-season drought impacts crop growth, whereas the late-season drought may affect the economic harvest (Das et al. 2015). Rain-fed agricultural lands are extremely influenced by drought in the Arab region. This results in decreasing yields and depleting vegetation in pasture lands which in turn affects livestock. Furthermore, land degradation is another consequence of drought by decreasing the lands covered by native plants (ESCWA 2015c).

In Syria, rain-fed agriculture is affected by fluctuation in precipitation and crop production and food availability is impacted by the long-frequent drought events over the country (Tolba and Saab 2009). A study by Zaitchik et al. (2007) indicated that climate fluctuations might result in significant change in vegetation in the Middle East. The authors concluded that the vegetation in the Euphrates Plain is predominantly limited by soil moisture availability. Moreover, The Eastern Mediterranean and the Middle East (EMME) regions are likely to be vulnerable to frequent and intense drought associated with hot weather conditions in the $21^{\text {st }}$ century (Lelieveld et al. 2012). 
This study aimed at two main goals: 1) characterizing all drought conditions using longterm (1948-2017) precipitation, soil moisture, and runoff data and studying the long-term drought behavior by analyzing their temporal trends. Here, meteorological, agricultural, and hydrological droughts were analyzed across the Middle East at different time scales

(i.e. : 3-, 6-, and 9-, 12-, 18-, and 24-months). 2) Finding the best model of food insecurity in the Middle East based on drought and socio-economic factors. A Bayesian approach was conducted to find the best model that can predict food insecurity in the region.

\subsection{Study Area and Data}

The proposed study area is the Middle East region, defined here as sixteen countries, namely, Arabian Peninsula, Iran, Syria, Lebanon, Israel, Palestine, Egypt, and Turkey. The Middle East is located in western Asia and northeastern Africa. The Middle East covers an area of roughly $6,928,000 \mathrm{~km} 2(2,674,916 \mathrm{mi} 2)$ having a population of about 320,079,932 Million people. According to the International Institute for Applied Systems Analysis (IIASA) and Food and Agriculture Organization (FAO), the dominant land cover pattern in the region is mostly barren land. Whereas, Turkey, northwestern Iran, northeastern Iraq and along the Tigris River in Iraq, western parts of Syria, Lebanon, northern Israel, and along the Nile River in Egypt where grass, woodlands, and cultivated lands are the dominant land cover. Forests cover the northern parts of Turkey and Iran, See Figure 3-1. 


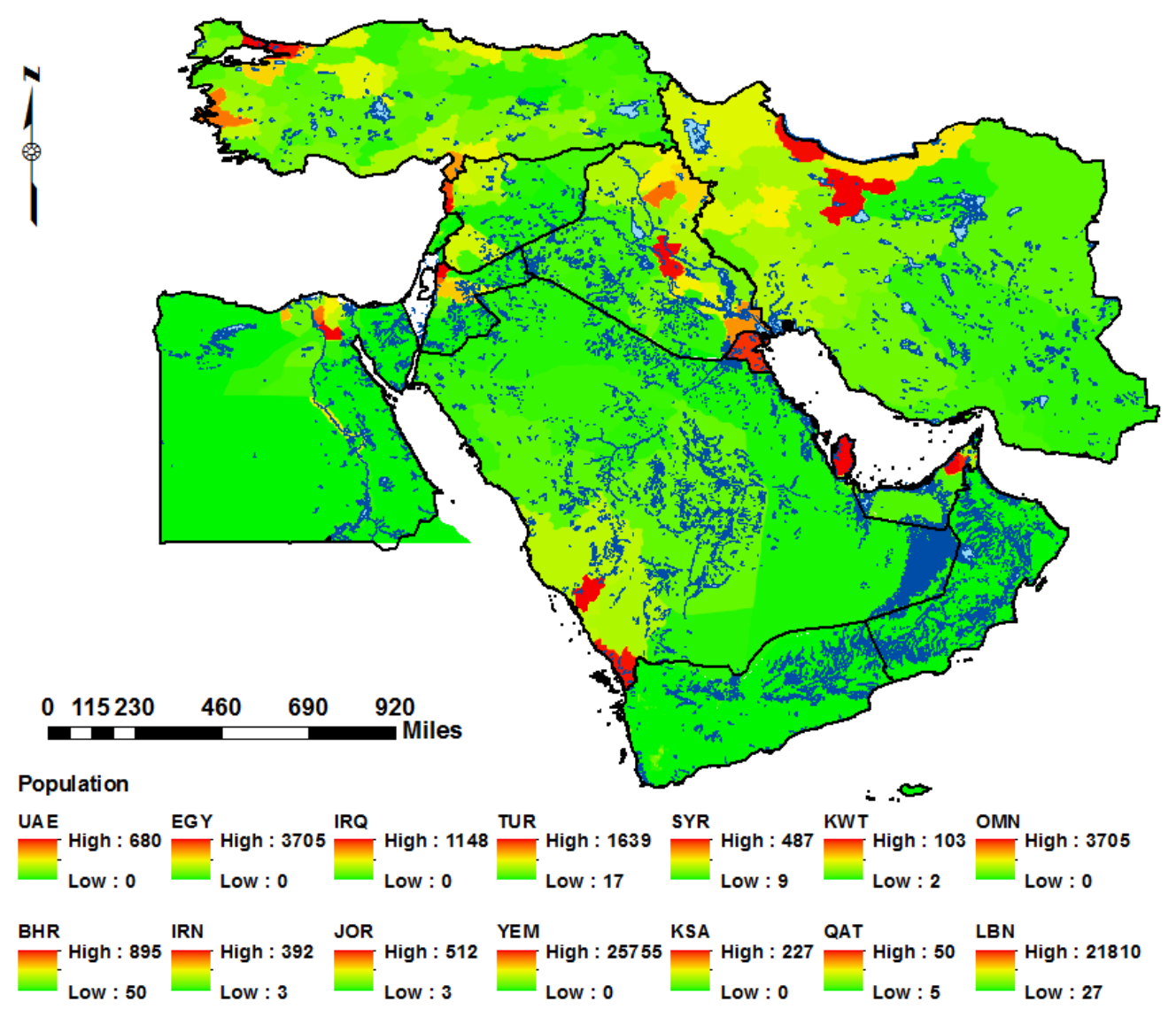

Figure 3-1 A population map of the Middle East

It should be noted that in this study and according to FAO dataset, crop production index (agricultural production for each year relative to the base period 2004-2006) and food deficit (kilocalories per person per day) are considered as food insecurity indicators in the Middle East. To quantify food insecurity in Middle East, it is required to identify the crucial factors that associate multi-dimensions of food impacts including drought, water stress, energy, and other socio-economic factors. Different data sources like International Energy Agency (IEA), Food and Agriculture Organization (FAO) of the United Nations, and the World Bank are explored to investigate the relative factors. Defining food 
insecurity for a certain region might not be suitable for all regions due to differences in natural and manmade resources. Therefore, knowledge about the study region is needed to overcome the difficulty of selecting decent factors to analyze, See Chapter 2.

Here, The Global Land Data Assimilation System (GLDAS-2) and (GLDAS-2.1) (Rodell et al. 2004; Beaudoing and Rodell 2015; Beaudoing and Rodell 2016) monthly precipitation, soil moisture, and runoff data with a $0.25^{\circ}$ spatial resolution are used to drive meteorological, agricultural, and hydrological droughts at multiple timescales over the Middle East for about seven decades for the period of 1948-2017.

\subsection{Methodology}

The food insecurity assessment of this study is performed as follows:

- Data selection, extraction, pre-processing, and reformatting

- Calculating drought indices: the Standardized Precipitation Index (SPI), Standardized Soil Moisture Index (SSI), and Standardized Runoff Index (SRI) at multiple timescales (i.e. 1-3-6-12-18-24 months)

- Calculating Multivariate Standardized Drought Index (MSDI) empirically (MSDIe) and parametrically (MSDIp).

- Normalizing factors to compare different variables

- Multi-collinearity test to remove redundant variables by performing Principle Component Analysis (PCA) and Variance Inflation Factors (VIF)

- Bayesian Linear Regression analysis and model verification 


\subsubsection{Drought Analysis}

In this study, the monthly precipitation (Total precipitation rate), soil moisture (0$10 \mathrm{~cm}$ ), root zone soil moisture, and surface-groundwater runoff are used to derive different types of drought indices: SPI, SSI, SSIrz, SRI, and MSDI. The drought indices are analyzed at different time scales: 3-, 6-, and 9-month for short term seasonal changes and 12-, 18-, and 24-month for long term drought changes over the Middle East. SSI, SSIrz, and SRI calculations are based on SPI (Mckee et al. 1993) as a reference (Shukla and Wood 2008; Wu et al. 2016; Hao et al. 2017; Zhang et al. 2017). SPI calculation requires a long-term monthly precipitation data for at least 30 years. The index is calculated by taking the difference of precipitation data from its mean at specific time scale then dividing it by the standard deviation and that can be defined as (McKee et al. 1993; Tsakiris and Vangelis 2004):

$$
S P I=\frac{x_{i}-\bar{x}}{\sigma}
$$

Where $x_{i}$ is the precipitation of the selected period during the $i$ th year, $\bar{x}$ is the mean of the selected period, and $\sigma$ is the standard deviation. SPI is a widely used probability based index detecting precipitation deficiency in a region by quantifying precipitation deviation from historical mean. To avoid dealing with data fitting to a distribution that is known to have some issues (Ahmadalipour and Moradkhani 2017), a nonparametric approach is implemented to calculate the univariate drought indices (i.e. SPI, SSI, SSIrz, and SRI) in this study. Precipitation, soil moisture, and runoff of each grid cell were accumulated to 
the desired accumulation period, and the empirical Gringorten plotting position (Gringorten 1963) was utilized as follows:

$$
p\left(x_{i}\right)=\frac{i-0.44}{n+0.12}
$$

Where $n$ is the sample size, $i$ denotes the rank of non-zero variable data from the smallest, and $\mathrm{p}\left(x_{i}\right)$ is the corresponding empirical probability. The outputs of Eq. (3-2) can be transformed into a Standardized Index (SI) as:

$$
S I=\emptyset^{-1} *(p)
$$

Where $\phi$ is the standard normal distribution function, and $\mathrm{p}$ is probability derived from Eq. (3-2). For each index and each timescale, drought intensity in each month was calculated as a drought index below -1, indicating moderate to extreme drought condition.

Motivated by the notion of providing more relevant and reliable drought monitoring based on multiple indicators or drought indices, the Multivariate Standardized Drought Index (MSDI) developed by (Hao and AghaKouchak 2013) is used in this study. This multi-index drought- modeling approach is based on the copula concept. The MSDI is similar to the original SPI and it can be used to monitor drought at different time scales (i.e., 3-, 6- and 12-month). The authors investigated meteorological and agricultural drought conditions by combining SPI and SSI probabilistically. Another study by Rad et al. (2017) has proposed the Standardized Precipitation-Streamflow Index (SPSI) that is integrating meteorological and hydrological drought conditions. In this study, the incorporation of agricultural-hydrological droughts are further investigated. In other words, this study used the MSDI to combine SSI-SRI in addition to SPI-SSI and SPI-SRI for overall characterization of drought over the Middle East. MSDI uses copula functions 
to derive the joint distribution of two variables (e.g. precipitation and soil moisture) regardless of their original marginal distributions by following the formula (Hao et al. 2014):

$$
P(X \leq x, Y \leq y)=C[F(X), G(Y)]=p
$$

Where $X$ and $Y$ are the selected variables (e.g. precipitation and soil moisture), $C$ is the copula, and $F(X)$ and $G(Y)$ are the marginal cumulative distribution functions of variables $X$ and $Y$. Three copulas, namely, Clayton, Frank, and Gumbel, are used to derive the joint probability distribution of the selected variables (Trivedi and Zimmer 2006; Nelsen 2007).

The Multivariate Standardized Drought Index (MSDI) can then be calculated from the cumulative joint probability $p$ shown in Equation (3-2):

$$
\operatorname{MSDI}=\varphi^{-1}(\mathrm{p})
$$

Where $\varphi$ is the standard normal distribution function. Equation (3-3) transforms the joint probability to the MSDI that is located in the same space as the original SPI and enables cross-comparison of distinct drought indices. Similar to SPI, negative values indicates drought conditions, while positive values indicates wet conditions. A value of zero represents normal climate conditions. Table (4-1) classifies the dry/wet conditions by the drought index as presented by McKee et al. (1993). The aforementioned approach is the empirical (parametric) MSDI. Gringorten plotting position (Gringorten 1963) and Weibull plotting position (Weibull 1939) can be used to estimate the marginal probability using the univariate form of the Gringorten/Weibull plotting position formula. 
Table 3-1 Categories of dry/wet classes by drought indices following McKee et al. (McKee et al. 1993).

\begin{tabular}{ll}
\hline \multirow{2}{*}{ Category } & SI value \\
\cline { 2 - 2 } & (min-max) \\
\hline Extremely dry & Less than -2 \\
Severe dry & -1.99 to -1.5 \\
Moderate dry & -1.49 to -1.0 \\
Near normal & -1.0 to 1.0 \\
Moderate wet & 1.0 to 1.49 \\
Severe wet & 1.50 to 1.99 \\
Extremely wet & More than 2 \\
\hline
\end{tabular}

\subsubsection{Mann-Kendall test and Sen Method}

A non-parametric monotonic trend test computing Mann-Kendall Tau, Tau-b, and Sen's slope estimator is implemented in this study for drought trend analysis (Burkey 2006). Mann-Kendall test (Mann 1945; Kendall 1955) is a well-known statistical test that has been used to verify the significance of temporal trends of variables in long-term behavior of time series (Das et al. 2015; Güner Bacanli 2017; Ahmadalipour et al. 2017c). The trends in this study are examined based on a significance level $\alpha=0.05$. The nonparametric procedure developed by (Sen 1968) is used to estimate the slope of the data, for more details (Drapela and Drapelova 2011).

To better understand the regional trends of drought intensity, the monthly variations and long-term linear trends are detected according to the univariate drought indices covered in this study. The estimated slope indicates the mean temporal change for each grid cell during the study period (1948-2017). 


\subsubsection{Food Insecurity Analysis}

A total of 32 factors were initially explored during 1960 to 2017 (Table 3-2). Table 3-2 explain each factor and its availability. Due to data availability and termination, some of these factors were eliminated. In this study, each chosen factor should be available for at least more than $1 / 2$ of the Middle Eastern countries and for a continuous period of time. Therefore, 19 factors remain to be considered during 1992 to 2015. Each of the chosen factors are normalized separately using the data from all countries to compare different variables.

Given that the principle component analysis (PCA) specifies the relationship among various variables, the method is performed in this study to eliminate the variables that introduce redundancy and multicollinearity. The PCA (Jolliffe 2002) is a popular statistical technique of multivariate analysis. PCA have been used by many researchers (Santos et al. 2010; Tielbörger et al. 2014; Liu et al. 2015; Meng et al. 2016; Tan et al. 2016; Ahmadalipour et al. 2017c; Kopec et al. 2018; Lecher et al. 2018; Malik et al. 2018; Thecla I et al. 2018; Zarekarizi et al. 2018) achieving different goals in their research. Most of PCA users are after one or more the goals that was mentioned by Wold (1987): simplification, data reduction, modeling, outlier detection, variable selection, classification, prediction, and unmixing. 
Table 3-2 The 32 factor considered in the analysis, and the availability of each factor during the historical period (1960-2017).

\begin{tabular}{|c|c|c|}
\hline \multirow[b]{2}{*}{ Factors } & \multicolumn{2}{|c|}{ Data Availability } \\
\hline & $\begin{array}{c}\text { No. of } \\
\text { Countries }\end{array}$ & Years \\
\hline Agricultural machinery, tractors per $100 \mathrm{sq} . \mathrm{km}$ of arable land & $16 / 16$ & $1961-2000$ \\
\hline Cereal production (metric tons) & $16 / 16$ & $1961-2016$ \\
\hline Cereal yield (kg per hectare) & $16 / 16$ & $1961-2016$ \\
\hline $\begin{array}{l}\text { Employment in agriculture (\% of total employment) (modeled ILO } \\
\text { estimate) }\end{array}$ & $16 / 16$ & $1991-2017$ \\
\hline Agricultural methane emissions ( $\%$ of total) & $15 / 16$ & $1970-2008$ \\
\hline Agricultural nitrous oxide emissions (\% of total) & $15 / 16$ & $1970-2008$ \\
\hline Disaster risk reduction progress score (1-5 scale; $5=$ best $)$ & $3 / 16$ & 2011 \\
\hline $\begin{array}{l}\text { Droughts, floods, extreme temperatures (\% of population, average } \\
1990-2009)\end{array}$ & $11 / 16$ & 2009 \\
\hline $\begin{array}{l}\text { Annual freshwater withdrawals, agriculture (\% of total freshwater } \\
\text { withdrawal) }\end{array}$ & $1-8 / 16$ & $1970-2015^{*}$ \\
\hline Depth of the food deficit (kilocalories per person per day) & $16 / 16$ & $1992-2015$ \\
\hline Agricultural machinery, tractors & $16 / 16$ & $1961-2000$ \\
\hline Arable land (\% of land area) & $16 / 16$ & $1961-2015$ \\
\hline Land under cereal production (hectares) & $16 / 16$ & $1961-2016$ \\
\hline Permanent cropland (\% of land area) & $16 / 16$ & $1961-2016$ \\
\hline Agricultural irrigated land (\% of total agricultural land) & $1-7 / 16$ & 2001_2015* \\
\hline Livestock production index $(2004-2006=100)$ & $16 / 16$ & $1961-2016$ \\
\hline Average precipitation in depth (mm per year) & $16 / 16$ & 1962-2014* \\
\hline Agricultural land (\% of land area) & $16 / 16$ & $1961-2015$ \\
\hline Agricultural land (sq. km) & $16 / 16$ & $1961-2015$ \\
\hline Crop production index $(2004-2006=100)$ & $16 / 16$ & $1961-2016$ \\
\hline Food production index $(2004-2006=100)$ & $16 / 16$ & $1961-2016$ \\
\hline Population growth (annual \%) & $16 / 16$ & $1960-2017$ \\
\hline Energy use for agriculture & $9 / 16$ & $1990-2015$ \\
\hline $\begin{array}{l}\text { Drought Indices (SPI, SSI, SSIrz, SRI, SPI-SSI, SPI-SSIrz, SPI- } \\
\text { SRI, SSI-SRI, SSIrz-SRI)** }\end{array}$ & $16 / 16$ & $1948-2017$ \\
\hline
\end{tabular}

* Data are not available for most of the period.

** SPI-SSI, SPI-SSIrz, SPI-SRI, SSI-SRI, and SSIrz-SRI represent the combined effect of two drought indices at a time.

To ensure the independency among the selected variables, the Variance Inflation Factor (VIF) is applied in this study (O’Brien 2007; Kim et al. 2015; Ahmadalipour and Moradkhani 2018). The VIF is a simple technique for measuring the degree of multicolinearity among variables, defined as: 


$$
V I F_{i}=\frac{1}{1-R_{i}^{2}}
$$

Note that VIF measures the impact of collinearity of the variable $\mathrm{Xi}, \mathrm{i}=1, \ldots, \mathrm{n}$, with the rest of the variables on the square of the radius of the confidence interval. $R_{i}$ is the correlation coefficient. In this study, a value of VIF $\geq 4$ indicates multicolinearity existence and that the factors are statistically insignificant. Therefore, one of the highly correlated factors should be used. Eventually, the results of the PCA and VIF lead to a selection of 9 independent factors for quantifying food insecurity in the Middle East.

Finally, a Bayesian framework is applied to find the best model that define food insecurity in the Middle East. For this, the Bayesian Linear Regression (BLR) method is used in this study.

\subsection{Results and Discussion}

\subsubsection{Drought Results}

A seven-decade record from January 1948 to December 2017 is used to conduct the drought indices analyzed in this study.

\section{- Trends of drought intensity}

It is of high importance to detect the trend analysis of droughts in a changing climate (Güner Bacanli 2017). Therefore, spatial variability of the temporal trends of meteorological, agricultural, and hydrological drought intensity are estimated over the Middle East in this study. Trends are calculated for short terms (i.e. 1-, 3-, and 6-month) to investigate seasonal drought attributes. Likewise, long terms (i.e. 12-, 18-, and 24-month) are determined to overcome drought attributes. First, a linear trend of each SI is estimated 
by the least squares method. Figure 3-2 shows the linear trend of each SI for each grid cell during the study period (1948-2017). The estimated slope represent the mean temporal change of the studied drought index. The positive slope value denotes a decrease in drought intensity, whereas, a negative value indicates a decreasing trend and therefore, an aggravation in drought intensity. From Figure 3-2, the SI-24 shows the most intensified droughts in the Middle East compared to other time scales. Results of SPI-1 indicates no meteorological drought in the region, whereas SPI-3 and SPI-6 reveal some patterns of meteorological drought in Egypt. However, results of SPI-12, -18, and -24 show more intensified meteorological drought over Egypt, Syria, Lebanon, southern Turkey, Iraq, eastern Iran, western and southern parts of Saudi Arabia, Oman, and Yemen. Hydrological drought for all time scales was mostly intensified in Egypt, western Iraq, eastern Iran, Saudi Arabia, and northern parts of Oman and Yemen. Moreover, agricultural drought indicates the worse and most intensified drought over the Middle East countries: Iraq, Syria, Lebanon, Palestine, Israel, northern Jordan, Egypt, Iran, southern Turkey, and Gulf region countries, See Figure 3-2. 

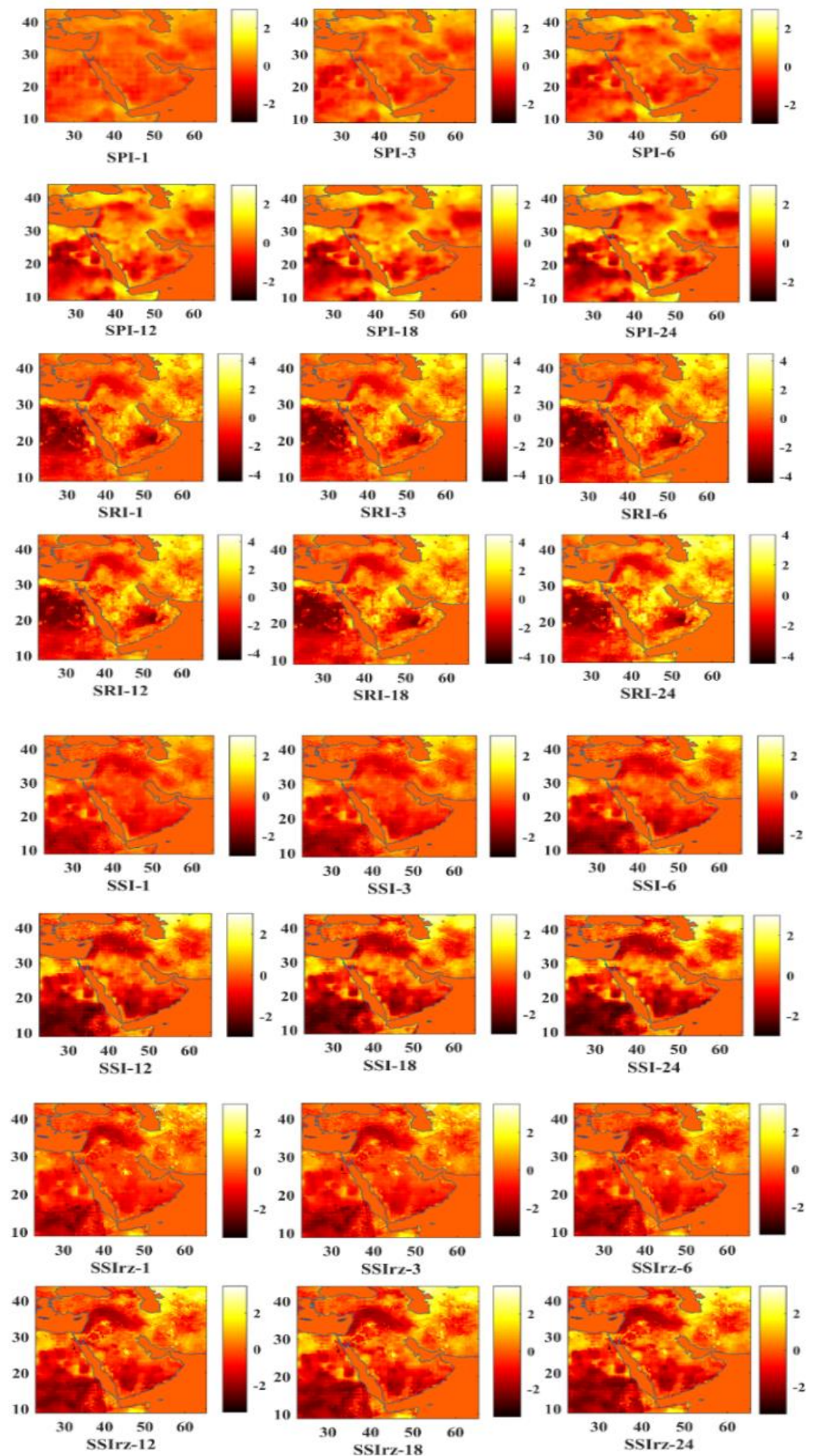

Figure 3-2 Long-term linear trends of drought intensity for the period 1948-2017 according to the SI-1, $-3,-6,-12,-18$, and -24 months over the Middle East. 
The analysis of Mann-Kendall test of hydrological and agricultural droughts revealed that the negative trends in drought magnitudes (intensified droughts) were significant (at 95\% level of significance). Although the least squares method has revealed negative trends in SPI-12, -18, and -24 months, the results of Mann-Kendall and Sen slope method has indicated that SPI series for all time scales were not significant at the 95\% significance level. The results of the applied Mann-Kendall and Sen slope estimator statistical tests for 1-, 3-, 6-, 12-, 18-, 24-monthly SIs are presented in Figure 3-3.

SRI, SSI, and SSIrz series were all showing significant decreasing trends for all time scales (i.e. 1-, 3-, 6-, 12-, 18-, 24-months) as shown in Figure 3-3. 

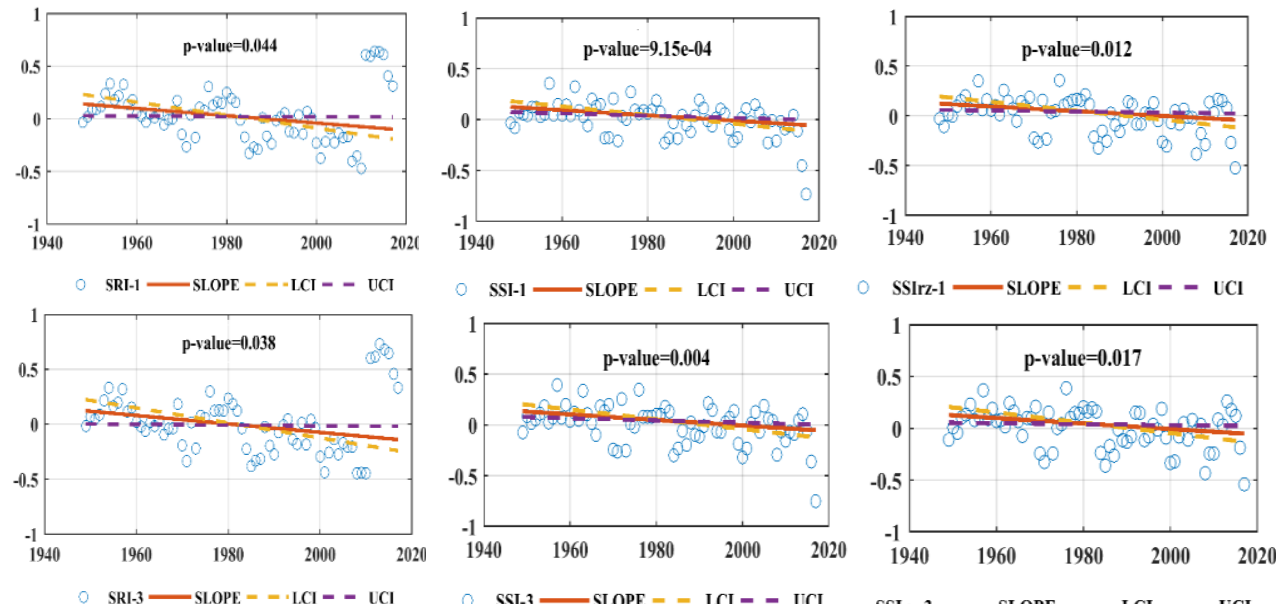

SSIrz-1 $\longrightarrow$ SLOPE - - LCI - - UCI

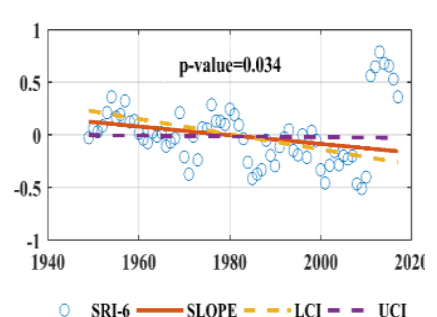

( $\quad$ SSI-3 - SLOPE -- LCI - - UCI
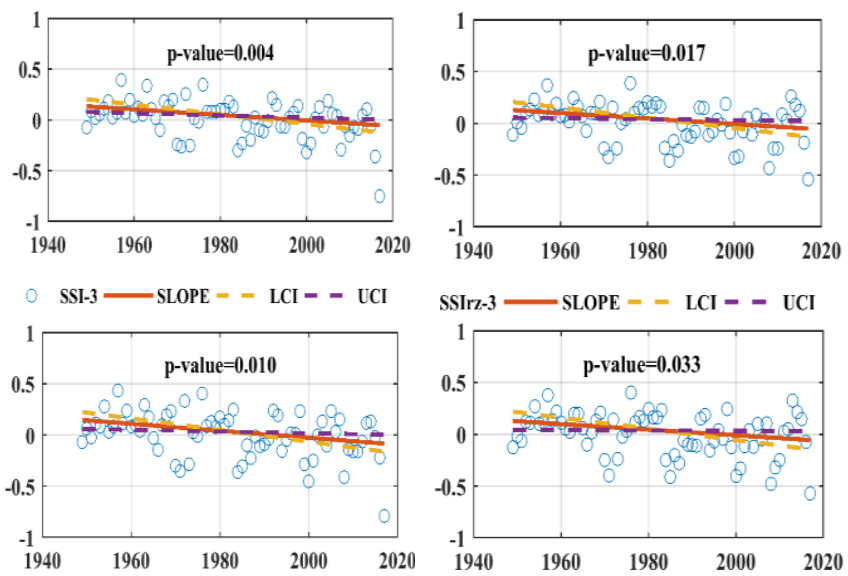

SSIrz-3 - SLOPE - - LCI - - UCI

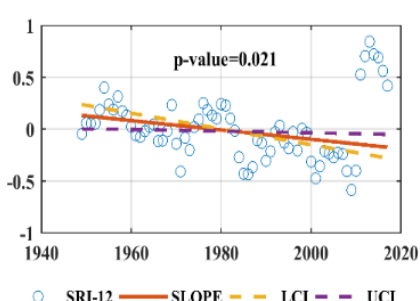

SSI- $6 \longrightarrow$ SLOPE - - LCI - - UCI
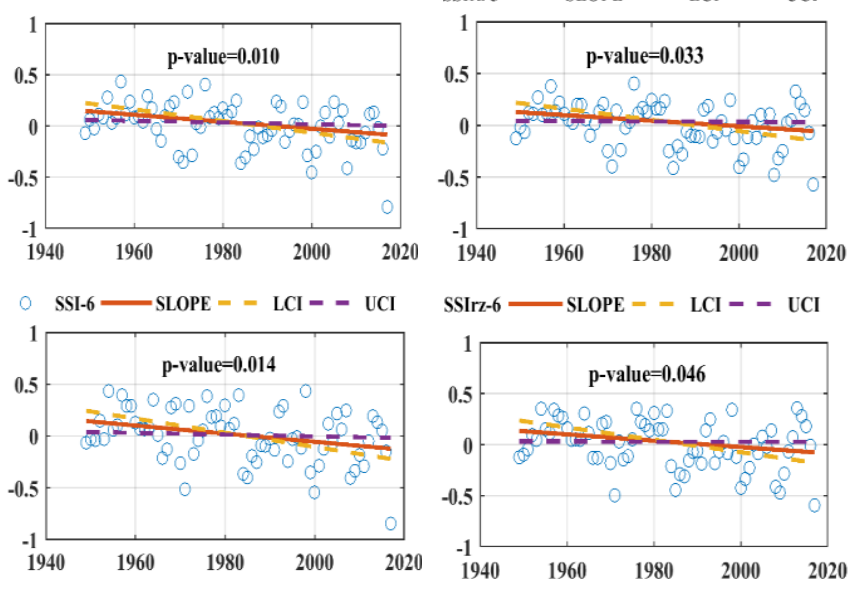

SSIrz-6 - SLOPE - - LCI - - UCI

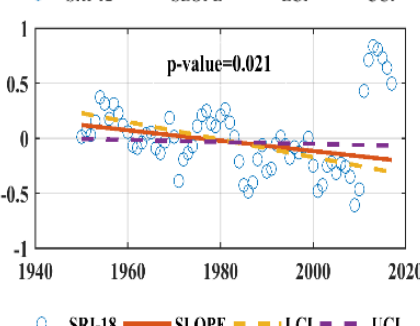

SSI-12 - SLOPE $=-$ LCI $=-$ UCI
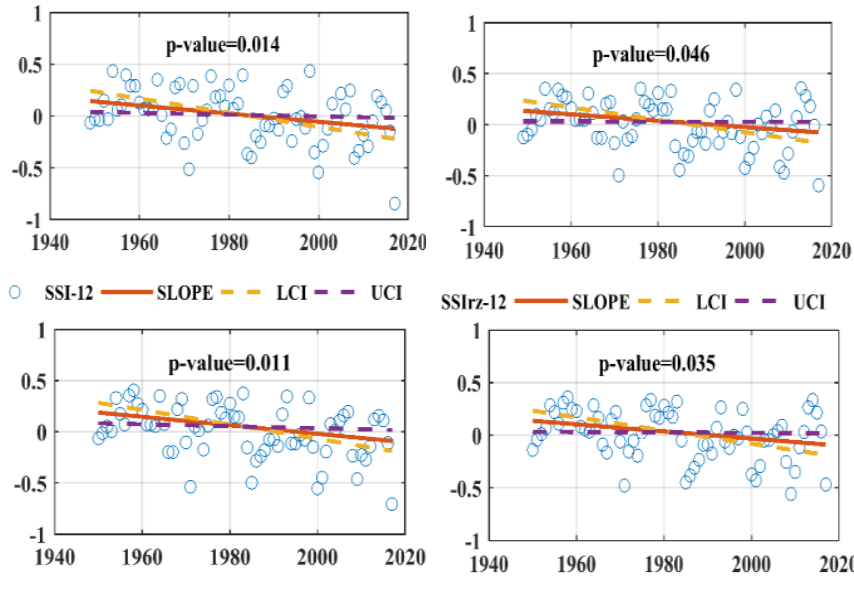

SSIrz-12 - SLOPE - - LCI - - UCI

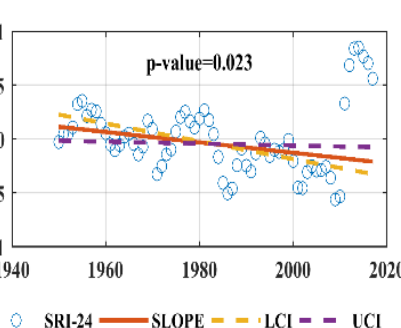

SSI-18 $\longrightarrow$ SLOPE - LCI - - UCI
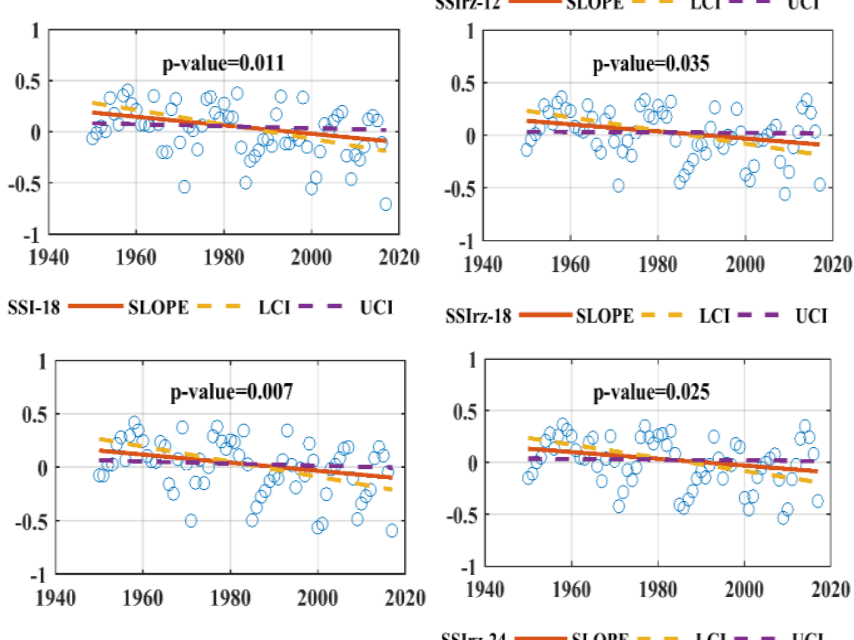

SSIrz-18 - SLOPE $=-$ LCI $=-$ UCI

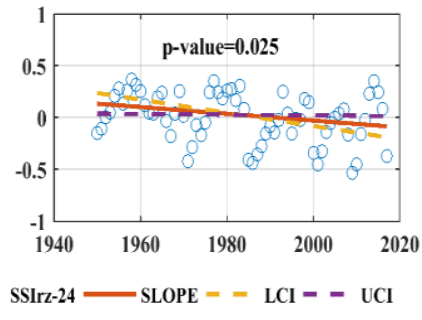

Figure 3-3 Trend test including Sen's slope method using Mann-Kendall Tau-b technique 


\section{- Spatial extent of drought}

The temporal variations of monthly drought condition (Index $<-1)$ and wet condition (Index $>1$ ) are investigated in this study. This is obtained by taking the ratio of the number of grids with Index $<-1$ and grids with Index $>1$ to the total number of grids in the Middle East during the study period of 1948-2017 (Figure 3-4). From Figure 3-4, SPI-12, SRI-12, SSI_12, and SSIrz_12 results are in coherent for most of the study period. However, SRI12 shows dry conditions for the period of 1999-2011 over the Middle East. Moreover, SSI12 and SSIrz_12 indicate that dry conditions govern most of the period of 2008-2017 across the Middle East.
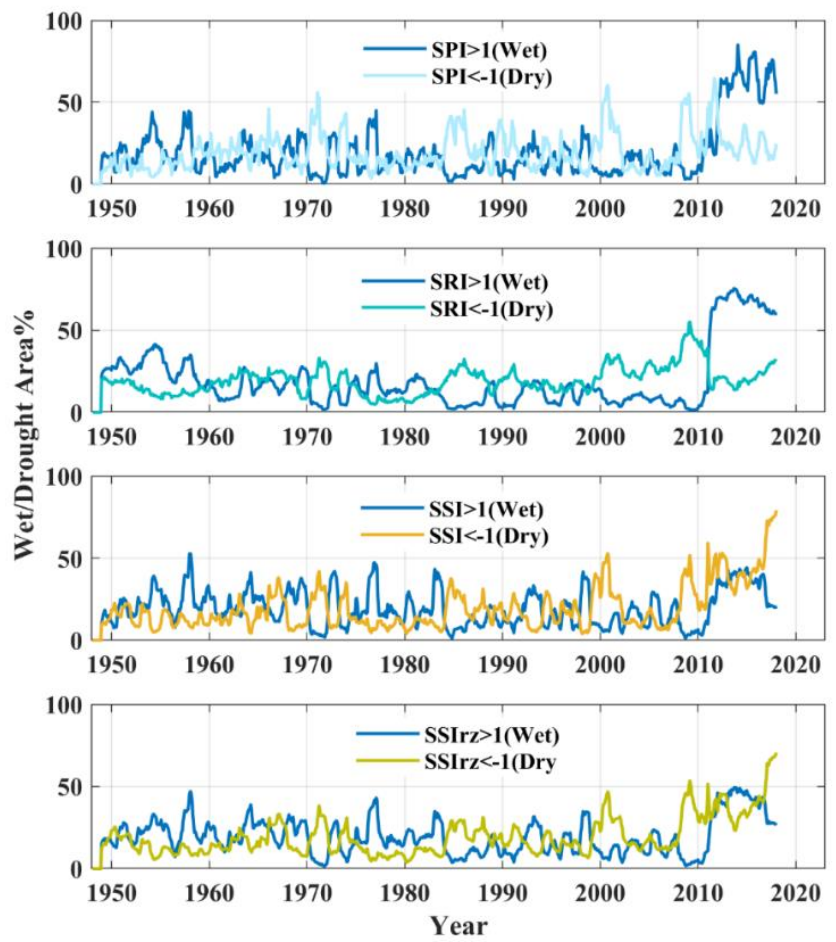

Figure 3-4 Temporal variations of monthly drought (Index of 12-month time scales $<-1$ ) and wet (Index of 12-month time scales > 1) extent over the Middle East 
To further investigate drought onset, termination, and persistence across the Middle East, the MSDI is applied combining two types of drought at a time (i.e. SPI-SSI, SPI-SRI, SPI-SSIrz, SSI-SRI, and SSIrz-SRI). The longer duration of drought (e.g. 12- to 24-month), the more consistent drought results are. That means the differences between drought indices tend to decrease (Hao and AghaKouchak 2013). Therefore, the 12-month time scale is selected for this analysis. Figures 3-5 through 3-9 show the results of comparing drought indices and their combined effect during the period from 1948 to 2017. Figure 3-5 captures up to 10 drought events during the period of 1948-2017. SPI shows severe drought onset on mid-end of 1960s, and early 1970s. Followed by longer extreme hydrological drought (near surface) more consistent and last longer. Longer extreme meteorological drought events were captured in mid1980s. Early- mid 1990s have experienced shorter drought events.

The longest severe agricultural droughts over the region were in late 1990s and early 2000s followed by shorter but more severe drought events from 2007 to 2011 . The region has experienced extreme agricultural drought in 2016. Figure 3-6 captured up to 13 drought events. In late 1960s and early 1970s, moderate to extreme agricultural drought has occurred followed by a moderate to severe hydrological drought in the Middle East. Agricultural drought lasts longer. However, moderate to extreme hydrological drought lasts for up to five years from 1982 to 1987 accompanied by moderate agricultural drought in the region. These drought events were followed by shorter drought events in early and mid 1990s. 


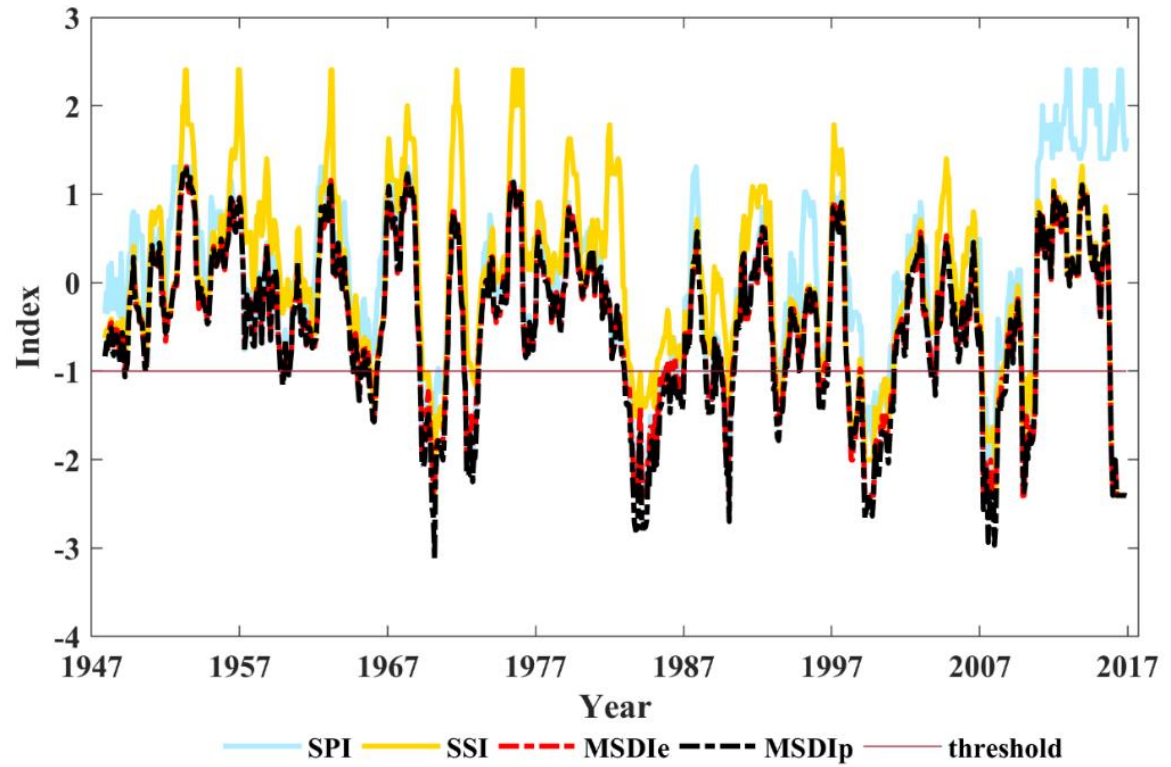

Figure 3-5 Comparison of spatially averaged 12-month time scales of MSDIe, MSDIp , SPI, and SSI over the Middle East during 1948-2017

Moreover, the Middle East has experienced several moderate to extreme hydrological drought events in late 1990s to mid 2000s. From Figures 3-5 and 3-6, agricultural drought was the most severe drought in the region for the period of 2007-2017. Figure 3-7 captured up to 13 drought events. Meteorological drought accounts for drought onset and termination whereas hydrological drought accounts for drought persistence. SPI shows more fluctuations than SRI. No meteorological and hydrological drought events were captured across the Middle East after 2013 for this study. 


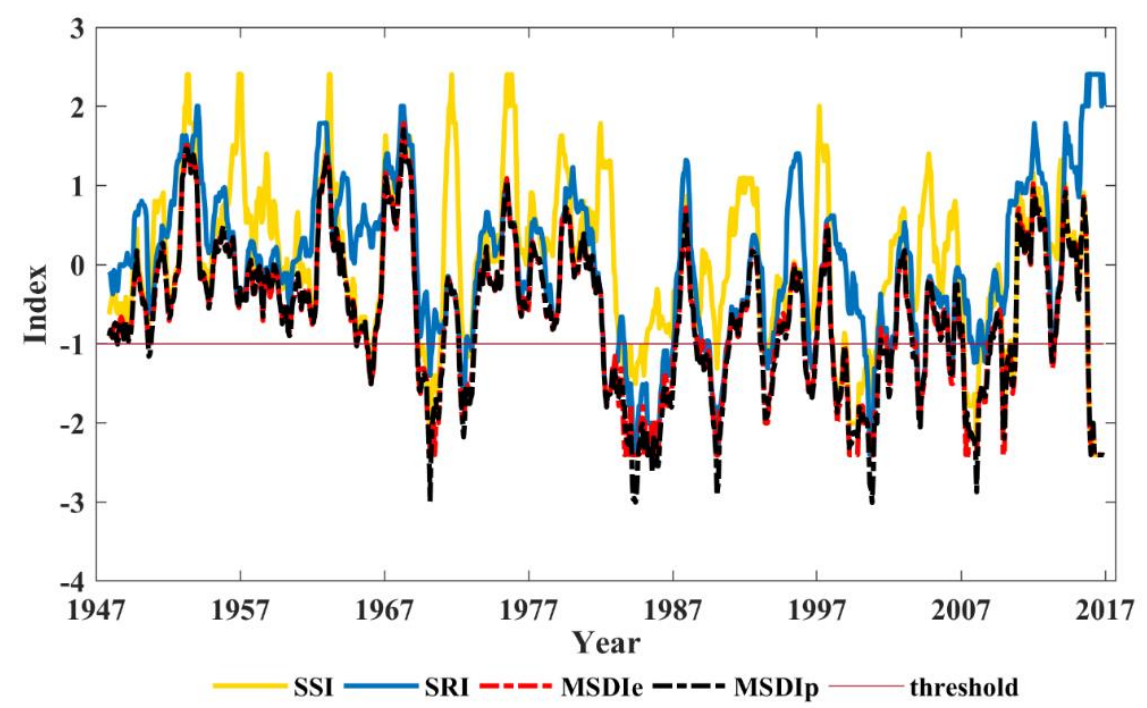

Figure 3-6 Comparison of spatially averaged 12-month time scales of MSDIe, MSDIp , SRI, and SSI over the Middle East during 1948-2017

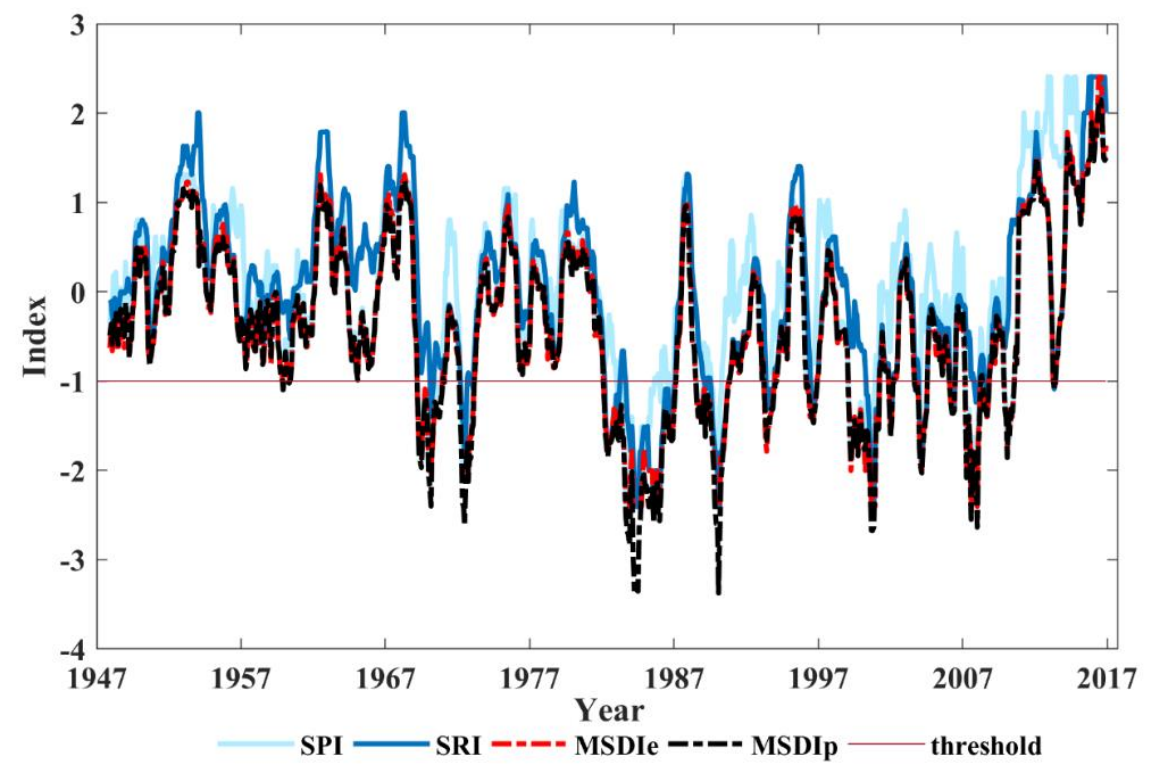

Figure 3-7 Comparison of spatially averaged 12-month time scales of MSDIe, MSDIp , SPI, and SRI over the Middle East during 1948-2017 
Figure 3-8 captured up to 11 drought events. Most of the SSIrz results were in coherent with SSI results. However, SSI (agricultural drought near the surface) did not capture the moderate agricultural drought at root zone in 1948. There was no agricultural drought in the root zone in mid 1960s. Furthermore, the SSIrz results show no agricultural drought at root zone was captured in 2010 across the region unlike the SSI results, see Figure 3-5.

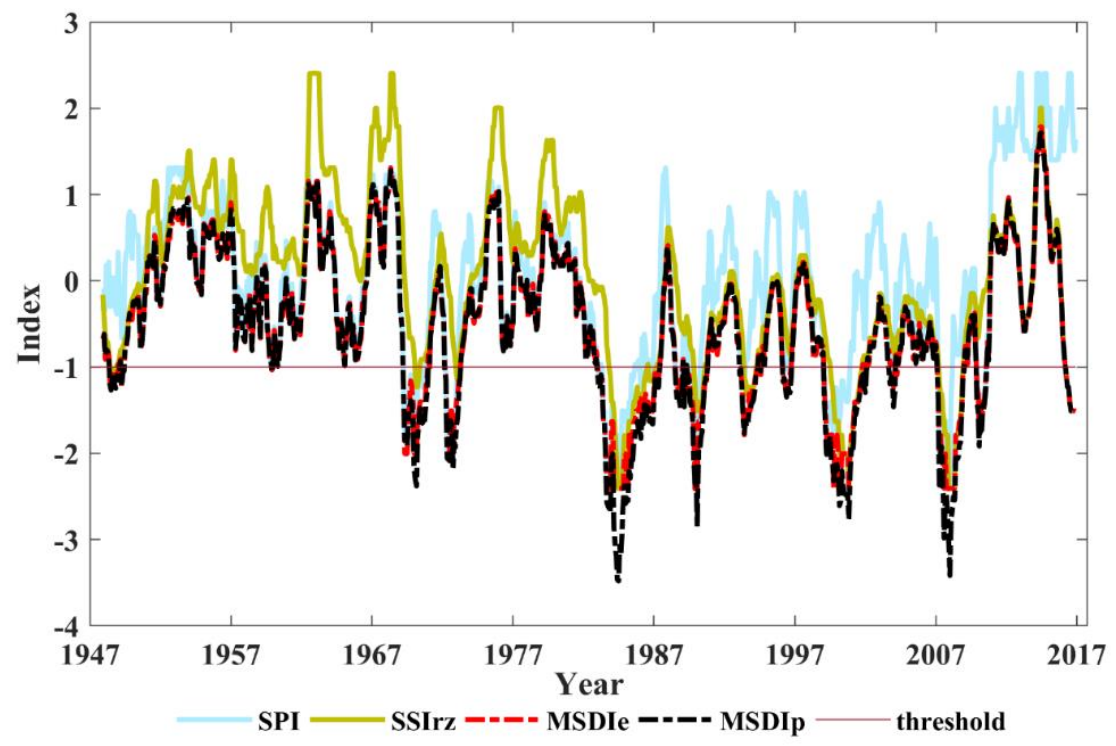

Figure 3-8 Comparison of spatially averaged 12-month time scales of MSDIe, MSDIp , SPI, and SSIrz over the Middle East during 1948-2017

Figure 3-9 captured up to 12 drought events. The SSIrz shows shorter moderate drought in late 1960s- early 1970s. However, it shows severe agricultural drought in mid 1980s. SSIrz shows shorter extreme agricultural drought in late 1990s-early 2000s. Whereas, SSI shows longer severe drought across the region during the same period. SSIrz results revealed moderate drought in 2016 unlike the SSI results that show extreme drought in same year. 


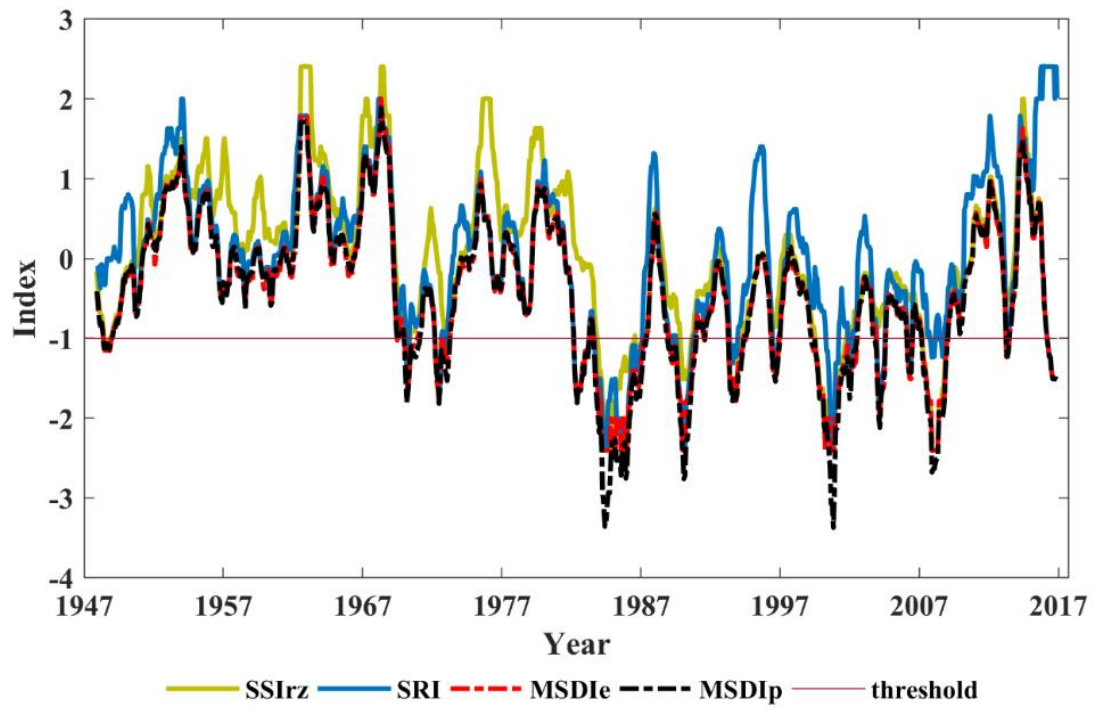

Figure 3-9 Comparison of spatially averaged 12-month time scales of MSDIe, MSDIp , SRI, and SSIrz over the Middle East during 1948-2017

In summary, meteorological drought accounts for drought onset and termination whereas hydrological drought accounts for drought persistence. Meteorological drought shows more fluctuations along the study period than agricultural and hydrological droughts. The changes of SRI were smoother than SSI during the study period.

It is worth mentioning that MSDI indicates a drought event whenever each or both of drought indices show a drought event in all the cases. The severity of MSDI resembles the severity of drought index of the lower value. However, MSDI will denote more severe drought when both indices indicating drought, for more details (Hao and AghaKouchak 2013). 


\subsubsection{Principle Component Analysis (PCA)}

The main purpose behind the PCA is dimensionality reduction of data comprising a large number of associated variables, meanwhile preserving as far as possible of data variation. This can be attained by transforming to a new set of variables (the principal components), which are uncorrelated and ordered in a way that the first few components capture most of the variant in all of the original variables (Jolliffe 2002). In this study, the percentage of variance explained by two component in PCA is presented in Figure 3-10. The user can decide the number of PCA's based on the acceptable level of variance explained by each PCA. In this study, PCA 1 explained about 53\% of total variance, whereas PCA 2 accounts for $25 \%$ of total variability. The length of each vector with respect to each PCA indicates the relative contribution of that factor to that PCA. In other words, the longer vectors contributing more than the shorter vectors with respect to a given component. Vectors that of same length and extend in the same direction representing correlated factors. For instance, crop production index and energy used in agriculture are correlated with PCA 1 and with each other, showing that as one of the two factors increased so that the other factor. Conversely, food deficit and arable land are negatively correlated with PCA1. This means as crop production index and energy increased, the food deficit and arable land decreased. Drought indices and population growth are correlated more strongly with PCA2. It is quite obvious that crop production index, food production, and cereal production have inverse relationship with food deficit. However, it is surprising that while these factors are increasing, agricultural land area and arable land are decreasing. Many factors might contribute to this finding. In particular, drought, population growth, 
urbanization, and intensive mechanized agricultural practice might be the main contributors to land degradation in the region. FAO (2011) stated that the Middle East is one of the regions that at risk of desertification, loss of agricultural land, and water scarcity due to climate change.

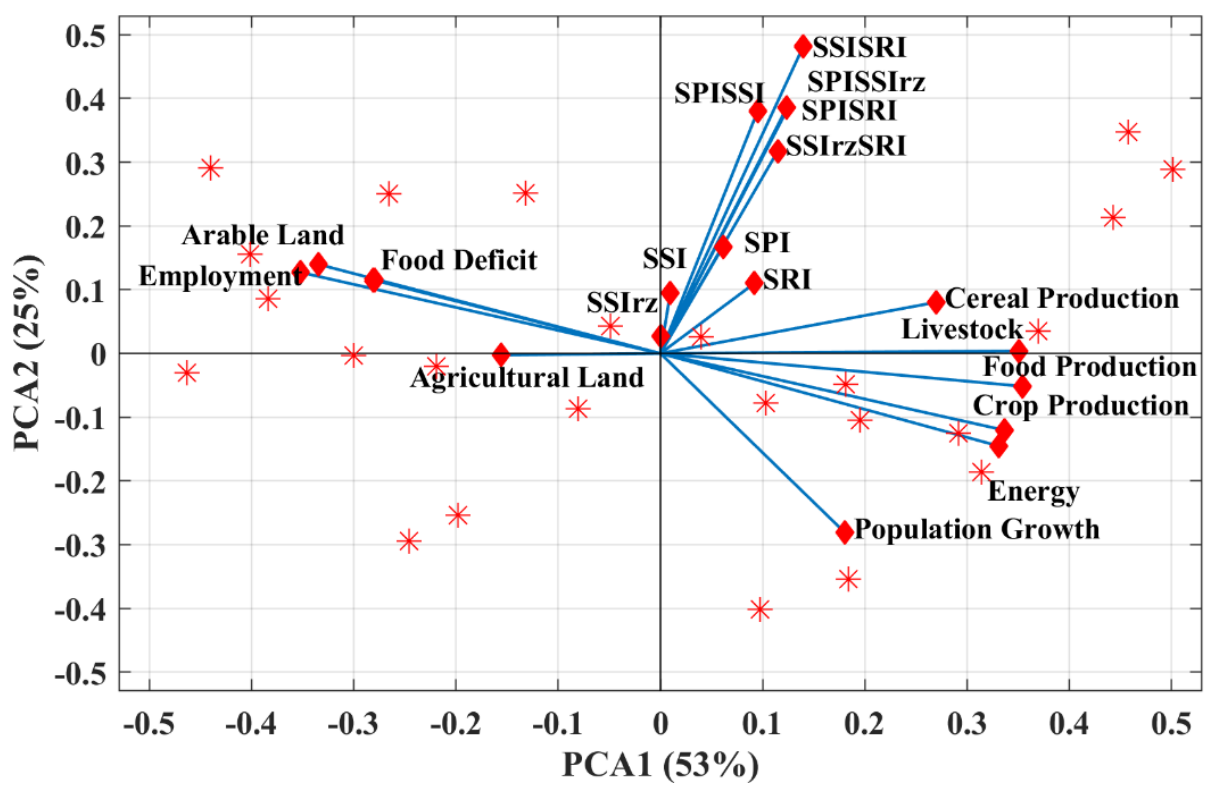

Figure 3-10 Results of the Principal Component Analysis (PCA). Components 1 and 2 accounted for $53 \%, 25 \%$ of the variability respectively. Coefficient vectors represent how much each factor contributed to the component, with the longer vectors contributing more than the shorter vectors.

\subsubsection{Bayesian Linear Regression Analysis}

Bayesian methods have appealing features that attract users from different disciplines to use. For instance, they assist in: Identifying the selection and prediction problems, allowing the performance of Markov chain Monte Carlo (MCMC) procedure to assimilate an optimal model, dealing with linear and non-linear states, handling small sample size of data (Vannucci et al. 2012). In addition, sometimes the Bayesian approach 
can be the only option to estimate model parameters rationally because of the ability to attain a prior knowledge about these parameters (Walter and Augustin 2010).

For the aforementioned attributes and the approach flexibility, the Bayesian linear regression model with semiconjugate prior for data likelihood has been used in this study. This model specifies that the conditional prior distribution of $\beta \mid \sigma^{2}$ is multivariate Gaussian with mean $\mu$ and variance $V$, and the prior distribution of $\sigma^{2}$ is inverse gamma with shape A and scale B. Specifically, the independent, normal-inverse-gamma semiconjugate model. The data likelihood defined as:

$$
\prod_{t=1}^{T} \varnothing\left(y_{t} ; x_{t} \beta, \rho^{2}\right)
$$

Where $\varnothing\left(\mathrm{y} \_\mathrm{t} ; \mathrm{x} \_\mathrm{t} \beta, \rho^{\wedge} 2\right)$ is the Gaussian probability density evaluated at yt with mean $\mathrm{xt} \beta$ and variance $\sigma 2$. The specified priors are semiconjugate for the likelihood, that is, the resulting conditional, but not marginal, posterior distributions are analytically tractable. To overcome multicolinearity existence among the selected factors in each model, PCA and VIF procedures are used as explained in Section (3.3.3). Therefore, only 9 of 19 variables are included in Bayesian models. Figure 3-11 shows temporal trend of the selected factors in the Middle East during the period of 1992- 2015. The factors are normalized around the mean (except drought indices); therefore, a value higher than zero means it is above the mean value. Whereas, a value lower than the zero indicates it is below the mean of the data of 24 years. The case is different though for drought indices. That is a value of drought index below -1 indicates drought condition whereas a value above -1 indicates wet condition across the region. The straight line in the $\mathrm{x}$-direction in Figure 3-11 represents the drought/wet threshold $(\mathrm{SI}=-1)$. 
From Figure 3-11, FAO-STAT data showed that the highest food deficit during 1992-2015 was in early 1990s. Whereas, crop production and livestock were at the lowest level during the same period. Agricultural land data showed a stable behavior until 2005 and after when data showed gradual decrease in agricultural land in the region. This can be as a result of, but not limited to, the unsustainable intensive agricultural practices. Especially, the region has experienced increasing trend in crop production, cereal production and livestock, population growth that reached the peak in 2007, and urbanization. Saab (2012) mentioned that boosting yields in the last two decades was the reason behind increasing cereal production in the Arab region and not agricultural land expansion. Maximizing crop production by agricultural intensification has to be done while minimizing its environmental side effects (Mohtar et al. 2015). Livestock can impact the soil in drylands as a result of soil compaction which preventing root development, decreasing infiltration, making cultivation harder, and thus energy consuming (Koohafkan and Stewart 2012).

In addition, Figure 3-11 shows the impact of the extreme agricultural-hydrological droughts on water availability (knowing that drought is a slow-onset phenomenon and its effects can last longer) in 2001 and 2009 across the Middle East. 


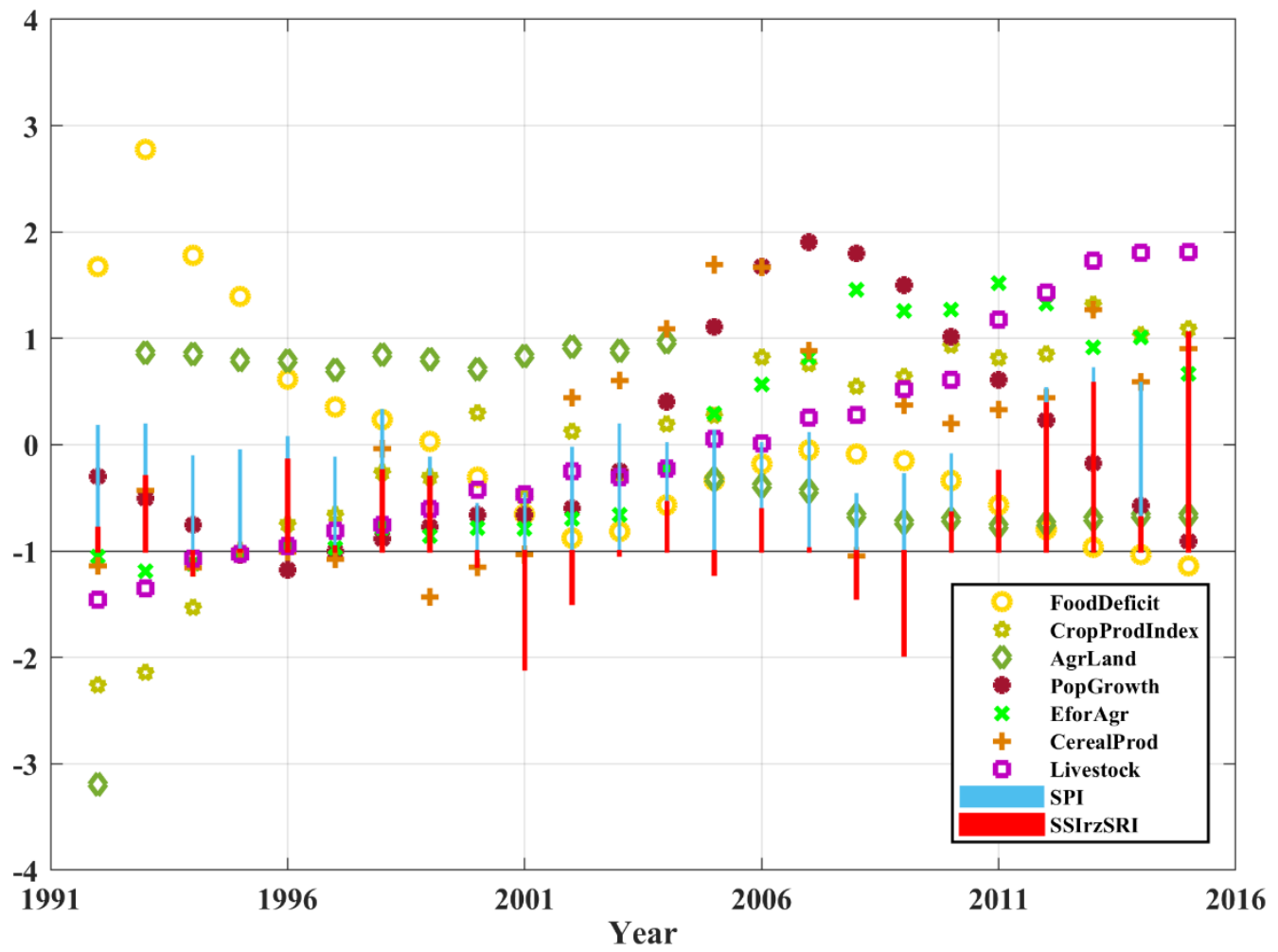

Figure 3-11 Comparing the time series of the selected factors as indicators of food insecurity in Middle East with drought indices based on precipitation (SPI, blue bars), runoff and soil moisture at root zone (SSIrzSRI, red bars) over the same period (19922015)

Food insecurity is defined in two ways in this study: food deficit and crop production index. A total of six models out of many other models are presented in this study. To evaluate the power (quality) of each model, Akaike information criteria (AIC; Akaike 1974) and Bayesian information criterion (BIC; Schwarz 1978) where utilized, and are defined as:

$$
\begin{gathered}
A I C(m)=-2 L+2 m \\
B I C(m)=-2 L+\operatorname{mlog}(n)
\end{gathered}
$$


Where $\mathrm{m}$ denotes the number of fitted parameters, $\mathrm{n}$ is the number of observations, and $\mathrm{L}$ is the maximized value of likelihood function of a statistical model for a given data. The lower values of AIC and BIC criteria, indicates the better model. AICc represents the corrected AIC for small sample size. Moreover, the root mean square error (RMSE) metric, which is the square root of the average of squared differences between prediction and actual observation, is used to evaluate the final model. The lower the RMSE value, the better model. Unlike the Coefficient of determination $\left(\mathrm{R}^{2}\right)$ where the higher value indicates a better model. The following section will present the final models that best predict food insecurity in Middle East.

\subsubsection{Food deficit and crop production index models as indicators of food insecurity in Middle East}

\section{a) Food Deficit Models}

Food deficit prediction models are based on agricultural land, population growth, energy used in agriculture, livestock, cereal production, meteorological drought, and agricultural-hydrological droughts. The second model below is the best model to define food deficit in the region based on the selected factors of this study. Whereas the third

model represents food deficit without including drought factor. Figures 3-12 to 3-14 show the correlation between the predicted model and observation for each model. 
1) $\quad$ Food Deficit $=0.3095-0.3232 *$ AgrLand $+0.4192 *$ PopGrowth $1.0633 *$ EforAgr $-0.5764 *$ SPI + 0.3888*SSIrzSRI

\begin{tabular}{ll}
\hline \multicolumn{1}{c}{ VIF } & \multicolumn{1}{c}{ Metrics } \\
\hline & RMSE: 0.80 \\
AgrLand: 1.51 & $\mathrm{R}^{2}: 0.50$ \\
PopGrowth: 3.03 & Adjusted $\mathrm{R}^{2}: 0.36$ \\
EforAgr: 2.99 & p-value $: 0.0192$ \\
SPI: 2.31 & AIC: $-1.63 \mathrm{e}+03$ \\
SSIrzSRI: 2.47 & AICc: $-1.62 \mathrm{e}+03$ \\
& BIC: $-1.62 \mathrm{e}+03$ \\
\hline
\end{tabular}

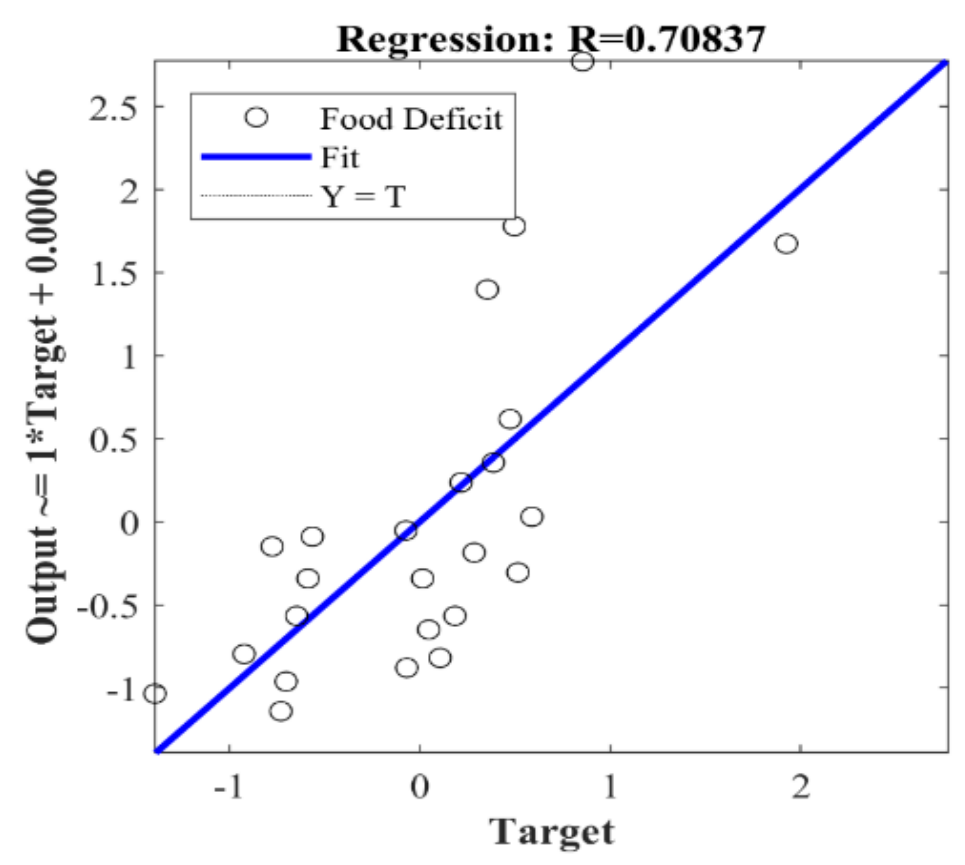

Figure 3-12 The correlation between the predicted food deficit and observation. The first model is based on agricultural land, population growth, energy used in agriculture, meteorological drought, and agricultural-hydrological droughts 
2) $\quad$ Food Deficit $=0.1111-0.8540 *$ Livestock $-0.4895 *$ CerealProd + $0.4326 *$ PopGrowth $+1.0662 *$ SPI $+0.2459 *$ SSIrzSRI

\begin{tabular}{ll}
\hline \multicolumn{1}{c}{ VIF } & \multicolumn{1}{c}{ Metrics } \\
& \\
\hline & RMSE: 0.60 \\
Livestock: 1.87 & R $^{2}: 0.72$ \\
CerealProd: 2.98 & Adjusted R ${ }^{2}: 0.64$ \\
PopGrowth: 2.30 & p-value $: 0.000192$ \\
SPI: 3.51 & AIC: $-1.64 \mathrm{e}+03$ \\
SSIrzSRI: 2.37 & AICc: $-1.64 \mathrm{e}+03$ \\
& BIC: $-1.63 \mathrm{e}+03$ \\
\hline
\end{tabular}

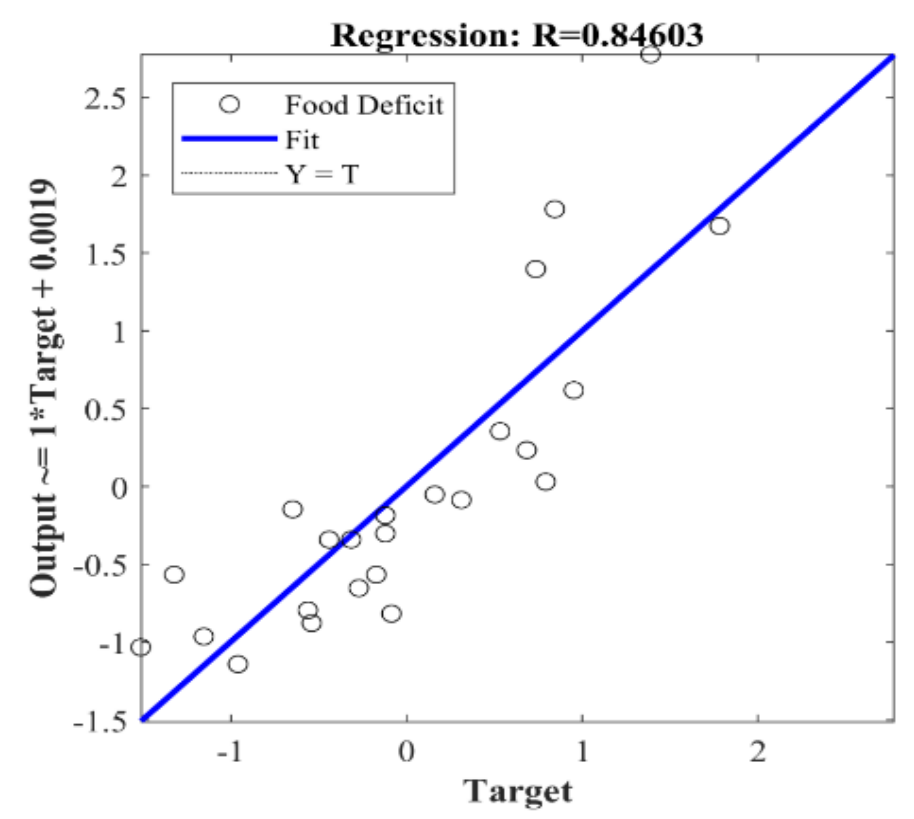

Figure 3-13 The correlation between the predicted food deficit and observation. The second model is based on livestock, cereal production, population growth, meteorological drought, and agricultural-hydrological droughts 
3) Food Deficit $=0.0005-0.6718 *$ Livestock $-0.1710 *$ CerealProd + 0.0777 *PopGrowth

\begin{tabular}{ll}
\multicolumn{1}{c}{ VIF } & \multicolumn{1}{c}{ Metrics } \\
\hline & RMSE: 0.69 \\
Livestock:1.58 & $\mathrm{R}^{2}: 0.58$ \\
CerealProd: 1.9 & Adjusted $\mathrm{R}^{2}: 0.52$ \\
PopGrowth: 1.33 & p-value $: 0.00047$ \\
& AIC: $-1.71 \mathrm{e}+03$ \\
& AICc: $-1.71 \mathrm{e}+03$ \\
& BIC: $-1.70 \mathrm{e}+03$ \\
\hline
\end{tabular}

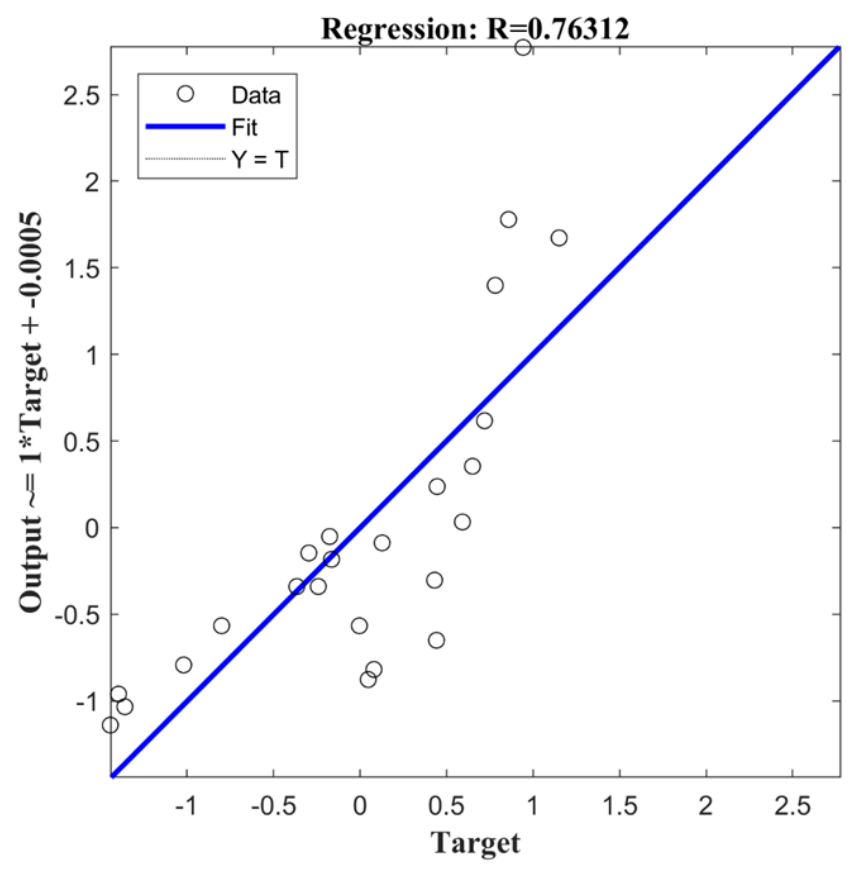

Figure 3-14 The correlation between the predicted food deficit and observation. The third model is based on livestock, cereal production, and population growth 


\section{b) Crop Production Index Models}

Crop production index is best explained by agricultural land, population growth, energy used in agriculture, food deficit, meteorological drought, and agriculturalhydrological droughts. However, the second model below can be selected to be the best model to predict crop production index in Middle East based on the factors suggested in this study. The correlation of this model with the observation was the highest $(\mathrm{R}=0.97)$. The third and last model is predicting crop production index without drought. Figures 315 to 3-17 show the correlation between the predicted model and observation for each model.

1) Crop Production Index $=-0.0424+0.3753 *$ AgrLand $-0.1188 *$ PopGrowth + $1.1000 *$ EforAgr $+0.3112 *$ SPI $-0.0336 *$ SSIrzSRI

\begin{tabular}{ll}
\hline \multicolumn{1}{c}{ VIF } & \multicolumn{1}{c}{ Metrics } \\
\hline & RMSE: 0.51 \\
AgrLand: 1.51 & $\mathrm{R}^{2}: 0.799$ \\
PopGrowth: 3.03 & Adjusted $\mathrm{R}^{2}: 0.744$ \\
EforAgr: 2.99 & p-value $: 9.62 \mathrm{e}-06$ \\
SPI: 2.31 & AIC: $-1.63 \mathrm{e}+03$ \\
SSIrzSRI: 2.47 & AICc: $-1.62 \mathrm{e}+03$ \\
& BIC: $-1.62 \mathrm{e}+03$ \\
\hline
\end{tabular}




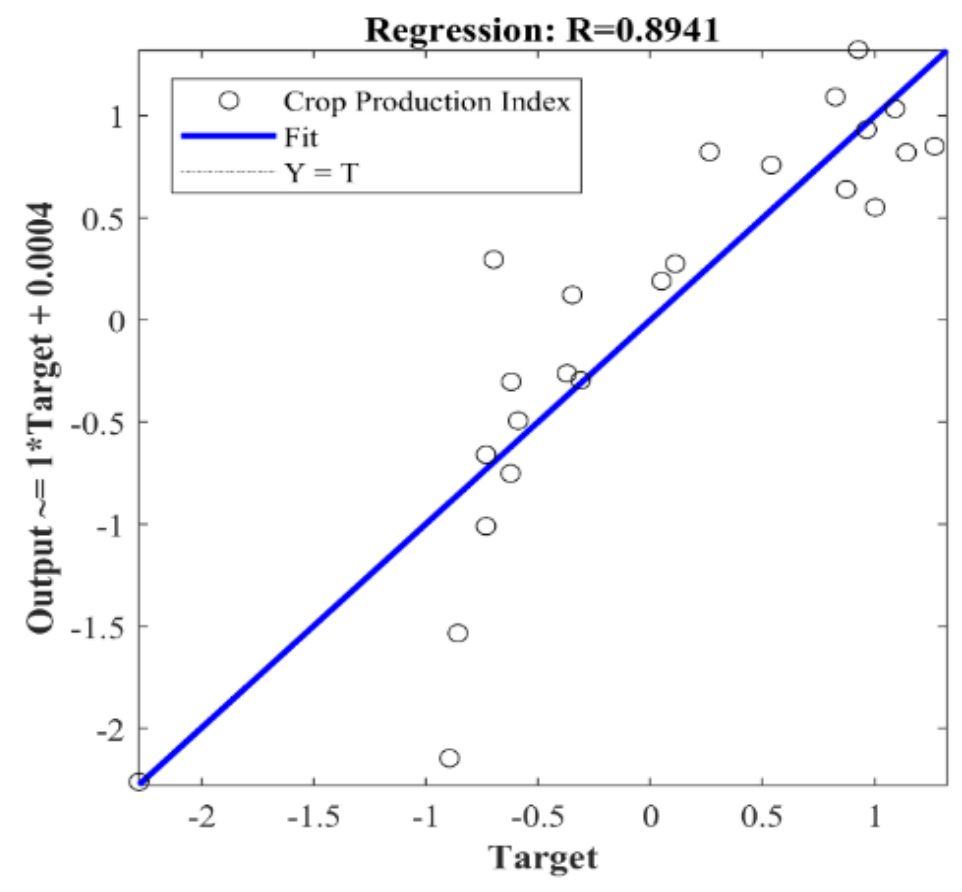

Figure 3-15 The correlation between the predicted crop production index and observation. The first model is based on agricultural land, population growth, energy used in agriculture, meteorological drought, and agricultural-hydrological droughts

2) Crop Production Index $=0.0918+0.1973 *$ AgrLand $-0.5076 *$ FoodDeficit + $0.6243 *$ EforAgr $-0.0202 *$ SPI + 0.1277*SSIrzSRI

\begin{tabular}{ll}
\multicolumn{1}{c}{ VIF } & \multicolumn{1}{c}{ Metrics } \\
\hline & RMSE: : 0.28 \\
AgrLand: 1.72 & $\mathrm{R}^{2}: 0.94$ \\
FoodDeficit: 1.80 & Adjusted R $\mathrm{R}^{2}: 0.92$ \\
EforAgr: 2.48 & p-value $: 2.7 \mathrm{e}-10$ \\
SPI: 2.39 & AIC: $-1.66 \mathrm{e}+03$ \\
SSIrzSRI: 2.25 & AICc: $-1.66 \mathrm{e}+03$ \\
& BIC: $-1.65 \mathrm{e}+03$ \\
\hline
\end{tabular}




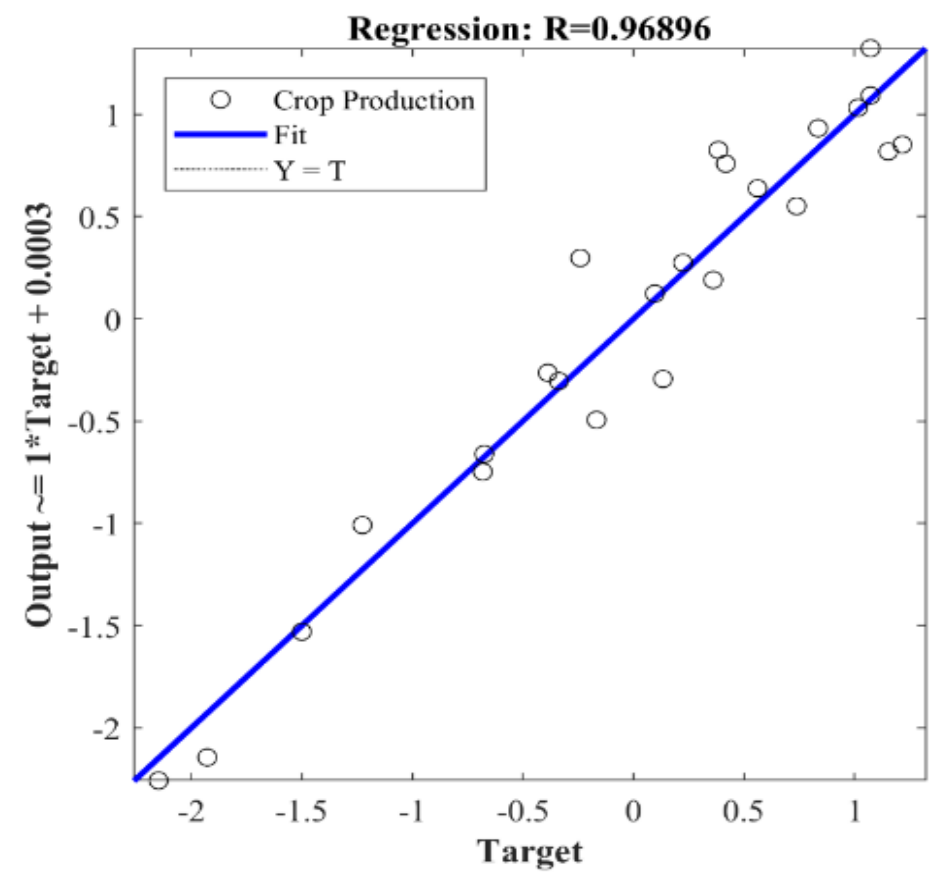

Figure 3-16 The correlation between the predicted crop production index and observation. The second model is based on agricultural land, food deficit, energy used in agriculture, meteorological drought, and agricultural-hydrological droughts

3) Crop Production Index $=0.0006+0.1861 *$ AgrLand $-0.5128 *$ FoodDeficit + $0.6330 *$ EforAgr

\begin{tabular}{ll}
\multicolumn{1}{c}{ VIF } & \multicolumn{1}{c}{ Metrics } \\
& \\
\hline & RMSE: 0.28 \\
AgrLand: 1.58 & $\mathrm{R}^{2}: 0.93$ \\
FoodDeficit: 1.68 & Adjusted $\mathrm{R}^{2}: 0.92$ \\
EforAgr: 2.35 & p-value $: 8.57 \mathrm{e}-12$ \\
& AIC: $-1.64 \mathrm{e}+03$ \\
& AICc: $-1.64 \mathrm{e}+03$ \\
& BIC: $-1.64 \mathrm{e}+03$ \\
\hline
\end{tabular}




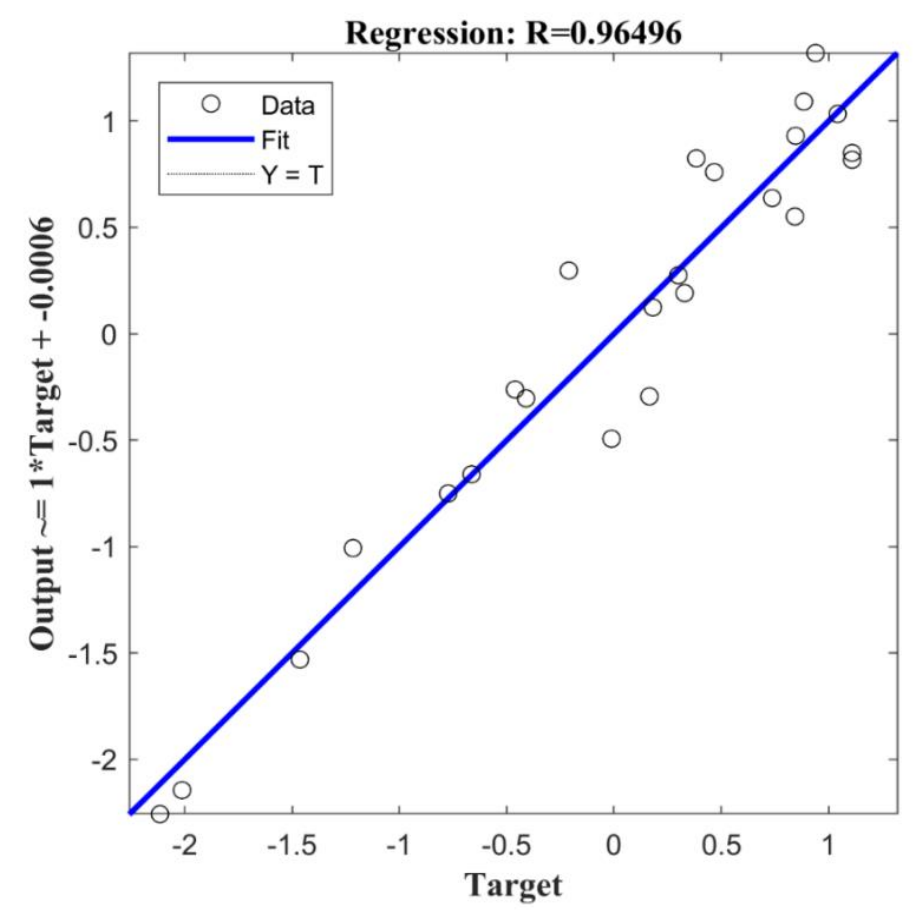

Figure 3-17 The correlation between the predicted crop production index and observation. The third model is based on agricultural land, food deficit, and energy used in agriculture

In summary, it should be noted that all the results of the selected models were statistically significant at $\alpha=0.05$. Moreover, the results suggest that drought is significantly affect food deficit in Middle East.

\subsection{Summary and conclusion}

This section provided the comprehensive assessment of food insecurity in Middle East, as a function of drought and socio-economic factors. The study first has characterized all drought conditions over the region using long-term (1948-2017) precipitation, soil moisture, and runoff data and studying the long-term drought behavior by analyzing their temporal trends. Second, the study has introduced the best models that defining food 
insecurity in the Middle East based on the factors used in this research. The Global Land Data Assimilation System (GLDAS-2) and (GLDAS-2.1) monthly precipitation, soil moisture, and runoff data with a $0.25^{\circ}$ spatial resolution were used to drive meteorological, agricultural, and hydrological droughts at multiple timescales over the Middle East for seven decades for the period of 1948-2017. Moreover, data from different sources like IEA, FAO of the United Nations were used to investigate the socio-economic factors related to food security in Middle East. The historical variations and trends of meteorological, agricultural, and hydrological droughts over the Middle East were investigated, and the main findings of the study are as follows:

- The results indicate that agricultural drought near surface is the worse and most intensified drought over the Middle East region during the study period.

- Hydrological drought for all time scales is mostly intensified in Egypt, western Iraq, eastern Iran, Saudi Arabia, and northern parts of Oman and Yemen.

- SRI-12 shows dry conditions for the period of 1999-2011 over the Middle East. Whereas, SSI-12 and SSIrz_12 results indicate that dry conditions govern most of the period of 2008-2017 across the Middle East.

- Drought is a serious concern in Middle East, as the majority of Middle Eastern countries are already dealing with water scarcity, and it will further exacerbate food insecurity in the region.

- The results demonstrated the significant impacts of drought (as a water stress factor), agricultural land availability, population growth, livestock, and cereal production on food insecurity in the Middle East 


\section{Chapter 4: Conclusions and Future Studies}

This study presented a comprehensive assessment of drought and food-waterenergy-security nexus across the Middle East using rigorous frameworks. Various drought indices and Bayesian approach for a historical period were implemented to identify food insecurity in Middle East. Drought is quantified at country and regional level using univariate and multivariate drought indices (i.e. SPI, SRI, SSI, SPEI, and MSDI) to provide more relevant and reliable drought monitoring over the region.

The results revealed that drought is a serious concern in Middle East, as the majority of Middle Eastern countries are already dealing with water scarcity, and it will further exacerbate food insecurity in the region. The assessment suggested that most of the selected countries are facing FEW insecure resources condition. However, water sector is the scarcest resource in the Middle East. Although large rivers are located in the region, transboundary water resources are additional problem.

The main limitation of this study was data availability. Better results could be achieved with the same approach if monthly or daily data are available for each of the socioeconomic factors that were included in this study. Energy data was another limited factor in this study. Water withdrawals was not available for most of the study period. Therefore, drought was used as an indicator of water stress in Middle East.

Climate change is expected to have considerable effects on future drought. Therefore, assessment of future drought conditions using Global Climate Models (GCMs) is of high importance for the Middle East, which can be further studied over the region. Moreover, Water policy in the Middle East is of high importance to shape the future of 
FEW security. Moreover, to solve water allocation issue, more participation and joint decisions need to take place between the transboundary countries. The lack of consistent management combined with unsustainable use of resources in the Middle East region will probably pose critical FEWS challenges in the near future. Finally, defining food insecurity for a certain region might not be suitable for all regions due to differences in natural and manmade resources. Therefore, knowledge about the study region is needed to overcome the difficulty of selecting decent factors to analyze. 


\section{References}

Adams RH (2004) Economic growth, inequality and poverty: Estimating the growth elasticity of poverty. World Dev 32:1989-2014. doi:

10.1016/j.worlddev.2004.08.006

AFED (2012) Environmental Housekeeping Handbook for Office Buildings in the Arab Countries. Arab Forum for Environment and Development

Ahmadalipour A, Moradkhani H (2017) Analyzing the uncertainty of ensemble-based gridded observations in land surface simulations and drought assessment. J Hydrol 555:557-568. doi: 10.1016/j.jhydrol.2017.10.059

Ahmadalipour A, Moradkhani H (2018) Multi-dimensional assessment of drought vulnerability in Africa: 1960-2100. Sci Total Environ 644:520-535. doi: 10.1016/j.scitotenv.2018.07.023

Ahmadalipour A, Moradkhani H, Demirel MC (2017a) A comparative assessment of projected meteorological and hydrological droughts: Elucidating the role of temperature. J Hydrol 553:785-797. doi: 10.1016/j.jhydrol.2017.08.047

Ahmadalipour A, Moradkhani H, Svoboda M (2016) Centennial drought outlook over the CONUS using NASA-NEX downscaled climate ensemble. Int J Climatol. doi: $10.1002 /$ joc. 4859

Ahmadalipour A, Moradkhani H, Yan H, Zarekarizi M (2017b) Remote Sensing of Drought: Vegetation, Soil Moisture and Data Assimilation, Remote Sensing of Hydrological Extremes. In: Remote Sensing of Hydrological Extremes. Springer 
International Publishing Switzerland, pp 121-149

Ahmadalipour A, Rana A, Moradkhani H, Sharma A (2017c) Multi-criteria evaluation of CMIP5 GCMs for climate change impact analysis. Theor Appl Climatol 128:71-87. doi: $10.1007 / \mathrm{s} 00704-015-1695-4$

Ahmed G, Hamrick D, Gereffi G (2014) Shifting Governance Structures in the Wheat Value Chain : Implications for Food Security in the Middle East and North Africa. $1-28$.

Ahmed SA, Holloway GJ (2017) Calories, conflict and correlates: Redistributive food security in post-conflict Iraq. Food Policy 68:89-99. doi: 10.1016/j.foodpol.2017.01.005

Akaike H (1974) A new look at the statistical model identification. IEEE Trans Autom Control 19:716-723. doi: 10.1109/TAC.1974.1100705

Al-Awad M, Harb N (2005) Financial development and economic growth in the Middle East. Appl Financ Econ 15:1041-1051. doi: 10.1080/09603100500120639

Al-Faraj FAM, Al-Dabbagh BNS (2015) Assessment of collective impact of upstream watershed development and basin-wide successive droughts on downstream flow regime: The Lesser Zab transboundary basin. J Hydrol 530:419-430. doi: 10.1016/j.jhydrol.2015.09.074

Al-Faraj FAM, Tigkas D (2016) Impacts of Multi-year Droughts and Upstream HumanInduced Activities on the Development of a Semi-arid Transboundary Basin. Water 
Resour Manag 30:5131-5143. doi: 10.1007/s11269-016-1473-9

Allen RG, Pruitt WO, Wright JL, et al (2006) A recommendation on standardized surface resistance for hourly calculation of reference ETo by the FAO56 Penman-Monteith method. Agric Water Manag 81:1-22. doi: 10.1016/j.agwat.2005.03.007

Al-Mulali U, Ozturk I (2015) The effect of energy consumption, urbanization, trade openness, industrial output, and the political stability on the environmental degradation in the MENA (Middle East and North African) region. Energy 84:382389. doi: 10.1016/j.energy.2015.03.004

Al-Saidi M, Birnbaum D, Buriti R, et al (2016) Water Resources Vulnerability Assessment of MENA Countries Considering Energy and Virtual Water Interactions. Procedia Eng 145:900-907. doi: 10.1016/j.proeng.2016.04.117

AL-Timimi YK, AL-Jiboori MH (2013) Assessment of spatial and temporal drought in Iraq during the period 1980-2010. Ijee 2:291-302.

Amin MT, Mahmoud SH, Alazba AA (2016) Observations, projections and impacts of climate change on water resources in Arabian Peninsula: current and future scenarios. Environ Earth Sci 75:1-17. doi: 10.1007/s12665-016-5684-4

Amini A, Zareie S, Taheri P, et al (2016) Drought analysis and water resources management inspection in Euphrates-Tigris basin. River basin Manag. doi: $10.5772 / 63148$

Antonelli M, Tamea S (2015) Food-water security and virtual water trade in the Middle 
East and North Africa. Int J Water Resour Dev 31:326-342. doi:

10.1080/07900627.2015.1030496

Awulachew S, Rebelo L-M, Molden D (2010) The Nile Basin: tapping the unmet agricultural potential of Nile waters. Water Int 35:623-654. doi:

$10.1080 / 02508060.2010 .513091$

Barker LJ, Hannaford J, Chiverton A, Svensson C (2016) From meteorological to hydrological drought using standardised indicators. Hydrol Earth Syst Sci 20:24832505. doi: 10.5194/hess-20-2483-2016

Beaudoing H, Rodell M (2015) GLDAS Noah Land Surface Model L4 monthly 0.25 x 0.25 degree V2.0. In: NASA/GSFC/HSL, Goddard Earth Sci. Data Inf. Serv. https://disc.gsfc.nasa.gov/datacollection/GLDAS_NOAH025_M_V2.0.html. Accessed 1 Jan 2018

Beaudoing H, Rodell M (2016) GLDAS Noah Land Surface Model L4 monthly 0.25 x 0.25 degree V2.1. In: NASA/GSFC/HSL, Goddard Earth Sci. Data Inf. Serv. https://disc.gsfc.nasa.gov/datacollection/GLDAS_NOAH025_M_V2.1.html. Accessed 1 Jan 2018

Beguería S, Vicente-Serrano SM, Reig F, Latorre B (2014) Standardized precipitation evapotranspiration index (SPEI) revisited: Parameter fitting, evapotranspiration models, tools, datasets and drought monitoring. Int J Climatol 34:3001-3023. doi: $10.1002 /$ joc. 3887

Bekhet HA, Matar A, Yasmin T (2017) CO2 emissions, energy consumption, economic 
growth, and financial development in GCC countries: Dynamic simultaneous equation models. Renew Sustain Energy Rev 70:117-132. doi:

10.1016/j.rser.2016.11.089

Berardy A, Chester M V. (2017) Climate Change Vulnerability in the Food, Energy, and Water Nexus: Concerns for Agricultural Production in Arizona and its Urban Export Supply. Environ Res Lett. doi: 10.1042/BJ20101136>

Berg C, Al Nimer S, Fileccia T, et al (2016) The Cost of Irrigation Water in the Jordan Valley. Washington, DC.

Borgomeo E, Jägerskog A, Talbi A, et al (2018) The Water-Energy-Food Nexus in the Middle East and North Africa Scenarios for a Sustainable Future.

Burkey J (2006) A non-parametric monotonic trend test computing Mann-Kendall Tau, Tau-b, and Sen's slope written in Mathworks-MATLAB implemented using matrix rotations.

Caporusso NB, Rolim GDS (2015) Reference evapotranspiration models using different time scales in the Jaboticabal region of São Paulo, Brazil. Acta Sci Agron 37:1-9. doi: 10.4025/actasciagron.v37i1.18277

Carrão H, Singleton A, Naumann G, et al (2014) An optimized system for the classification of meteorological drought intensity with applications in drought frequency analysis. J Appl Meteorol Climatol 53:1943-1960. doi: 10.1175/JAMCD-13-0167.1 
Chang Y, Li G, Yao Y, et al (2016) Quantifying the water-energy-food nexus: Current status and trends. Energies 9:1-17. doi: 10.3390/en9020065

Chenoweth J, Hadjinicolaou P, Bruggeman A, et al (2011) Impact of climate change on the water resources of the eastern Mediterranean and Middle East region: Modeled 21 st century changes and implications. Water Resour Res. doi: 10.1029/2010WR010269

Colaizzi PD, Agam N, Tolk JA, et al (2014) Two-Source Energy Balance Model to Calculate E, T, and ET: Comparison of Priestley-Taylor and Penman-Monteith Formulations and Two Time Scaling Methods. Trans ASABE 57:479-498. doi: $10.13031 /$ trans. 57.10423

Cook BI, Smerdon JE, Seager R, Coats S (2014) Global warming and 21st century drying. Clim Dyn 1-21. doi: 10.1007/s00382-014-2075-y

Daher BT, Mohtar RH (2015) Water-energy-food (WEF) Nexus Tool 2.0: guiding integrative resource planning and decision-making. Water Int 1-24. doi: $10.1080 / 02508060.2015 .1074148$

Dai A (2011a) Drought under global warming: A review. Wiley Interdiscip Rev Clim Chang 2:45-65. doi: 10.1002/wcc.81

Dai A (2011b) Characteristics and trends in various forms of the Palmer Drought Severity Index during 1900-2008. J Geophys Res Atmos. doi: 10.1029/2010JD015541 
Damerau K, van Vliet OPR, Patt AG (2015) Direct impacts of alternative energy scenarios on water demand in the Middle East and North Africa. Clim Change 130:171-183. doi: 10.1007/s10584-015-1345-y

Dargin J (2010) The Dubai Initiative.

Das PK, Dutta D, Sharma JR, Dadhwal VK (2015) Trends and behaviour of meteorological drought (1901-2008) over Indian region using standardized precipitation-evapotranspiration index. Int J Climatol 9. doi: 10.1002/joc.4392

Deng L, McCabe MF, Stenchikov G, et al (2015) Simulation of Flash-Flood-Producing Storm Events in Saudi Arabia Using the Weather Research and Forecasting Model. J Hydrometeorol 16:615-630. doi: 10.1175/JHM-D-14-0126.1

Deo RC, Byun H-R, Adamowski JF, Begum K (2016) Application of effective drought index for quantification of meteorological drought events: a case study in Australia. Theor Appl Climatol. doi: 10.1007/s00704-015-1706-5

Devarajan S, Mottaghi L (2017) The Economics of Post-Conflict Reconstruction in MENA. Middle East North Africa Econ Monit (April), World Bank, Washington, DC. doi: 10.1596/978-1-4648-1085-5

Devarajan S, Mottaghi L, Do Q-T, et al (2016) WORLD BANK MIDDLE EAST AND NORTH AFRICA REGION Economic and Social Inclusion to Prevent Violent Extremism. Middle East North Africa Econ Monit (October), World Bank, Washington, DC. doi: 10.1596/ 978-1- 4648-0990-3 
Drapela K, Drapelova I (2011) Application of Mann-Kendall test and the Sen's slope estimates for trend detection in deposition data from Bily Kriz (Beskydy Mts., the Czech Republic) 1997--2010. Beskydy 4:133-146.

Dubreuil A, Assoumou E, Bouckaert S, et al (2013) Water modeling in an energy optimization framework - The water-scarce middle east context. Appl Energy 101:268-279. doi: 10.1016/j.apenergy.2012.06.032

Dutra E, Wetterhall F, Di Giuseppe F, et al (2014) Global meteorological drought-Part 1: Probabilistic monitoring. Hydrol Earth Syst Sci 18:2657-2667. doi: 10.5194/hess$18-2657-2014$

EIA (2016) International Energy Outlook 2016:With Projections to 2040.

\section{EIU (2017) GLOBAL FOOD SECURITY INDEX 2017: MEASURING FOOD SECURITY AND THE IMPACT OF RESOURCE RISKS.}

Eklund L, Seaquist J (2015) Meteorological, agricultural and socioeconomic drought in the Duhok Governorate, Iraqi Kurdistan. Nat Hazards 76:421-441. doi: 10.1007/s11069-014-1504-x

El Bassam N (2017) Technologies and Options of Solar Energy Applications in the Middle East. In: Water, Energy \& Food Sustainability in the Middle East. Springer, Cham,

El Kharraz J, El-Sadek A, Ghaffour N, Mino E (2012) Water scarcity and drought in WANA countries. Procedia Eng 33:14-29. doi: 10.1016/j.proeng.2012.01.1172 
Elasha BO (2010) Mapping Climate Change Threats and Human Development Impacts in the Arab Region. Arab Human Development Report Research Paper. 51.

Endo A, Tsurita I, Burnett K, Orencio PM (2015) A review of the current state of research on the water, energy, and food nexus. J Hydrol Reg Stud. doi: 10.1016/j.ejrh.2015.11.010

ESCWA (2011) Assessing the Impact of Climate Change on Water Resources and SocioEconomic Vulnerability in the Arab Region : Assessing the Impact of Climate Change on Water Resources and Socio-Economic Vulnerability in the Arab Region:

ESCWA (2010) Food Security and Conflict in the Escwa Region Economic and Social Commission for Western Asia ( Escwa ). World 134.

ESCWA (2016a) Developing the Capacity of ESCWA Member Countries to Address the Water and Energy Nexus for Achieving Sustainable Development Goals.

ESCWA (2016b) The Water, Energy and Food Security Nexus in the Arab Region. Bierut

ESCWA (2015a) Assessing Arab Economic Integration Towards the Arab Customs Union Assessing Arab Economic Integration Towards the Arab Customs Union. Beirut

ESCWA (2015b) Social Development Bulletin Urbanization and Sustainable Development in the Arab Region.

ESCWA (2015c) Overcoming Population Vulnerability to Water Scarcity in the Arab 
Region: Population and Development Report Issue No. 7.

Falkenmark M, Lundqvist J (1998) Towards water security: political determination and human adaptation crucial. Nat Resour Forum 21:37-51. doi: 10.1111/j.14778947.1998.tb00708.x

FAO (2017) Drought characteristics and management in Central Asia and Turkey. Rome

FAO (2016) Fao / Wfp Crop and Food Security Assessment Mission to the Syrian Arab Republic. FOOD AND AGRICULTURE ORGANIZATION OF THE UNITED NATIONS

FAO (2011) The State of the World's land and water resources for Food and Agriculture. Managing systems at risk.

Feitelson E, Tubi A (2017) A main driver or an intermediate variable? Climate change, water and security in the Middle East. Glob Environ Chang 44:39-48. doi: 10.1016/j.gloenvcha.2017.03.001

Gao Z, Xu N, Fu C, et al (2015) Evaluating Drought Monitoring Methods Using Remote Sensing : A Dynamic Correlation Analysis Between Heat Fluxes and Land Cover Patterns. 8:298-303.

Garcia DJ, You FQ (2016) The water-energy-food nexus and process systems engineering: A new focus. Comput Chem Eng. doi: 10.1016/j.compchemeng.2016.03.003

Gleick PH (2014) Water, Drought, Climate Change, and Conflict in Syria. Weather Clim 
Soc 6:331-340. doi: 10.1175/WCAS-D-13-00059.1

Griffiths S (2017) A review and assessment of energy policy in the Middle East and North Africa region. Energy Policy 102:249-269. doi: 10.1016/j.enpol.2016.12.023

Gringorten II (1963) A plotting rule for extreme probability paper. J Geophys Res 68:813-814. doi: doi:10.1029/JZ068i003p00813

Güner Bacanli Ü (2017) Trend analysis of precipitation and drought in the Aegean region, Turkey. Meteorol Appl 24:239-249. doi: 10.1002/met.1622

Gupta M Das (2013) Population, Poverty, and Climate Change.

Hajj MR (2017) Wind Power and Potential for its Exploitation in the Arab World. In: Water, Energy \& Food Sustainability in the Middle East. Springer, Cham,

Hamdy A, Driouech N, Hmid A (2014) THE WATER- ENERGY-FOOD SECURITY NEXUS IN THE MEDITERRANEAN: CHALLENGES AND OPPORTUNITIES.

Fifth Int Sci Agric Symp Agrosym 23-26. doi: 10.7251/AGSY1404023H

Hameed M, Ahmadalipour A, Moradkhani H (2018) Apprehensive Drought

Characteristics over Iraq: Results of a Multidecadal Spatiotemporal Assessment. Geosciences 8:58. doi: 10.3390/geosciences8020058

Hao Z, AghaKouchak A (2013) Multivariate Standardized Drought Index: A parametric multi-index model. Adv Water Resour 57:12-18. doi: 10.1016/j.advwatres.2013.03.009

Hao Z, Hao F, Singh VP, et al (2017) An integrated package for drought monitoring, 
prediction and analysis to aid drought modeling and assessment. Environ Model Softw 91:199-209. doi: 10.1016/j.envsoft.2017.02.008

Hargreaves GH, Samani ZA (1985) Reference crop evapotranspiration from temperature. Appl Eng Agric 1:96-99. doi: 10.13031/2013.26773

Hillman JR, Baydoun E (2017) Food Security in an Insecure Future. In: Energy \& Food Sustainability in the Middle East. Springer, Cham,

Hoerling M, Eischeid J, Perlwitz J, et al (2012) On the increased frequency of mediterranean drought. J Clim 25:2146-2161. doi: 10.1175/JCLI-D-11-00296.1

Howarth C, Monasterolo I (2016) Understanding barriers to decision making in the UK energy-food-water nexus: The added value of interdisciplinary approaches. Environ Sci Policy 61:53-60. doi: 10.1016/j.envsci.2016.03.014

Huang S, Huang Q, Chang J, et al (2015) Drought structure based on a nonparametric multivariate standardized drought index across the Yellow River basin, China. J Hydrol 530:127-136.

Huang S, Huang Q, Leng G, Liu S (2016) A nonparametric multivariate standardized drought index for characterizing socioeconomic drought: A case study in the Heihe River Basin. J Hydrol 542:875-883. doi: 10.1016/j.jhydrol.2016.09.059

Hulme M, Marsh R, Jones PD (1992) Global changes in a humidity index between 193160 and 1961-90. Clim Res 2:1-22. doi: 10.3354/cr002001

Ianchovichina E, Mottaghi L, Devarajan S (2015) Inequality, Uprisings, and Conflict in 
the Arab World. Washington, DC

IEA (2014) Water- - - Energy Nexus. 1-12. doi: 10.1021/es903811p

IEA (2016) World Energy Resources | 2016.

IFPRI (2017) 2017 Global Food Policy Report. Washington, DC

Jolliffe IT (2002) Principal Component Analysis, Second Edition. Encycl Stat Behav Sci 30:487. doi: 10.2307/1270093

Kendall MG (1955) Rank correlation methods, 2nd edn. Hafner Publishing Co, Oxford, England

Keulertz M, Sowers J, Woertz E, Mohtar R (2016) The Water-Energy-Food Nexus in Arid Regions.

Khan MA, Khan MZ, Zaman K, Arif M (2014) Global estimates of energy-growth nexus: Application of seemingly unrelated regressions. Renew Sustain Energy Rev 29:6371. doi: 10.1016/j.rser.2013.08.088

Kim H, Park J, Yoo J, Kim TW (2015) Assessment of drought hazard, vulnerability, and risk: A case study foradministrative districts in South Korea. J Hydro-Environment Res 9:28-35. doi: 10.1016/j.jher.2013.07.003

King C, Jaafar H (2015) Rapid assessment of the water-energy-food-climate nexus in six selected basins of North Africa and West Asia undergoing transitions and scarcity threats. Int J Water Resour Dev 0627:1-17. doi:

$10.1080 / 07900627.2015 .1026436$ 
Koohafkan P. b, Stewart BA. (2012) Water and cereals in drylands.

Kopec BG, Feng X, Posmentier ES, et al (2018) Use of principal component analysis to extract environmental information from lake water isotopic compositions. Limnol Oceanogr 63:1340-1354. doi: 10.1002/lno.10776

Lecher A, Murray J, Paytan A (2018) Quantifying Processes Governing Nutrient Concentrations in a Coastal Aquifer via Principal Component Analysis. Hydrology 5:15. doi: 10.3390/hydrology5010015

Lelieveld J, Hadjinicolaou P, Kostopoulou E, et al (2012) Climate change and impacts in the Eastern Mediterranean and the Middle East. Clim Change 114:667-687. doi: $10.1007 / \mathrm{s} 10584-012-0418-4$

Liu X, Wang S, Zhou Y, et al (2015) Regionalization and Spatiotemporal Variation of Drought in China Based on Standardized Precipitation Evapotranspiration Index (1961-2013). Adv Meteorol. doi: 10.1155/2015/950262

Longuevergne L, Wilson CR, Scanlon BR, Crétaux JF (2013) GRACE water storage estimates for the middle east and other regions with significant reservoir and lake storage. Hydrol Earth Syst Sci 17:4817-4830. doi: 10.5194/hess-17-4817-2013

Lorenzo-Lacruz J, Vicente-Serrano SM, González-Hidalgo JC, et al (2013) Hydrological drought response to meteorological drought in the Iberian Peninsula. Clim Res 58:117-131. doi: $10.3354 / \mathrm{cr} 01177$

Madadgar S, Moradkhani H (2013a) Drought Analysis under Climate Change Using 
Copula. J Hydrol Eng. doi: http://dx.doi.org/10.1061/(ASCE)HE.19435584.0000532

Madadgar S, Moradkhani H (2013b) A Bayesian Framework for Probabilistic Seasonal Drought Forecasting. J Hydrometeorol 14:1685-1705. doi: 10.1175/JHM-D-13010.1

Magazzino C (2016) $\mathrm{CO}_{2}$ emissions, economic growth, and energy use in the Middle East countries: A panel VAR approach. Energy Sources, Part B Econ Planning, Policy 11:960-968. doi: 10.1080/15567249.2014.940092

Maia R, Vivas E, Serralheiro R, de Carvalho M (2015) Socioeconomic Evaluation of Drought Effects. Main Principles and Application to Guadiana and Algarve Case Studies. Water Resour Manag 29:575-588. doi: 10.1007/s11269-014-0883-9

Makkonen L (2006) Plotting positions in extreme value analysis. J Appl Meteorol Climatol 45:334-340. doi: 10.1175/JAM2349.1

Malik MR, Isaac BJ, Coussement A, et al (2018) Principal component analysis coupled with nonlinear regression for chemistry reduction. Combust Flame 187:30-41. doi: 10.1016/j.combustflame.2017.08.012

Mann HB (1945) Nonparametric tests against trend. Econom J Econom Soc 13:245-259.

Mavromatis T. (2007) Drought index evaluation for assessing future wheat production in Greece. Int J Climatol 27:911-924. doi: 10.1002/joc.1444

McDonnell RA (2014) Circulations and transformations of energy and water in Abu 
Dhabi’s hydrosocial cycle. Geoforum 57:225-233. doi:

10.1016/j.geoforum.2013.11.009

Mckee TB, Doesken NJ, Kleist J (1993) The relationship of drought frequency and duration to time scales. AMS 8th Conf Appl Climatol 179-184. doi: citeulikearticle-id: 10490403

McKee TB, Doeskin NJ, Kleist J (1993) The relationship of drought frequency and duration to time scales. In: 8th Conf. on Applied Climatology. Anaheim, Canada OR - Am. Meteorol. Soc., pp 179-184

Meng L, Dong T, Zhang W (2016) Drought monitoring using an Integrated Drought Condition Index (IDCI) derived from multi-sensor remote sensing data. Nat Hazards 80:1135-1152. doi: 10.1007/s11069-015-2014-1

Miller T, Kim AB (2017) 2017 Index Of Economic Freedom. Herit Found 492.

Mishra AK, Ines AVM, Das NN, et al (2015) Anatomy of a local-scale drought: Application of assimilated remote sensing products, crop model, and statistical methods to an agricultural drought study. J Hydrol 526:15-29. doi: 10.1016/j.jhydrol.2014.10.038

Mishra AK, Singh VP (2010) A review of drought concepts. J Hydrol 391:202-216. doi: 10.1016/j.jhydrol.2010.07.012

Mo KC, Lettenmaier DP (2014) Objective Drought Classification Using Multiple Land Surface Models. J Hydrometeorol 15:990-1010. doi: 10.1175/JHM-D-13-071.1 
Mo KC, Lyon B (2015) Global Meteorological Drought Prediction Using the North American Multi-Model Ensemble. J Hydrometeorol 16:1409-1424. doi: 10.1175/JHM-D-14-0192.1

Mohammed R, Scholz M (2017) Impact of Evapotranspiration Formulations at Various Elevations on the Reconnaissance Drought Index. Water Resour Manag 31:531548. doi: 10.1007/s11269-016-1546-9

Mohtar RH, Assi AT, Daher BT (2015) Bridging the Water and Food Gap : The Role of the Water-Energy-Food Nexus. Unu-Flores 1-31.

Mohtar RH, Assi AT, Daher BT (2017) Current Water for Food Situational Analysis in the Arab Region and Expected Changes Due to Dynamic Externalities. In: The Water, Energy, and Food Security Nexus in the Arab Region. Water Security in a New World. Springer, Cham,

Ncube M, Anyanwu JC, Hausken K (2014) Inequality, Economic Growth and Poverty in the Middle East and North Africa (MENA). African Dev Rev 26:435-453. doi: $10.1111 / 1467-8268.12103$

Negewo BD (2012) Renewable Energy Desalination: An Emerging Solution to Clos de Water Gap in the Middle Eas and North Africa.

Nelsen RB (2007) An introduction to copulas. Springer Science \& Business Media.

Nematollahi O, Hoghooghi H, Rasti M, Sedaghat A (2016) Energy demands and renewable energy resources in the Middle East. Renew Sustain Energy Rev 
54:1172-1181. doi: 10.1016/j.rser.2015.10.058

Nichol JE, Abbas S (2015) Integration of remote sensing datasets for local scale assessment and prediction of drought. Sci Total Environ 505:503-507. doi: 10.1016/j.scitotenv.2014.09.099

Notaro M, Yu Y, Kalashnikova O V. (2015) Regime shift in Arabian dust activity, triggered by persistent Fertile Crescent drought. J Geophys Res Atmos 120:1022910249. doi: 10.1002/2015JD023855

O’Brien RM (2007) A caution regarding rules of thumb for variance inflation factors. Qual Quant 41:673-690. doi: 10.1007/s11135-006-9018-6

Ozcan B (2013) The nexus between carbon emissions, energy consumption and economic growth in Middle East countries: A panel data analysis. Energy Policy 62:11381147. doi: 10.1016/j.enpol.2013.07.016

Palmer WC (1965) Meteorological Drought. U.S. Weather Bur. Res. Pap. No. 4558.

Paul P, Al Tenaiji AK, Braimah N (2016) A review of the water and energy sectors and the use of a nexus approach in Abu Dhabi. Int J Environ Res Public Health. doi: 10.3390/ijerph13040364

Population Institute (2015) Demographic Vulnerability:Where Population Growth Poses the Greatest Challenges.

PRIESTLEY CHB, TAYLOR RJ (1972) On the Assessment of Surface Heat Flux and Evaporation Using Large-Scale Parameters. Mon Weather Rev 100:81-92. doi: 


\subsection{5/1520-0493(1972)100<0081:OTAOSH >2.3.CO;2}

Purnama A, Al-Barwani HH, Smith R (2005) Calculating the environmental cost of seawater desalination in the Arabian marginal seas. Desalination 185:79-86. doi: 10.1016/j.desal.2005.03.072

Qadir M, Sharma BR, Bruggeman A, et al (2007) Non-conventional water resources and opportunities for water augmentation to achieve food security in water scarce countries. Agric Water Manag 87:2-22. doi: 10.1016/j.agwat.2006.03.018

Rad AM, Ghahraman B, Khalili D, et al (2017) Integrated meteorological and hydrological drought model: A management tool for proactive water resources planning of semi-arid regions. Adv Water Resour 107:336-353. doi: 10.1016/j.advwatres.2017.07.007

Rajsekhar D, Singh VP, Mishra AK (2015) Integrated drought causality, hazard, and vulnerability assessment for future socioeconomic scenarios: An information theory perspective. J Geophys Res Atmos 120:6346-6378. doi: 10.1002/2014JD022670

RCREEE (2015) Arab Future Energy Index ${ }^{\mathrm{TM}}$ (AFEX) Energy Efficiency 2015. Egypt

Rijsberman FR (2006) Water scarcity: Fact or fiction? Agric Water Manag 80:5-22. doi: 10.1016/j.agwat.2005.07.001

Robaa, S. M., Al-Barazanji, Z. J. (2013) Trends of annual mean surface air temperature over Iraq. Nat Sci 11:138-145.

Rodell M, Houser PR, Jambor U, et al (2004) The Globel Land Data Assimilation 
System. Am Meteorol Soc 381-394. doi: 10.1175/BAMS-85-3-381

Saab N (2012) Arab Environment 5. Survival Options - Ecological Footprints of Arab Countries.

Saif O, Mezher T, Arafat HA (2014) Water security in the GCC countries: challenges and opportunities. J Environ Stud Sci 4:329-346. doi: 10.1007/s13412-014-0178-8

Sakhel SR, Geissen S-U, Vogelpohl a. (2013) Virtual industrial water usage and wastewater generation in the Middle East/North African region. Hydrol Earth Syst Sci Discuss 10:999-1039. doi: 10.5194/hessd-10-999-2013

Saleh W, Jayyousi AF, Almasri MN (2010) State of Freshwater Ecosystems. pp 39-54

Santos JF, Pulido-Calvo I, Portela MM (2010) Spatial and temporal variability of droughts in Portugal. Water Resour Res 46:1-13. doi: 10.1029/2009WR008071

Scanlon BR, Duncan I, Reedy RC (2013) Drought and the water-energy nexus in Texas. Environ Res Lett 8:045033. doi: 10.1088/1748-9326/8/4/045033

Scanlon BR, Ruddell BL, Reed PM, et al (2017) The food-energy-water nexus: Transforming science for society. Water Resour Res 1-7. doi: 10.1002/2017WR020889

Schwarz G (1978) Estimating the Dimension of a Model. Ann Stat 6:461-464. doi: $10.1214 / \mathrm{aos} / 1176344136$

Sen PK (1968) Estimates of the Regression Coefficient Based on Kendall's Tau. J Am Stat Assoc 63:1379-1389. doi: 10.1080/01621459.1968.10480934 
Sewilam H, Nasr P (2017) Desalinated Water for Food Production in the Arab Region. In: The Water, Energy, and Food Security Nexus in the Arab Region.Water Security in a New World. Springer, Cham,

Shubbar RM, Salman HH, Lee DI (2016) Characteristics of climate variation indices in Iraq using a statistical factor analysis. Int J Climatol. doi: 10.1002/joc.4749

Shukla S, Wood AW (2008) Use of a standardized runoff index for characterizing hydrologic drought. Geophys Res Lett 35:1-7. doi: 10.1029/2007GL032487

Siddiqi A, Anadon LD (2011) The water-energy nexus in Middle East and North Africa. Energy Policy 39:4529-4540. doi: 10.1016/j.enpol.2011.04.023

Silva W, Amorim D, Blasi I, et al (2018) The nexus between water, energy, and food in the context of the global risks : An analysis of the interactions between food, water, and energy security. Environ Impact Assess Rev 72:1-11. doi:

10.1016/j.eiar.2018.05.002

Sowers J (2014) Water, energy and human insecurity in the middle east. Middle East Rep $44: 2-5+48$.

Sowers J, Vengosh A, Weinthal E (2011) Climate change, water resources, and the politics of adaptation in the Middle East and North Africa. Clim Change 104:599627. doi: 10.1007/s10584-010-9835-4

Stagge J, Tallaksen L (2014) Standardized precipitation-evapotranspiration index (SPEI): Sensitivity to potential evapotranspiration model and parameters. Int Assoc Hydrol 
Sci 10:367-373.

Stagge JH, Kohn I, Tallaksen LM, Stahl K (2015a) Modeling drought impact occurrence based on meteorological drought indices in Europe. J Hydrol 530:37-50. doi: 10.1016/j.jhydrol.2015.09.039

Stagge JH, Tallaksen LM, Gudmundsson L, et al (2015b) Candidate Distributions for Climatological Drought Indices (SPI and SPEI). Int J Climatol 35:4027-4040. doi: $10.1002 /$ joc. 4267

Tan P, Zhang C, Xia J, et al (2016) NO\&lt;sub\&gt;X\&lt;/sub\&gt; Emission Model for Coal-Fired Boilers Using Principle Component Analysis and Support Vector Regression. J Chem Eng Japan 49:211-216. doi: 10.1252/jcej.15we066

The World Bank (2006) Iraq - Country water resource assistance strategy : addressing major threats to people's livelihoods. 1-97. doi: 36297-IQ

The World Bank (2014) Natural disasters in the Middle East and North Africa : A regional overview. 1-114.

Thecla I A, George O K, Alice A O-O (2018) Principal component analysis of the effects of flooding on food security in agrarian communities of south eastern Nigeria. Int $\mathbf{J}$ Hydrol. doi: 10.15406/ijh.2018.02.00070

Thornthwaite CW (1948) An Approach Toward a Rational Classification of Climate. Soil Sci 66:77. doi: 10.1097/00010694-194807000-00007

Tielbörger K, Bilton MC, Metz J, et al (2014) Middle-Eastern plant communities tolerate 
9 years of drought in a multi-site climate manipulation experiment. Nat Commun 5:5102. doi: $10.1038 /$ ncomms6102

Tolba MK, Saab NW (2009) Arab Environment : Climate Change - Impact of Climate Change on Arab Countries.

Touma D, Ashfaq M, Nayak M a., et al (2015) A multi-model and multi-index evaluation of drought characteristics in the 21st century. J Hydrol 526:196-207. doi: 10.1016/j.jhydrol.2014.12.011

Trivedi PK, Zimmer DM (2006) Copula Modeling: An Introduction for Practitioners. Found Trends® Econom 1:1-111. doi: 10.1561/0800000005

Tsakiris G, Vangelis H (2004) Towards a Drought Watch System based on spatial SPI. Water Resour Manag 18:1-12. doi: 10.1023/B:WARM.0000015410.47014.a4

UNDP (2010) Impact Assessment, Recovery and Mitigation Framework and Regional Project Design in Kurdistan Region ( KR ). Iraq 78.

UNESCO (2014) Integrated Drought Risk Management - DRM (National Framework for Iraq). 28.

United Nations (2015) World Urbanization Prospects.

UN-Water (2011) Climate Change Adaptation: The Pivotal Role of Water. 1-18.

UN-Water (2013) Water Security and the Global Water Agenda.

Van Loon AF (2015) Hydrological drought explained. Wiley Interdiscip Rev Water 2:359-392. doi: 10.1002/wat2.1085 
Van Loon AF, Laaha G (2015) Hydrological drought severity explained by climate and catchment characteristics. J Hydrol 526:3-14. doi: 10.1016/j.jhydrol.2014.10.059

van Loon AF, Ploum SW, Parajka J, et al (2014) Hydrological drought typology: temperature-related drought types and associated societal impacts. Hydrol Earth Syst Sci Discuss 11:10465-10514. doi: 10.5194/hessd-11-10465-2014

Vangelis H, Tigkas D, Tsakiris G (2013) The effect of PET method on Reconnaissance Drought Index (RDI) calculation. J Arid Environ 88:130-140. doi: 10.1016/j.jaridenv.2012.07.020

Vannucci M, Stingo FC, Berzuini C (2012) Bayesian Models for Variable Selection that Incorporate Biological Information. Bayesian Stat 9. doi:

10.1093/acprof:oso/9780199694587.003.0022

Vicente-Serrano S, Cabello D, Tomás-Burguera M, et al (2015) Drought Variability and Land Degradation in Semiarid Regions: Assessment Using Remote Sensing Data and Drought Indices (1982-2011). Remote Sens 7:4391-4423. doi: $10.3390 /$ rs 70404391

Vicente-Serrano SM, Beguería S, López-Moreno JI (2010) A multiscalar drought index sensitive to global warming: The standardized precipitation evapotranspiration index. J Clim 23:1696-1718. doi: 10.1175/2009JCLI2909.1

von Grebmer K, Bernstein J, Nabarro D, et al (2016) 2016 Global hunger index: Getting to zero hunger. Food Policy Research Institute, and Concern Worldwide. 
Voss KA, Famiglietti JS, Lo M, et al (2013) Groundwater depletion in the Middle East from GRACE with implications for transboundary water management in the TigrisEuphrates-Western Iran region. Water Resour Res 49:904-914. doi: $10.1002 /$ wrcr.20078

Walter G, Augustin T (2010) Bayesian linear regression - Different conjugate models and their (In)sensitivity to prior-data conflict. Stat Model Regres Struct Festschrift Honour Ludwig Fahrmeir 59-78. doi: 10.1007/978-3-7908-2413-1_4

Waterbury J (2017) Water and Water Supply in The MENA: Less of the Same. In: Water, Energy \& Food Sustainability in the Middle East. Springer International Publishing, pp 57-84

WEF (2010) The Middle East and North Africa at Risk 2010.

Weibull W (1939) A statistical theory of the strength of materials. R. Swedish Inst. Eng. Res. 151:1-45.

Willis HH, Groves DG, Ringel JS, et al (2016) Developing the Pardee RAND FoodEnergy-Water Security Index. Santa Monica, Calif.

Willmott CJ, Rowe CM, Mintz Y (1985) Climatology of the terrestrial seasonal water cycle. J Climatol 5:589-606. doi: 10.1002/joc.3370050602

Wold S (1987) Principal Component Analysis. 2:37-52. doi: 10.1016/01697439(87)80084-9

Wu Z, Mao Y, Li X, et al (2016) Exploring spatiotemporal relationships among 
meteorological, agricultural, and hydrological droughts in Southwest China. Stoch Environ Res Risk Assess 30:1033-1044. doi: 10.1007/s00477-015-1080-y

Yan H, Moradkhani H, Zarekarizi M (2017) A probabilistic drought forecasting framework: A combined dynamical and statistical approach. J Hydrol 548:291-304. doi: 10.1016/j.jhydrol.2017.03.004

Zarekarizi M, Rana A, Moradkhani H (2018) Precipitation extremes and their relation to climatic indices in the Pacific Northwest USA. Clim Dyn 50:4519-4537. doi: $10.1007 / \mathrm{s} 00382-017-3888-2$

Zhang B, Zhao X, Jin J, Wu P (2015) Development and evaluation of a physically based multiscalar drought index: The Standardized Moisture Anomaly Index. J Geophys Res Atmos 120:11,575-11,588. doi: 10.1002/ 2015JD023772

Zhang D, Chen P, Zhang Q, Li X (2017) Copula-based probability of concurrent hydrological drought in the Poyang lake-catchment-river system (China) from 1960 to 2013. J Hydrol 553:773-784. doi: 10.1016/j.jhydrol.2017.08.046

Zhao T, Dai A (2015) The Magnitude and Causes of Global Drought Changes in the Twenty-First Century under a Low-Moderate Emissions Scenario. J Clim 28:44904512. doi: 10.1175/JCLI-D-14-00363.1 